\title{
DOE Explosives Safety Manual
}

August 1994

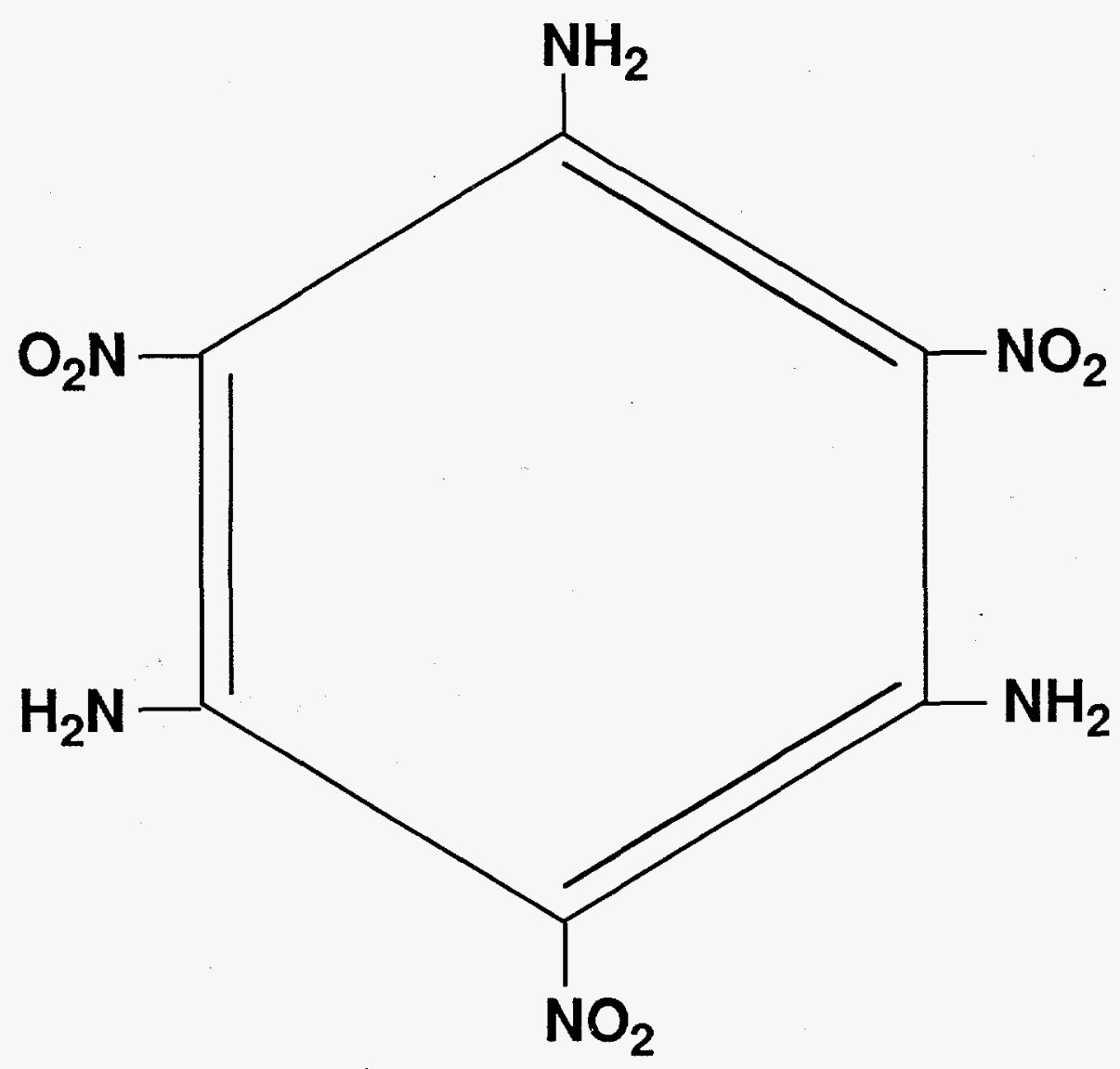

U.S. Department of Energy

Assistant Secretary for Environment,

Safety, and Health

Office of Occupational Safety

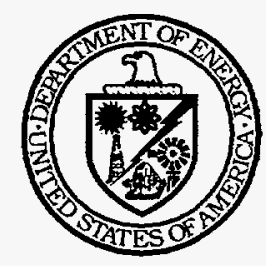




\section{DISCLAIMER}

This document was prepared as an acccount of work sponsored by an agency of the United States Government. Neither the United States Government nor the University of California nor any of their employees, makes any warranty, express or implied, or assumes any legal liability or responsibility for the accuracy, completeness, or usefulness of any information, apparatus, product, or process disclosed, or represents that its use would not infringe privately own rights. Reference herein to any specific commercial products, process, or service by trade name, trademark, manufacturer, or otherwise, does not necessarily constitute or imply its endorsement, recommendation, or favoring by the United States Government or the University of California. The views and opinions of authors expressed herein do not necessarily state or reflect those of the United States Government or the University of California, and shall not be used for advertising or product endorsement purposes.

This report has been reproduced directly from the best available copy.

Available to DOE and DOE contractors from the Office of Scientific and Technical Information P.O. Box 62, Oak Ridge, TN 37831

Prices available from (615) 576-8401, FTS 626-8401

Available to the public from the National Technical Information Service

U.S. Department of Commerce 5285 Port Royal Rd., Springfield, VA 22161

Work performed under the auspices of the U.S. Department of Energy by Lawrence Livermore National Laboratory under Contract W-7405-Eng-48. 


\section{DOE Explosives Safety Manual}

August 1994

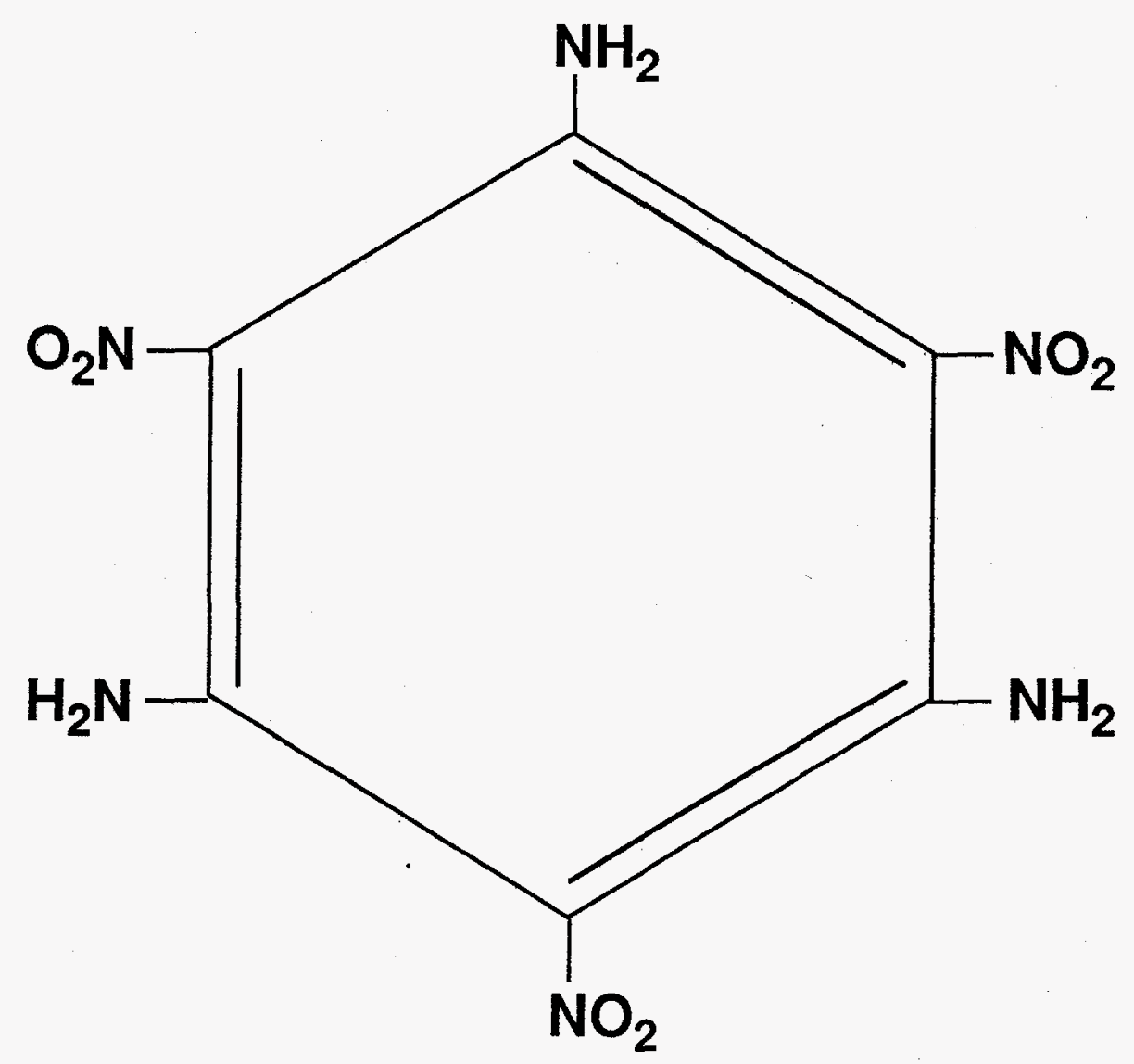

U.S. Department of Energy Assistant Secretary for Environment, Safety, and Health

Office of Occupational Safety

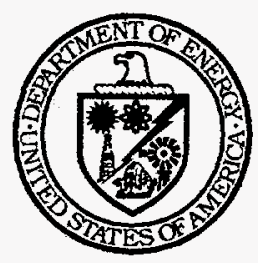




\section{DISCLAIMER}

Portions of this document may be illegible in electronic image products. Images are produced from the best available original document. 


\section{Foreword}

The Department of Energy (DOE) policy requires that all DOE activities be conducted in a manner that protects the safety of the public and provides a safe and healthful workplace for employees.

DOE has also prescribed that all personnel be protected in any explosives operation undertaken. The level of safety provided shall be at least equivalent to that of the best industrial practice. The risk of death or serious injury shall be limited to the lowest practicable minimum.

DOE and contractors shall continually review their explosives operations with the aim of achieving further refinements and improvements in safety practices and protective features.

This manual describes the Department'sexplosive safety requirements applicable to operations involving the development, testing, handling, and processing of explosives or assemblies containing explosives. It is intended to reflect the state-of-the-art in explosives safety. In addition, it is essential that applicable criteria and requirements for implementing this policy be readily available and known to those responsible for conducting DOE programs. This document shall be periodically reviewed and updated to establish new requirements as appropriate. Users are requested to submit suggestions for improving the DOE Explosives Safety Manual through their appropriate Operations Office to the Office of Occupational Safety.

The DOE Explosives Safety Manual, Revision 7, is dedicated in the memory of the late Phil Kelley, a former member of the DOE Explosives Safety Committee, for his many contributions to the explosives safety program. 


\section{Table of Contents}

Chapter I Introduction .................................................................................................................. I-1

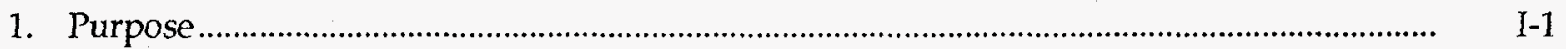

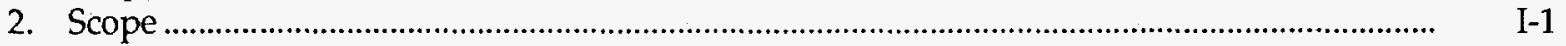

3. Exemptions and Waivers .................................................................................................... I

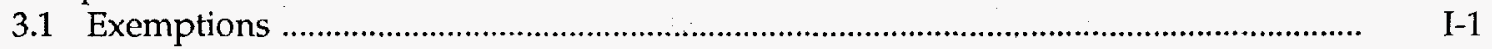

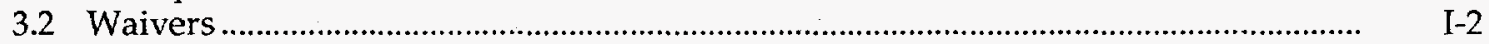

4. Manual Administration and Management ........................................................................ I-2

4.1 DOE Explosives Safety Committee Organization ....................................................... I-2

4.2 DOE Explosives Safety Committee Functions ............................................................ I- I-2

5. Definitions ........................................................................................................................... I-3

Chapter II Operational Safety …............................................................................................. II

1. General Operations Safety Guidelines ……........................................................................ II-1

1.1 Protection of Explosives ................................................................................................ II

1.2 Equipment Checks .............................................................................................. II

1.3 Inspection Frequency ……..................................................................................... II-1

1.4 Laboratory Operations ............................................................................................... II-1

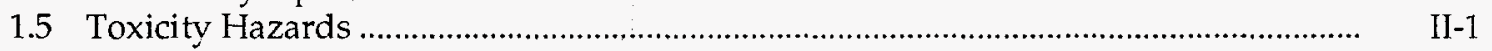

1.6 Hazard Identification and Communication ............................................................ II-1

2. Work Environment ....................................................................................................... II-3

2.1 General Requirements .............................................................................................. II-3

2.2 Emergency Exit Requirements for Explosives Operations …...................................... II-3

2.2.1 Building or Structure Classification ................................................................... II-3

2.2.2 Hazard of Contents Classification .............................................................. II-3

2.2.3 Personnel Protective Restrictions and Requirements ................................... II-3

2.2.4 Travel Distances ........................................................................................... II

2.2.5 Single Exits ........................................................................................... II-4

2.2.6 Blast-Resistant Doors .............................................................................. II-4

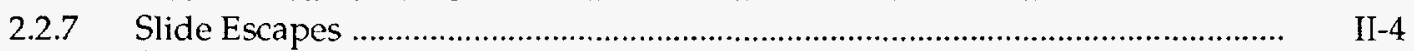

3. Building and Equipment Maintenance .............................................................................. II-7

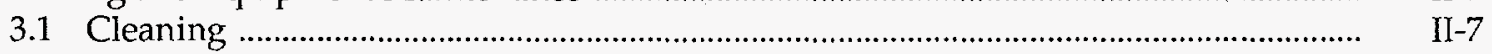

3.2 Maintenance and Repair .................................................................................. II

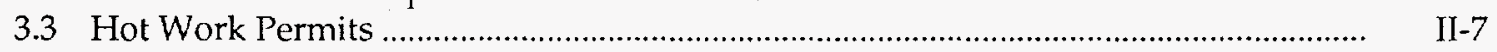

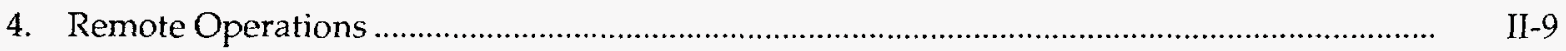

4.1 Personnel Protection Criteria ............................................................................. II

4.2 Access and Equipment Controls ...........................................................................

5. General Explosives Area Controls ................................................................................ II-11

5.1 Smoking, Matches, Lighters, Metal Articles .................................................................. II-

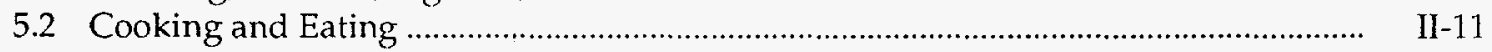

5.3 Access to Explosives Areas ..................................................................................... II-11

6. Electrical Storms and Lightning Protection .................................................................... II -13

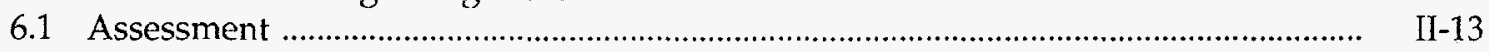

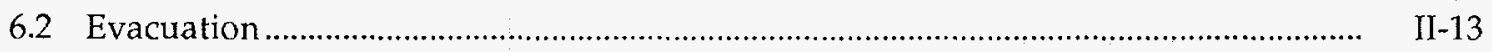

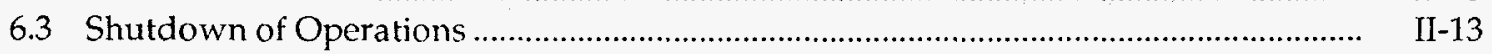

6.4 Lightning Protection ........................................................................................ II

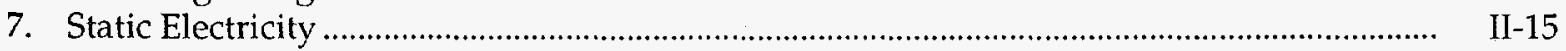

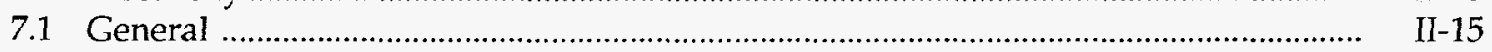

7.2 Bonding and Grounding of Equipment ................................................................. II-15

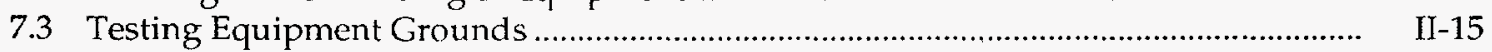

7.4 Conductive Floors, Shoes, Mats, and Wristbands ................................................... II-15 
7.5 Conductive Floor and Wristband Specifications ........................................................ II-16

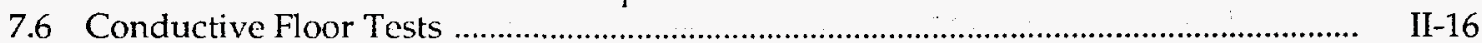

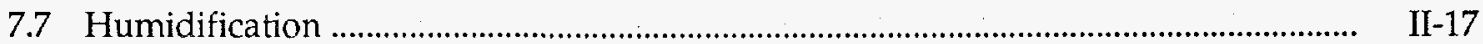

7.8 Ground Fault Circuit Interrupter .......................................................................... II

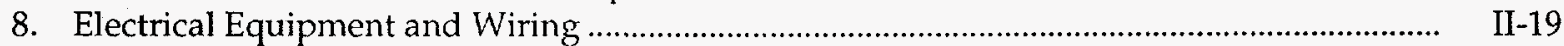

8.1 Permanent Equipment and Wiring …................................................................... II

8.2 Hazardous Locations ................................................................................................ II

8.3 Electrical Supply Systems ..................................................................................... II-20

8.4 Building Service Entrance ......................................................................................... II-20

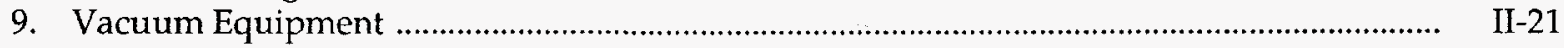

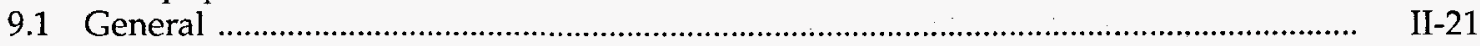

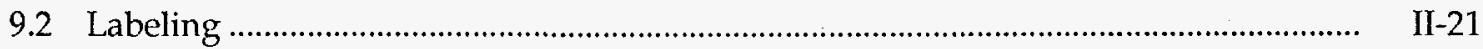

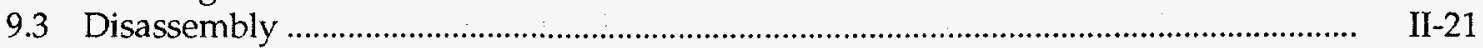

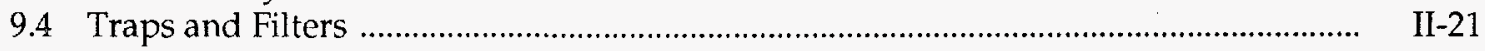

10. Explosives Dust Exhaust Ventilation and Collection Systems ........................................... II-23

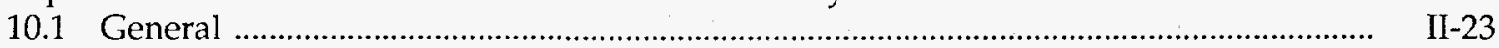

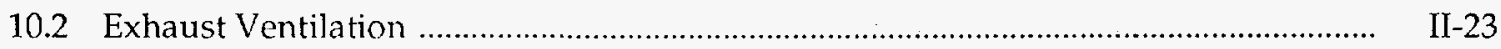

10.3 Dust Collection Systems ........................................................................................ II

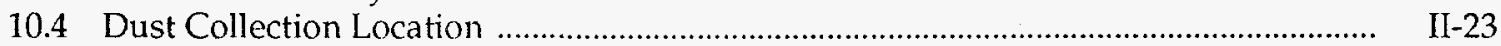

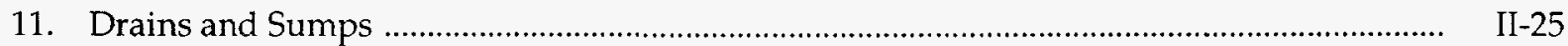

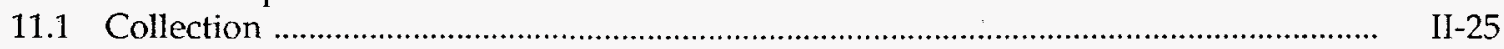

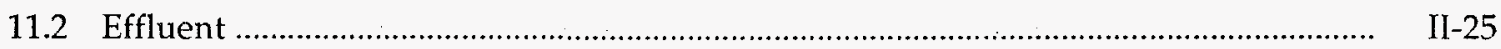

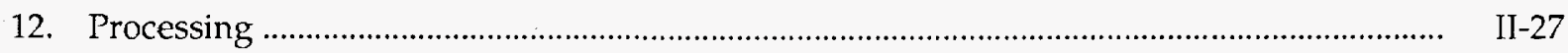

12.1 Heating, Drying, and Thermal Conditioning …...................................................... II-27

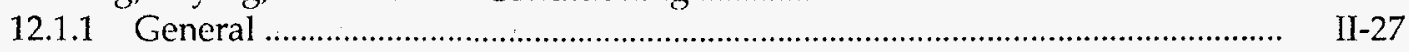

12.1.2 Heating and Drying Equipment ................................................................... II-28

12.1.3 Heating and Drying Operations ................................................................... II-28

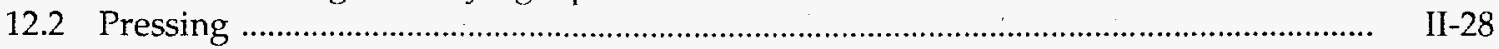

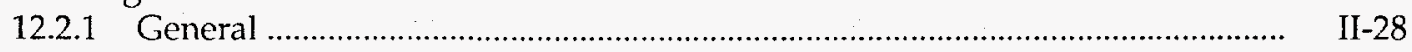

12.2.2 Isostatic/Hydrostatic Pressing …............................................................ II-29

12.2.3 Punch and Die Pressing ............................................................................... II-29

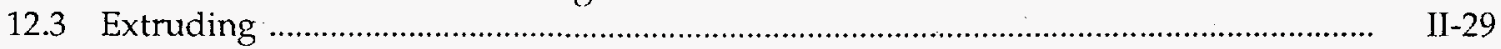

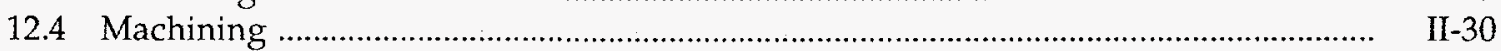

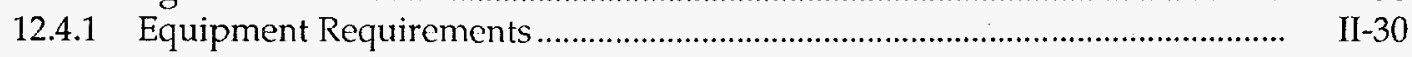

12.4.2 Contact or Remote Operations ................................................................. II

12.4.3 Setup and Preparation ......................................................................... II-31

12.4.4 Operations Guidelines ......................................................................... II-31

12.4.5 Specific Machining Operations ................................................................. II

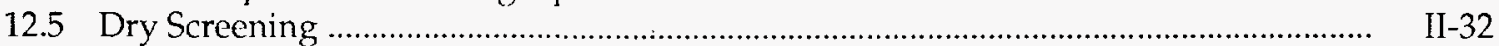

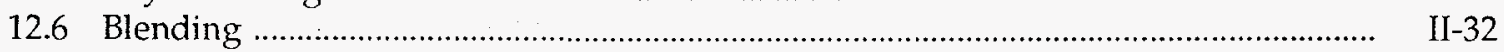

12.7 Melting ....................................................................................................... II

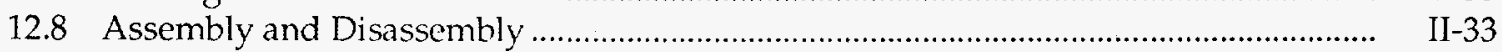

12.8.1 Assembly Operations .................................................................................... II

12.8.2 Loading Assemblies with Plastic or Extrudable Explosives …........................ II-33

12.8.3 Disassembly Operations ........................................................................... II-33

12.8.4 Personnel Protection for Disassembly Operations ....................................... II-33

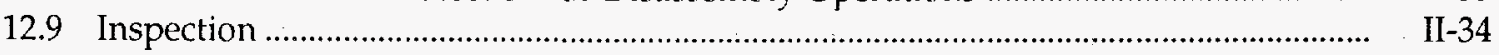

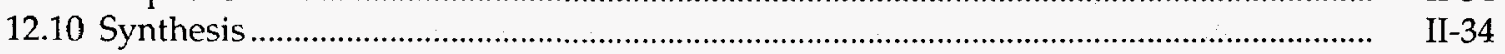

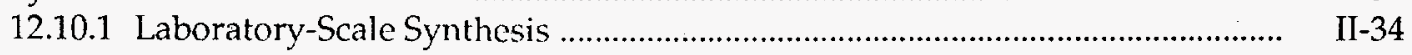

12.10.2 Pilot- or Processing-Scale Synthesis ................................................................ II-34

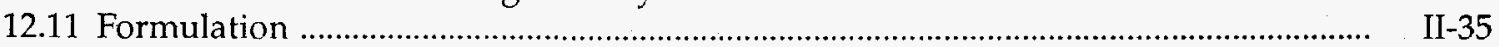

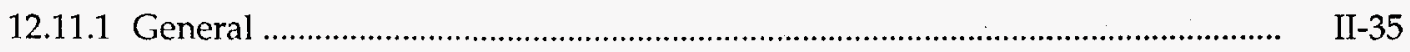

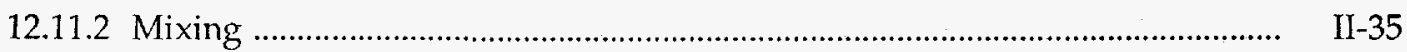




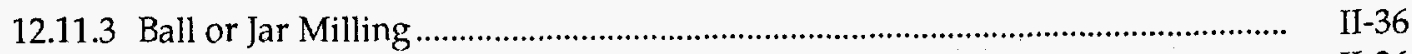

12.11.4 Roll Milling ............................................................................................. II

12.12 Concurrent Contact Operations .......................................................................... II-36

12.13 Contamination Prevention ............................................................................... II

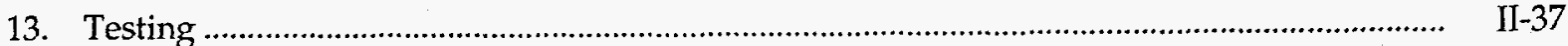

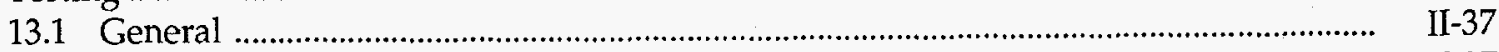

13.2 Test Planning …......................................................................................... II -37

13.2.1 Hazards Analysis ................................................................................ II

13.2.2 Firing Areas ............................................................................... II -37

13.3 Test Firing …............................................................................................... II

13.3.1 General Range Standards ................................................................ II-37

13.3.2 Test Setup ................................................................................... II

13.3.3 Pin Switches and Other Noninitiating Circuits ........................................... II

13.3.4 Lightning Storms .............................................................................. II-38

13.3.5 Low-Energy Electroexplosive Devices (EEDs) .......................................... II-38

13.3.6 Explosives Storage in Firing Areas ............................................................. II-39

13.3.7 Warning Signals ............................................................................. II -39

13.3.8 Grass Fires .................................................................................... II

13.3.9 Firing Leads ................................................................................... II

13.3.10 Unattended Test Assemblies ..................................................................... II

13.3.11 Postfiring Controls .............................................................................. II

13.3.12 Contamination of Firing Areas ................................................................. II-40

13.3.13 Test Range Firing Circuit Criteria ............................................................ II

13.4 Test Firing in Tanks or Chambers ........................................................................ II-41

13.5 Gun Firings ......................................................................................................... II

13.6 Ballistic, Environmental, Physical Property, and Sensitivity Testing ......................... II-41

13.6.1 Checkout of Dynamic Engineering Test Equipment for
Explosive Assemblies .................................................................................. II 41

13.6.2 Testing Explosives and Hazardous Radioactive Materials ............................ II $\quad$ If

13.6.3 Heating of Explosives Test Specimens ...................................................... II

13.6.4 Instrumentation ............................................................................... II

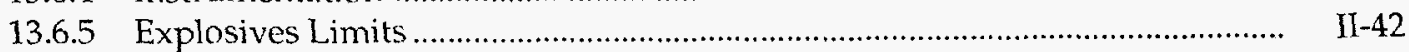

13.6.6 Drop Testing ................................................................................. II

13.7 Test Failures and Misfires ................................................................................... II

13.7.1 Explosives Misfire ................................................................................... II

13.7.2 Misfire of a Remotely Fired Gun ............................................................... II

13.8 Electrical Instruments for Use with Explosives Systems .......................................... II -43

13.8.1 Classification ................................................................................. II-43

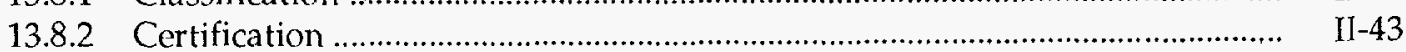

13.8.3 Electrical Instruments for Use with Initiating Electrical Circuits .................... II-43

13.8.4 Electrical Instruments for Use with Noninitiating Electrical Circuits ........... II-44

14. Materials Handling ..................................................................................................... II

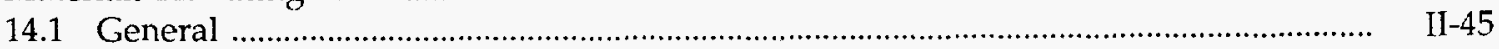

14.2 Manual Handling of Bare Consolidated Explosives ............................................... II

14.3 Carts and Hand Trucks .................................................................................. II

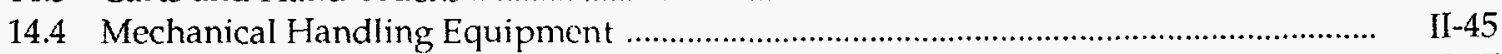

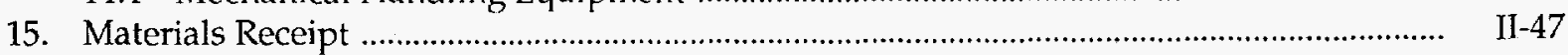

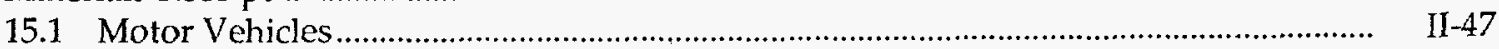

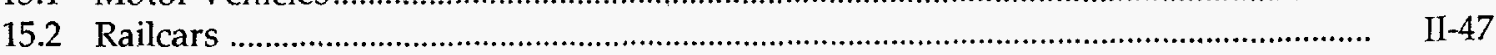

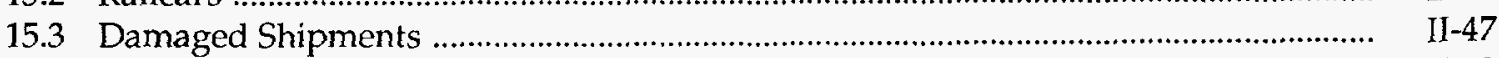

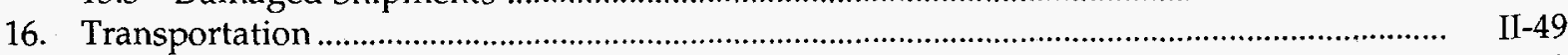

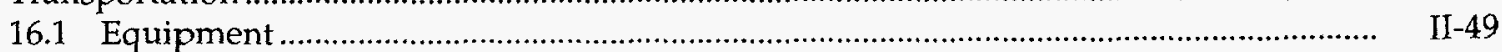

16.1.1 General ......................................................................................... II 49

16.1.2 Motor Vehicles ............................................................................ II 


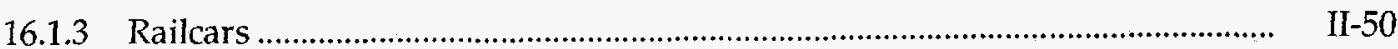

16.1.4 Materials Handling Equipment ................................................................ II-50

16.2 General Operation Guidelines ............................................................................... II

16.3 Emergency Conditions ........................................................................................ II-51

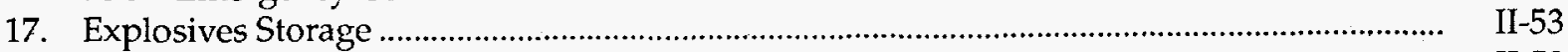

17.1 Storage Magazine Facilities ................................................................................. II

17.2 Storage Magazine Operations ….......................................................................... II-53

17.3 Storage Review Program ................................................................................... II-54

17.4 Storage Compatibility ................................................................................... II

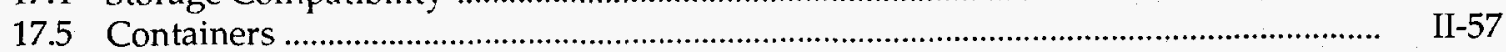

17.6 Storage in Buildings Other Than Storage Magazines .................................................. II-57

17.6.1 Packing and Shipping Buildings .............................................................. II-57

17.6.2 Service Magazines …....................................................................... II-58

17.6.3 Warehouses ........................................................................................... II

17.6.4 Prepositioned Storage of Security Response Munitions ................................. II-59

18. Decontamination and Cleaning ........................................................................................... II-61

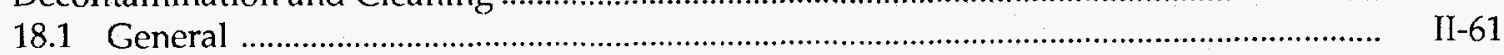

18.2 Cleaning Contaminated Equipment …................................................................. II

18.3 Cleaning Screw Threads ...................................................................................... II

18.4 Final Decontamination and Disposal of Equipment .................................................. II-61

18.5 Inspection .......................................................................................................... II 62

18.6 Identification and Control of Decontaminated Items ................................................. II-62

18.7 Decontamination of Real Estate ..................................................................... II-62

18.8 Decontamination and Cleaning References ........................................................ II-62

19. Waste Collection ....................................................................................................... II -63

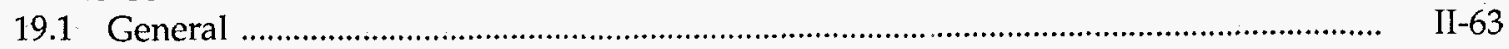

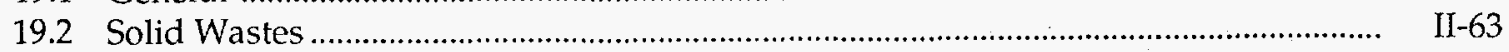

19.3 Vacuum Collection of Explosives Dusts ...................................................................... II-63

19.4 Explosives Slurries .......................................................................................... II-64

19.5 Metal Scrap …..................................................................................................... II-64

19.6 Explosives Recovery and Reuse ............................................................................. II-64

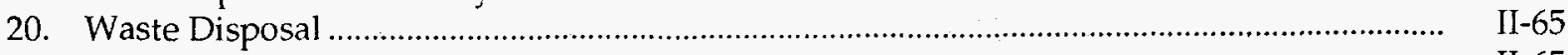

20.1 Preparation for Open Burning …........................................................................... II-65

20.2 Destruction of Burning or Flashing …................................................................... II-65

20.3 Ignition System Malfunctions ............................................................................. II-65

20.4 Postburn Operations .......................................................................................... II 65

20.5 Disposal Area .................................................................................................... II-66

20.6 Destruction by Detonation ................................................................................. II -66

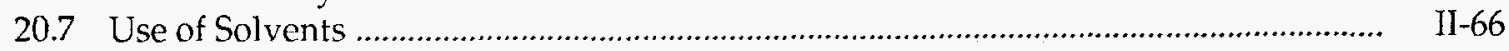

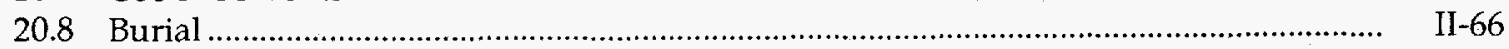

21. Laboratory Operations ............................................................................................. II-67

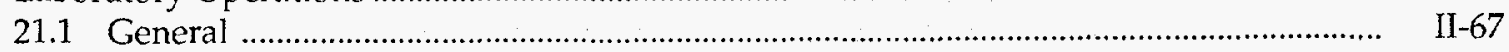

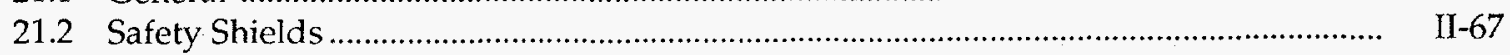

21.3 Heating Operations ............................................................................................ II-68

21.4 Laboratory Setups ........................................................................................... II-68

21.5 Low Concentration of Explosives in Solution ............................................................ II-68

21.6 Explosives Sample Control ................................................................................. II -68

22. Emergency Control ............................................................................................... II 69

22.1 Placarding and Firing Symbols .............................................................................. II 69

22.2 Explosives Emergency Control Plans .................................................................. II-69

Chapter III Explosives and Personnel Limits and Control ................................................................ III-1

1. Explosives Limits .......................................................................................................... III

2. Personnel Limits .................................................................................................. III-1 


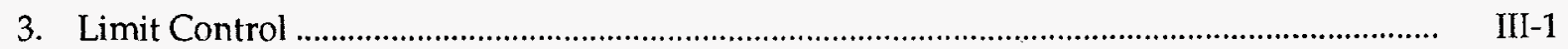

3.1 Posting and Recording .............................................................................................. III

3.2 Limit Review and Approvals ....................................................................................... III-1

3.3 Personnel Controls ................................................................................................. III-1

4. IHE Limits .................................................................................................................. III-2

Chapter IV Personal Protective Clothing and Equipment ......................................................... IV-1

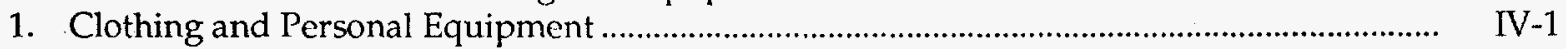

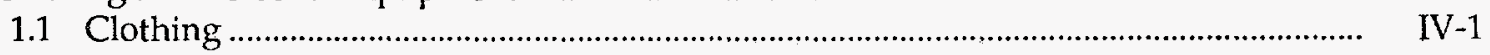

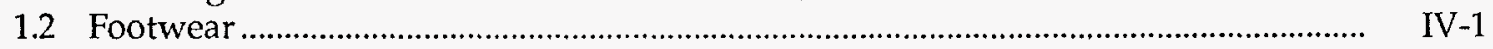

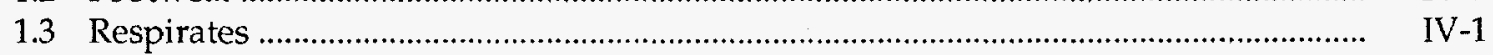

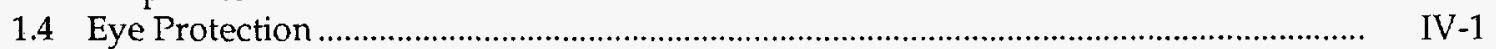

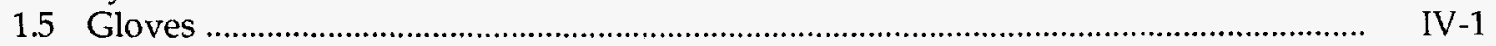

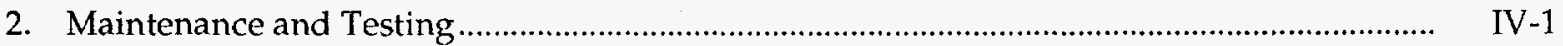

2.1 Equipment Maintenance and Inspection ................................................................. IV-1

2.2 Conductivity Testing ................................................................................................. IV -1

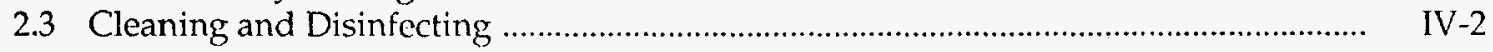

2.4 Contaminated Clothing ..................................................................................... IV

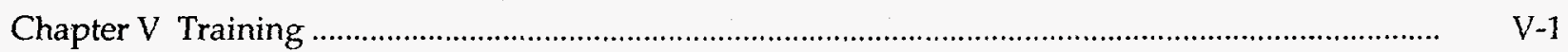

1. General ............................................................................................................. V

2. Supervisory Responsibility ..................................................................................... V-1

3. Training and Qualification Programs ............................................................................. $\quad \mathrm{V}-1$

Chapter VI Quantity-Distance and Level-of-Protection Criteria for Explosives Activities ............... VI-1

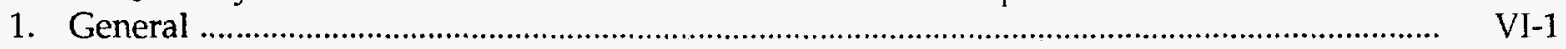

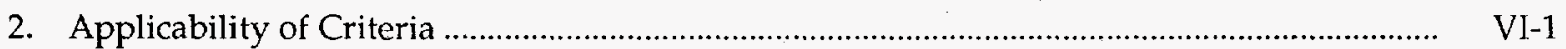

2.1 Specific Applications ............................................................................................ VI-1

2.2 Explosives Limits ..................................................................................................... VI

2.3 Areas Where Criteria Are Not Applicable …...................................................... VI

3. Quantity-Distance Criteria .................................................................................................. VI-1

3.1 Hazard Classes and Class Division ............................................................................... VI-1

3.2 Establishing Quantity of Explosives and Distances .................................................. VI-3

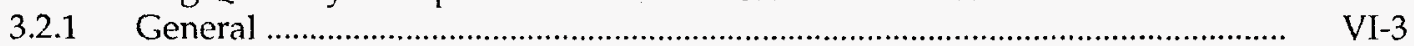

3.2.2 Use of Metric System ............................................................................ VI-3

3.2.3 Railcars and Transport Vehicles ............................................................... VI-3

3.2.4 Utilities Installations .............................................................................. VI-3

4. Level of Protection Criteria ................................................................................................. VI-4

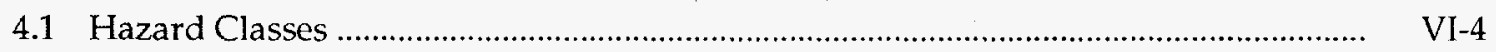

4.2 Required Level of Protection .............................................................................. VI-5

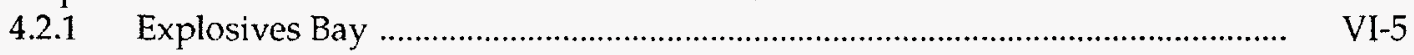

4.2.2 Bays for Joint Explosives-Plutonium Activities ................................................ VI-6

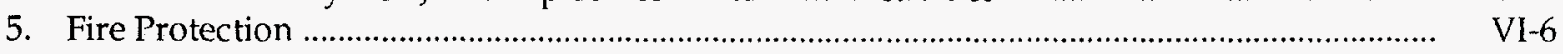

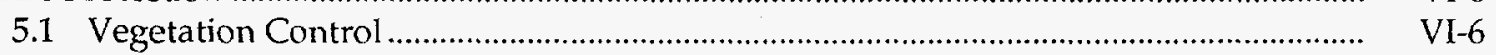

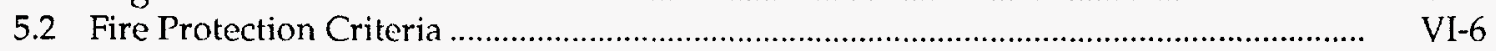

6. Explosives Facility Siting and Design Criteria References .................................................. VI-7

Chapter VII Operating Procedures ........................................................................................... VII-1

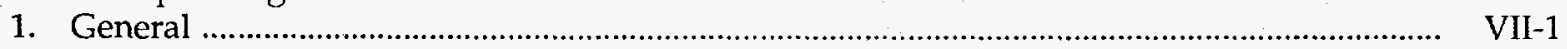

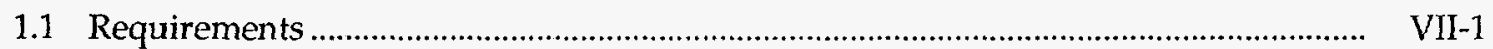

1.2 Types of Procedures ......................................................................................... VII -1

2. Guidelines ................................................................................................................... VII

2.1 Before Operation ............................................................................................... VII-1

2.2 Supervisory Responsibility …....................................................................... VIII 


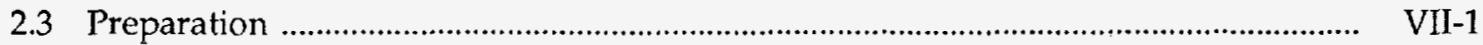

2.4 Approval ………..................................................................................................... VII

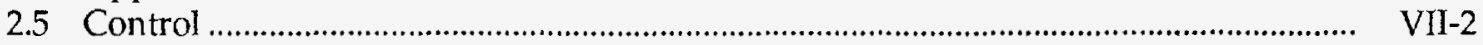

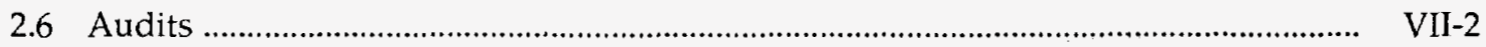

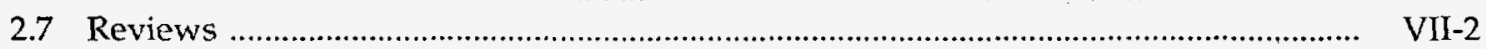

2.8 Content of Standard Operating Procedures ......................................................... VII-2

2.8.1 General Operating Procedures ....................................................................... VII-2

2.8.2 Unit Operating Procedures ..................................................................... VII-2

2.9 Content of Special or Experimental Procedures ............................................................. VII-3

Chapter VIII Formulation Scaleup ……............................................................................................... VIII-1

1. Explosives Development Program ........................................................................................ VIII-1

1.1 Explosives Development Committee ....................................................................... VIII-1

1.2 Phase-by-Phase Approvals ....................................................................................... VIII-1

1.3 Modified Formulations ................................................................................................ VIII-1

1.4 Sensitivity Data from Another Laboratory ................................................................ VIII-1

2. Development Procedures .................................................................................................. VIII-1

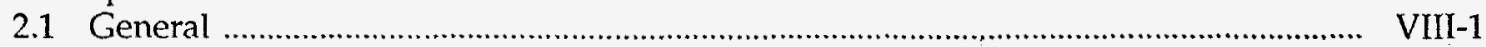

2.2 Synthesis Phase ................................................................................................... VIII-1

2.3 Compatibility Testing ……….................................................................................... VIII-2

2.4 Thase I--Preliminary Explosive Testing ....................................................................... VIII-3

2.5 Phase II-Experimental Characterization and Development ....................................... VIII-3

2.6 Phase III-Full Scale Testing and Production .............................................................. VIII-3

Chapter IX Insensitive High Explosives Qualification .................................................................... IX-1

1. Insensitive High Explosives (IHE) .................................................................................. IX

2. IHE Subassemblies ....................................................................................................... IX-2

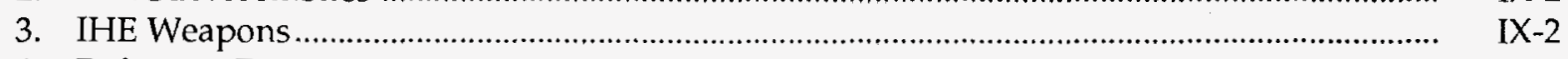

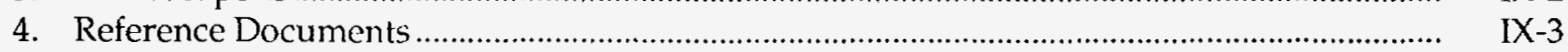

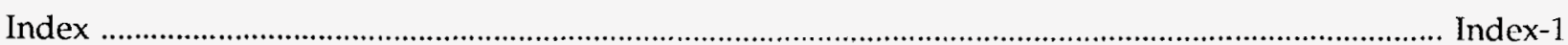




\section{CHAPTER I}

\section{INTRODUCTION}

\section{Purpose}

This manual prescribes the Department of Energy (DOE) safety rules used to implement the DOE safety policy for operations involving explosives.

Explosives handling and processing operations by the DOE are an integral part of weapons and weapons-related development and manufacturing activities. Safety of all operations associated with weapons development is an ongoing, prime concern and nust continually be given high priority in all program direction and management. This manual has been prepared to provide a uniform set of standards for all DOE installations involved in explosives handling or processing.

\section{Scope}

This manual is applicable to all DOE facilities engaged in operations of development, manufacturing, handling, storage, transportation, processing, or testing of explosives, pyrotechnics and propellants, or assemblies containing these materials. The standards of this manual deal with the operations involving explosives, pyrotechnics and propellants, and the safe management of such operations.

The design of all new explosives facilities shall conform to the requirements established in this manual and implemented in DOE 6430.1A, "General Design Criteria Manual." It is not intended that existing physical facilities be changed arbitrarily to comply with these provisions, except as required by law. Existing facilities that do not comply with these standards may continue to bo used for the balance of their functional life, as long as the current operation presents no significantly greater risk than that assumed when the facility was originally designed and it can be demonstrated clearly that a modification to bring the facility into compliance is not feasible. However, in the case of a major renovation, the facility must be brought into compliance with current standards.

The standards are presented as either mandatory or advisory. Mandatory standards, denoted by the words "shall," "must," or "will," are requirements that must be followed unless written authority for deviation is granted as an exemption by the DOE. Advisory standards denoted by "should" or "may" are standards that may be deviated from with a waiver granted by facility management.

\section{Exemptions and Waivers}

\subsection{Exemptions}

An exemption is a written release from a mandatory standard of this manual that has been granted, as applicable, by the DOE Assistant Secretary for Environment, Safety, and Health (EH-1) or by the Operations Office Manager.

The DOE Operations Office Manager is permitted to grant exemptions from the mandatory standards of this manual provided compliance is not feasible, and the facility operator has demonstrated that the conditions, practices, means, methods, or processes to be used will not decrease the level of safety. Requests for exemption shall be submitted to the DOE Operations Office Manager for action. Each such request shall contain the following information:

- Description of condition

- Safety standard requiring deviation

- Reason why compliance cannot be achieved

- Steps taken to provide protection

- Statement of whether equivalent safety is provided and, if not, assessment of the residual risk 
- Any proposed corrective action and schedule

- Duration of exemption.

The DOE Director, Office of Occupational Safety, shall be notified and sent copies of all exemptions granted.

The DOE Operations Office Manager shall submit to the DOE Office of Occupational Safety all requests for exemption from a standard where equivalent protection of operating personnel, the public, and property cannot be achieved. After review of the request for exemption, the $D O E$ I Director, Office of Occupational Safety, shall recommend to EH-1 whether to grant approval of the exemption. EH-1 is responsible for final determination to grantor disapprove the exemption, and for notification to the DOE Operations Office Manager. The DOE Operations Office Manager may grant a temporary exemption for the period of time an exemption request is being processed at DOE Headquarters.

\subsection{Waivers}

If any activity, operation, or process is determined to be not in compliance with the manual's advisory standards but that activity, operation, or process is determined to be safe and necessary, facility management may grant a waiver. Waivers will be granted for the minimum time necessary, and those of an ongoing nature shall be updated every three years. A central file of active waivers shall be maintained by facility management and a copy of each waiver be provided to the local DOE contracting officer. Each waiver shall contain, as a minimum, the following information:

- Description of condition

- Safety standard requiring deviation

- Reason why compliance is not achieved

- Steps taken to provide protection

- Any proposed correctiveactionsand schedule

- Waiver duration or expiration date.

\section{Manual Administration and Management}

Theadministration and management of the DOE Explosives Safety Manual shall be accomplished through the DOE Director, Office of Occupational Safety, by the DOE Explosives Safety Committee.

\subsection{DOE Explosives Safety Committee Organization}

The DOE Explosives Safety Committee is composed of a member from each of the following:

- DOE Office of Occupational Safety

- DOE Office of Military Application

- DOE Field Office, Albuquerque

- DOE Field Office, Oakland

- DOE Nevada Test Site Operations

- DOE Kirtland Area Office

- DOE Field Office, Idaho

- Los Alamos National Laboratory

- Lawrence Livermore National Laboratory Company

- Pantex Plant, Mason \& Hanger-Silas Mason

- Mound, EG\&G Applied Technologies, Inc.

- Kansas City Plant, Allied-Signal Inc.
- EG\&G Idaho, Inc.

- Reynolds Electrical \& Engineering Co., Inc., Nevada Test Site

- Sandia National Laboratories.

The committee shall be chaired by the DOE Office of Occupational Safety Representative, and will report directly to the DOE Director, Office of Occupational Safety, through the Chairperson.

\subsection{DOE Explosives Safety Committee Functions}

The DOE Explosives Safety Committee shall:

- Review, evaluate, and act under authority delegated from the DOE Director, Office of Occupational Safety, on proposed changes or revisions to this manual

- Evaluate and respond to requests for interpretations of the manual

- Meet periodically, as appropriate, to review and evaluate manual adequacy and existing exemptions, and to initiate manual changes as needed.

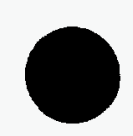




\section{Definitions}

For purposes of this manual, the following terms are defined:

APPROVED. Complying with the provision(s) of this manual and with instructions and details issued by the authority having jurisdiction or with those of other approving agencies specified herein.

ARM. A general term that implies the energizing of electronic and electrical circuitry, which in turn controls power sources or other components used to initiate explosives. The arming operation completes all steps preparatory to clectrical initiation of explosives except the actual fire signal.

BARRICADE. An intervening approved barrier, natural or artificial, of such type, size, and construction as to limit in a prescribed manner the effect of an explosion on nearby buildings or personnel.

BAY. A location (room, cubicle, cell, work area, etc.) containing a single type of explosives activity, which affords the required protection specified for appropriate hazard classification of the activity involved.

BLENDING. The mixing of solid materials (usually dry) by gravity flow, usually induced by vessel rotation.

BOOSTER. Booster or boostering explosives are explosives used in an explosive train to amplify the shock output of the initiating device and cause detonation of the main explosive charge.

CASUAL. A person other than an operator who intermittently visits an explosives operation for the purpose of supervision, inspection, maintenance, etc.

COMBUSTIBLE MATERIAL. Any material which, when ignited, will sustain burning.

COMPATIBILITY. The chemical property of materials to coexist without adverse reaction for an acceptable period of time.

Compatibility in storage exists when storing materials together does not increase the probability of an accident or, for a given quantity, the magnitude of the effects of such an accident. Storage compatibility groups are assigned to provide for segregated storage.

CONCURRENT OPERATIONS. Operations performed simultaneously and in close enough proximity that an incident with one operation could adversely influence the other.
CONTACT OPERATIONS. An operation in which an operator and an explosive item are both present with no operational shield.

CONTROL POINT. The location used for personnel control and operation coordination in an explosives operating or test area.

CORING. A machining operation that removes material in the form of a cylinder by cutting at the circumference to create a hole or recover the material from the center of the cut.

CRITICAL TEMPERATURE. Temperature above which the self-heating of an explosive causes a runaway reaction. It is dependent on mass, geometry, and thermal boundary conditions.

DANGER ZONE. That area around a test site where personnel could be in physical jeopardy due to overpressure, fragments, or firebrands released during an explosive test.

DEFLAGRATION. A rapid chemical reaction in which the output of heat is sufficient to enable the reaction to proceed and be accelerated without input of heat from another source. Deflagration is a surface phenomenon with the reaction products flowing away from the unreacted material along the surface at subsonic velocity. The effect of a true deflagration under confinement is an explosion. Confinement of the reaction increases pressure, rate of reaction, and temperature and may cause transition into a detonation.

DETONATION. A violent chemical reaction within a chemical compound or mechanical mixture evolving heat and pressure. A detonation is a reaction that proceeds through the reacted material toward the unreacted material at a supersonic velocity. The result of the chemical reaction is exertion of extremely high pressure on the surrounding medium, forming a propagating shock wave that is originally of supersonic velocity. When the material is located on or near the surface of the ground, a detonation is normally characterized by a crater.

DIFFERENTIAL SCANNING CALORIMETRY. A technique in which the difference in energy inputs into a substance and a reference material is measured as a function of temperature or time while the substance and the reference material are subjected to a controlled temperature program, or are held isothermally. The record is the DSC curve; the energy input is substituted for DT and is plotted in the same manner as a normal DTA curve. 
DIFFERENTIAL THERMAL ANALYSIS. A technique in which the temperature difference between a substance and a reference material is measured as a function of temperature while the substance and the reference material are subjected to a controlled temperature program. The record is the differential thermal analysis or DTA curve.

DRYING. The removal of volatiles from ingredients or mixtures.

DSC. See DIFFERENTIAL SCANNING CALORIMETRY.

DTA. See DIFFERENTIAL THERMAL ANALYSIS.

EBW. See EXPLODING BRIDGEWIRE.

EED. See ELECTROEXPLOSIVE DEVICE.

ELECTRICAL BONDING. Electrical connection between two conductive objects intended to prevent development of an electrical potential between them.

ELECTROEXPLOSIVE DEVICE (EED). An EED is a device containing some reaction mixture (explosive or pyrotechnic) that is electrically initiated. The output of the initiation is heat, shock, or mechanical action. See also LOW-ENERGY EED.

EXPERIMENTAL OPERATING PROCEDURE. A procedure prepared for conducting a specific experiment a limited number of times under close technical supervision.

EXPLODING BRIDGEWIRE (EBW). An EED that is initiated by the discharge of a high current through the device bridgewire, causing the wire to explode and produce a shockwave. An EBW as defined herein is a device containing no primary explosive.

EXPLOSIVE. Any chemical compound or mechanical mixture which, when subjected to heat, impact, friction, shock, or other suitable initiation stimulus, undergoes a very rapid chemical change with the evolution of large volumes of highly heated gases that exert pressures in the surrounding medium. The term applies to materials that either detonate or deflagrate. DOE explosives may be dyed various colors except pink which is reserved for mock explosive.

EXPLOSIVE DECONTAMINATION. The removal of hazardous explosive material.

EXTRUDING. Forcing a plastic-type material, under pressure, into a confined space or through a confined opening to produce a desired configuration.

FACILITY. A groupofbuildingsor equipment used for explosive operations at one geographic location, generally owned by DOE.
FACILITY MANAGEMENT. Management staff of the facility operator (the contractor).

FACILITY OPERATOR. The organization having responsibility for conducting operations at a DOE facility.

FIREBRAND. A projected burning or hot fragment whose thermal energy is transferred to a receptor.

FIRING PAD. The prepared site where explosive items are fired for test data acquisition.

FIRING SITE. Controlled access area where test firing of explosives is conducted.

FLAMMABLE LIQUID. Any liquid having a flash point below $60^{\circ} \mathrm{C}$ and a vapor pressure not excecding $280 \mathrm{kPa}\left(41 \mathrm{psia}\right.$ ) at $37.8^{\circ} \mathrm{C}$. This is the definition as applied in this manual; it includes some materials defined as combustible liquids by the Department of Transportation (DOT).

FLASH POINT. The temperature at which a liquid or volatile solid gives off a vapor sufficient to form an ignitable mixture with air near the surface of the material or within the test vessel.

FORMULATION. Theoperation of combining ingredients to produce a mixture of a final desired composition possessing specific physical and explosive properties.

An explosives composition.

HEATING LIMITS. The conditions established for safely heating an explosive system (maximum temperature, heating time, heating rate, etc.). These limits are based on the estimated critical temperature of the explosive system with a suitable margin of safety.

HIGH-ENERGY INITIATOR. Exploding bridge wire systems, slapper detonators, and EEDs with similar energy requirements for initiation.

HOLE (as applied to machine explosives). Any cavity that is more than one-half diameter deep, being cut by any tool with the direction of feed along the axis of rotation.

HOT WORK (thermal). Any operation requiring the use of a flame-producing device, an electrically heated tool producing a temperature higher than $109^{\circ} \mathrm{C}$, or a mechanical tool that can produce sparks or heat explosives or explosives contamination to provide an initiation stimulus.

HYDROSTATIC PRESSING. The operation of compacting a material that is confined in a press by a diaphragm by hydraulically applying pressure to the diaphragm.

IHE. SEINSENSITIVE HIGHEXPLOLSIVES.

IHE SUBASSEMBLIES. IHE hemispheres or spheres with booster charges, with or without deto- 
nators, that pass the DOE qualification tests listed in Table IX-3.

IHE WEAPONS. Weapons listed in TP 20-7 as being exempt from storage and transportation limits are classified as IHE weapons when stored or transported alone or in combination with each other. This classification is valid only if the spacing between individual units is that provided by storage/ shipping containers or, if not in containers, by the spacing specified in TP 20-7.

INERT MATERIALS. The material shows no exothermic decomposition when tested by DSC or DTA. Moreover, the inert material shall not show any incompatibility with energetic material with which it may be combined when tested by recognized compatibility tests. Inert material shall neither alter the onset of exotherm of the DSC or DTA trace of the energetic materialnorincrease the rate ofdecomposition or gas evolution of the energetic material.

IN-PROCESS STORAGE MAGAZINE (facility, vault, rest house, etc.). See SERVICE MAGAZINE.

INHABITED BUILDING. A building or structure other than operating buildings, magazines, and auxiliary buildings occupied in whole or in part as a habitation for people or where people are accustomed to assemble, both within and outside DOE facilities. Land outside DOE facilities shall be considered as sites for inhabited buildings.

INHABITED BUILDING DISTANCE. The minimum distance permitted between explosives locations and inhabited buildings, administrative areas, site boundaries, main power stations, and other facilities of vital or strategic nature. Also, the distance between adjacent operating lines.

INITIATION STIMULUS. Energy input to an explosive in a form potentially capable of initiating a rapid decomposition reaction. Typical initiation stimuli are heat, friction, impact, electrical discharge, and shock.

INITIATION, WITH ITS OWN MEANS. Explosives or ammunition having their normal initiating device (e.g., detonators, squibs) assembled to them so that this device is considered to present a significant risk of activation during storage.

INITIATION, WITHOUT ITS OWN MEANS. Explosives or ammunition that (1) are not stored with an initiating device assembled to them; or (2) have the initiating device assembled to them, but (a) safety features preclude initiation of the explosives filler of the end item in the event of accidental functioning of the initiating device, or (b) the initiating device does not contain any primary explosives and has a high threshold of initiation (e.g., EBW or Slapper detonators). The power source for the initiator(s) should not be present within the assembly or system. If the initiator(s) power source is present, two or more management-certified safety devices connected in series shall be present to interrupt any flow of energy from the power source to the initiator(s).

INSENSITIVE HIGH EXPLOSIVES (IHE). Explosive substances which, although mass detonating, are so insensitive that there is negligible probability of accidental initiation or transition from burning to detonation. The materials passing the DOE qualification tests in Table IX-1 are classified as IHE, and are listed in Table IX-2.

INTRALINE DISTANCE. The distance to be maintained between any two operating buildings or sites within an operating line, at least one of which contains, or is designed to contain, explosives.

ISOSTATIC PRESSING. Theoperation of compacting a material in a sealed flexible container. The container is submerged in a pressure vessel, and the vessel is pressurized with liquid.

LABORATORYOPERATIONS. Experimental study, testing, and analysis of small quantities of cnergetic materials. Manufacturing processes with small quantities of materials are not included.

$L E L$. See LOWER EXPLOSIVE LIMIT.

LFL. See LOWER FLAMMABLE LIMIT.

LOW-ENERGY EED. All EED's except exploding bridgewire (EBW) detonators and slapper detonators.

LOWER EXPLOSIVE LIMIT (LEL). The concentration of vapor or dust in air below which an explosion cannot occur.

LOWER FLAMMABLE LIMIT (LFL). The concentration of a vapor or dust in air below which a burning reaction cannot be sustained.

MACHINING. A forming operation accomplished by removing material with a mechanically operated cutting tool.

MACHINING OVERTEST. A test to evaluate the susceptibility of an explosive material to initiation during machining.

MAGAZINE. See SERVICE MAGAZINE or STORAGE MAGAZINE.

MAGAZINE DISTANCE. The minimum distance permitted between any two storage magazines. The distance required is determined by the type(s) of magazine and also the type and quantity of explosives stored therein.

MAXIMUM CREDIBLE EVENT (MCE). The MCE from a hypothesized accidental explosion orfire 
is the worst single event that is likely to occur from a given quantity and disposition of explosives/explosives devices. The event must be realistic with a reasonable probability of occurrence considering the explosivepropagation,burning ratecharacteristics, and physical protection given to the items involved.

MELTING. Operations involving change in explosives' physical state from solid to liquid.

MILLING. (1) Operations that either reduce solid material particle size by attrition or apply highshear mixing to incorporate solid materials into plastic binders; (2) a surface machining operation performed on a mill.

MIXING. A mechanical operation that combines dissimilar materials.

MOCK EXPLOSIVE. Substances bearing similar physical properties (texture, density, cohesion, etc.) to an explosive material. They are nondetonable, however some are exothermic materials and will burn. They are used to represent an explosive for purposes such as dry run testing of equipment. DOE mock explosives are normally pink in color.

NEW (OR EXPERIMENTAL) EXPLOSIVE. Explosive, explosive mixture, or explosiveand binder mixture that has not been characterized by the Explosives Development Committee.

NON-DOE FACILITY PERSONNEL. Personnel of a contractor who does not have a continuing contract with DOE at the facility concerned.

OPERATIONAL SHIELD. A barricade constructed to protect personnel, material, or equipment from the effects of a possible fire or explosion occurring at a particular operation.

PERSONNEL BARRIER. A device designed to limit or prevent personnel access to a building or an area during hazardous operations.

PRESSING. The operation of increasing the density of explosive material by the application of pressure.

PROPELLANT. Explosive composition used for propelling projectiles and rockets and to generate gases for powering auxiliary devices.

PUBLIC TRAFFIC ROUTE DISTANCE. Any public street, road, highway, or passenger railroad (including roads on DOE-controlled land open to public travel).

PUNCH AND DIE PRESSING. The operation of compacting a material confined by a die by forcing a punch or punches into the die and against the material.

PYROTECHNIC MATERIAL. Physical mixtures of finely divided fuels and oxidizer powders; may include various organic binders and color in- tensifiers. The material is intended to produce an effect by heat, light, sound, gas or smoke, or a combination of these as the result of non-detonative, selfsustaining exothermic chemical reactions.

REMOTE OPERATION. An operation performed in a manner so as to provide protection to personnel in the event of an accidental explosion. This can be accomplished by distance, shielding, barricades, or a combination thereof.

RISK. A measure of the combination of the probability and consequences of the hazards of an operation, cxpressed in qualitative or quantitative terms.

SAFETYANALYSIS. A document prepared to systematically identify the hazards of a DOE operation; describeand analyze the adequacy of measures taken to eliminate, control, or mitigate identified hazards; and analyze and evaluate potential accidents and their associated risks.

SCREENING. An operation using screens to separate particles of differing sizes.

SERVICE MAGAZINE, REST HOUSE, ETC. An auxiliary building or suitably designated room (vault) used for the intermediate storage of explosives materials not exceeding the minimum amount necessary for safe and efficient operation.

SHUNT. Electrically interconnecting various portions of EED circuitry to prevent the development of an electrical charge differential between the shunted parts.

SLAPPERDETONATOR. AnEEDinitiated by a rapid discharge of a high current through a metal foil. The expansion of the metal vapor causes a plastic or metal covering to be propelled across an air gap and detonate a high-density explosive pellet.

SMALL ARMS AMMUNITION. (1) Ammunition designed to be fired from a pistol, revolver, rifle, or shotgun held by the hand or to the shoulder; (2) ammunition of caliber less than $20 \mathrm{~mm}$ with incendiary, solid, inert, or empty projectiles (with or without tracers) designed to be fired from machine guns or cannons; (3) blank cartridges.

SOP. See STANDARD (STANDING) OPERATING PROCEDURE.

SPECIAL OPERATING PROCEDURE. A procedure prepared for performance of a specific task on a one-time basis, or for situations not encountered in normal operation.

STANDARD (STANDING) OPERATING PROCEDURE (SOP). A procedure prepared for operation of a facility or performance of a task on a routine basis.

STORAGE MAGAZINE. A structure designed or specifically designated for the long-term storage of explosives or ammunition. 
SUBSTANTIAL DIVIDING WALL. An interior wall designed to prevent the propagation of an accidental detonation on one side of a wall to explosives on the other side.

SYNTHESIS. The chemical operation(s) required to produce a desired chemical compound.

TARGET. The area, structure, or material into which a projectile is fired.

TNT EQUTVALENT. A measure of the blast effects from explosion of a given quantity of material expressed in terms of the weight of TNT that would produce the same blast effects when detonated.

TRANSIENT. Any person within inhabited building distance but not inside an explosives bay or other occupied areas (offices, break areas, shops, etc.).
UNTTED NATIONS ORGANIZATION (UNO) CLASS 1 EXPLOSIVES. (a) Explosive substances (a substance that is not itself an explosive but that can form an explosive atmosphere of gas, vapor, or dust is not included in Class 1), except those that are too dangerous to transport or those where the predominant hazard is appropriate to another class; (b) Explosive articles, except devices containing explosive substances in such quantity or of such a character that their inadvertent or accidental ignition or initiation during transport shall not cause any effect external to the device either by projection, fire, smoke, heat, or loud noise; and (c) Substances and articles not mentioned under (a) and (b) that are manufactured with a view of producing a practical, explosive or pyrotechnic effect. 


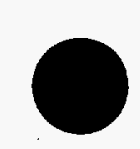

○

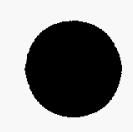




\section{CHAPTER II}

\section{OPERATIONAL SAFETY}

\section{General Operations Safety Guidelines}

\subsection{Protection of Explosives}

Explosives are energetic materials that can react violently. Explosives should be protected from abnormal stimuli or environments, including-

- Friction forces

- Excessive pressures

- Excessive temperatures

- Impact, shock, pinching

- Deformation

- Electrical sparks, abrasive or welding sparks, open flame

- Contamination

- Contact with incompatible materials.

\subsection{Equipment Checks}

Before being used in the explosives process, and at established intervals, processing and test equipment shall be checked for-

- Proper design

- Proper function

- Specified clearances between parts in relative motion

- Abnormal metal-to-metal rubbing of moving parts potentially contacting explosive materials

- Cracks, voids, or screw threads where explosives may accumulate

- Contamination that is incompatible with the materials to be introduced.

This checkout may require the use of mock explosives in process or test conditions.

Explosive materials must not be pinched or confined between equipment lids or covers and their mating surfaces. These surfaces shall be cleaned before cover placement. This includes pressing operations.

\subsection{Inspection Frequency}

When an inspection is called for by this manual but the inspection interval is not specified, such inspection interval shall be established by local facility management. Inspection intervals shall be modified when experience dictates a need.

\subsection{Laboratory Operations}

The special safety guidelines applicable to general laboratory operations involving explosive materials are contained in Section 21 of this chapter.

\subsection{Toxicity Hazards}

Explosives materials, explosives components (additives or adhesives), and materials such as organic solvents used in explosives processing can be toxic when inhaled, ingested, or absorbed through the skin. Skin contact with explosives materials, or with solvents and adhesives used in conjunction with explosives operations, can result in a skin rash. This is the most frequently reported effect from working with these materials. The following general precautions should be used to prevent overexposure to these materials during explosives processing and handling:

a. Know the health hazard and controls before beginning operations.

b. Have the operation evaluated during startup to assure that occupational exposure limits are not exceeded; routine operations should be monitored periodically.

c. Handle in a well ventilated area; local exhaust ventilation is preferred.

d. Avoid skin contact; use appropriate protective clothing.

e. Practice good personal cleanliness; wash before eating, smoking, or using toilet facilities; end-of-shift showers may be required for some operators.

\subsection{Hazard Identification and Communication}

Before beginning explosives operations, managers shall-

a. Identify and maintain a current list of explosives and other hazardous materials used in conjunction with their operations.

b. Determine the hazardous properties and toxicity of these materials through the use of the 
manufacturer's Material Safety Data Sheets (MSDS) or other information sources and through consultation with the facility Industrial Hygienestaff. For explosives without published toxicological data, guidance can be obtained through the DOE Toxic Materials Advisory Committee (TMAC). Health hazard information must be communicated to employees who work with or generate hazardous materials. c. Educate and train employees in the hazards and precautions required for handling explosives and materials used in conjunction with explosives operations. This training should be part of the employee training and qualification program specified in Chapter V. 


\section{CHAPTER II}

\section{Work Environment}

\subsection{General Requirements}

a. An adequate work space shall be provided to perform safe and efficient operations.

b. Work shall be organized in a manner that eliminates clutter in the area while operations are being performed.

c. Walkways should be kept clear.

d. In work environments where solid, bare explosive pieces are handled, the floor should be cushioned, and all hard objects that may be struck by explosives in a handling incident should be cushioned where it is practical.

e. An accounting procedure should be established for hand tools that may be inadvertently dropped into an explosives processing operation, thus creating a hazard.

f. Personnel shall be assigned in a manner such that each worker's presence is frequently monitored and assistance can be provided or aid summoned in the event of an emergency.

g. Safety analysis of explosives facilities shall be performed according to the current version of DOE 5481.1, "Safety Analysis and Review System" and DOE 6430.1A, "General Design Criteria." The safety analysis shall be performed during the design of new explosives facilities or in the redesign of existing facilities. Facility management shall maintain readily available analyses documentation.

$h$. Noisy environments caused by explosives testing operations or process and handling equipment shall be evaluated. Areas with noise above the allowable occupational exposure limits must be posted and appropriate control measures instituted (e.g., engineering controls, protective equipment, and a hearing conservation program).

\subsection{Emergency Exit Requirements for Explosives Operations}

Exit requirements for any building or structure containing explosives shall comply with the intent of the Life Safety Code, NFPA 101, except as otherwise permitted in this section. In someaccident situations, there may not be sufficient time to use exits. These rules provide an opportunity for safe exit of personnel during a fire situation. Emergency exit routes shall be preplanned, and escape drills shall be conducted periodically.

\subsubsection{Building or Structure Classification}

In determining NFPA 101 requirements, explosives operating buildings shall be classified as industrial occupancies (NFPA 101, Chapter 28) of the special-purpose industrial or high-hazard industrial type, as applicable. Explosives storage or staging buildings or structures shall be classified as storage occupancies (NFPA 101, Chapter 29) with either high-hazard or ordinary-hazard contents, as applicable.

\subsubsection{Hazard of Contents Classification}

The hazard of contents classification of any explosives occupancy shall be determined using the guidelines given in NFPA 101 and the following requirements:

a. High-hazard explosives contents are those which, because of form, character, or volume, are likely to burn with extreme rapidity or from which poisonous fumes or explosions can be expected in the event of fire. The expectation of poisonous fumes or explosions is a relative matter to be determined on a case-by-case judgment basis. Operating buildings containing propellant, pyrotechnic, or explosive powders shall be classified as highhazard occupancies if a life safety threat could result.

b. Ordinary-hazard explosives contents are those that burn with moderate or less rapidity, may give off considerable amounts of smoke, but are not expected to produce poisonous fumes or a detonation from a fire within a 2-minute period. This 2-minute period is necessary for personnel to escape from the fire area in an orderly evacuation to a point of safety.

\subsubsection{Personnel Protective Restrictions and Requirements}

DOE occupancies containing high explosives dictate personnel protection from blast overpressures and fragments (and spread of plutonium in some occupancies) from an accidental detonation. This accidental detonation of explosives is usually the result of stimuli other than a fire. Where noncompliance with some NFPA 101 provisions is required to provide this protection (such as those covcring exit doors, exit travel distance, number and 
location of exits, and common path of travel to exits), the following additional personnel protective restrictions or requirements should be imposed:

a. The building and means of egress should be protected by supervised automatic sprinkler systems connected to sound evacuation alarms.

b. The building and means of egress should have automatic, early warning fire detection systems connected to sound evacuation alarms where such early warning might reasonably aid in prevention or mitigation of personnel injury.

c. Personnel limits within the explosives work area (bay, cell, etc.) should be maintained and controlled not to exceed 20 for ordinary-hazard occupancies and not to exceed 6 for high-hazard occupancies.

d. The interior finish in the exits should be Class A (0-25 flame spread).

e. Emergency lighting should be provided for the structure and means of egress.

\subsubsection{Travel Distances}

Where provisions for personnel protection from blast make it necessary to exceed travel distances or common path of travel distances allowed by NFPA 101 , the following are required in addition to the requirements of paragraph 2.2.3:

a. Travel to exits shall be kept as short as possible. The distance shall not exceed 150 feet from any point to the nearest exit for ordinary-hazard or general industrial occupancies. The distance shall not exceed 100 feet for high-hazard occupancies. Travel distances shall be measured as required by NFPA 101.

b. The common path of travel to a point outside the fire area of the room, bay, or cell containing the explosives operations shall be as short as possible, not to exceed 50 feet for any occupancy.

c. Dead ends shall be as short as possible, not to exceed 50 feet.

\subsubsection{Single Exits}

Where at least two exits are required by NFPA 101 and provisions for personnel protection from a blast will not permit at least two exits from a room or structure, a single exit is acceptable, provided the requirements of paragraphs 2.2.3 and 2.2.4 and the following are met:

a. The path of exit travel shall be arranged so it is not through or toward a hazardous operation.

b. The room containing a high-hazard explosive occupancy shall not exceed 500 square feet, and the occupant load of the room shall be restricted to two operators and two transients.

c. The room containing an ordinary-hazard explosive occupancy shall not exceed 1,000 square feet.

\subsubsection{Blast-Resistant Doors}

Blast-resistant doors required for the purpose of personnel protection from the effects of an accidental detonation may be located in the means of egress, provided the requirements of paragraphs 2.2.3 through 2.2 .5 and the following are met:

a. The doors shall swing in the direction of exit travel (except revolving doors).

b. The doors shall be panic-hard ware operated (except revolving doors).

c. The doors shall have the capability of being unlatched and opened with the forces specified in NFPA 101. Where power-operated doors are required to accomplish unlatching and opening, they shall have reliable power supplies and shall be capable of being opened manually (to permit exit travel) or closed where necessary to safeguard the exits.

d. The time required to fully open or close a door shall be as short as reasonably possible, not to exceed 15 seconds.

e. A revolving door is acceptable if a secondary means of escape (with swinging doors) is provided at the same location. The revolving door must also be prevented from rotating at too rapid a rate in order to permit orderly exit of personnel.

\subsubsection{Slide Escapes}

Slide escapes should be provided for elevated explosives operating locations from which rapid exit may be vital and cannot be obtained by other means. Slide escapes should be located on opposite sides of the explosives operation to reduce the likelihood of personnel being trapped by fire between them and a single slide. Exits to slide escapes must open onto platforms that are not less than 3 feet square, and the platforms must be equipped with guardrails. The slides shall begin at the outside edge of the platform, not at the edge of the buildings. Slide escapelandings shall be located at selected places leading directly to escape routes that are free from tripping hazards, low guy lines, drains, ditches, or other obstructions. Manually or automatically controlled devices (trips) that sound an alarm in the operating building shall be installed at or near the entrances to slide escapes. These devices may also actuate deluge valves and water curtains in the building or room affected. 
Recommended slide escape specifications:

- Angle, 40 to 50 degrees horizontal

- Slide depth, 24 inches

- Radius at bottom of slide, 12 inches

- Height at lower end of slide, not over 24 inches above the landing.

If necessary, the end of the slide must have a horizontal run sufficient to prevent an employee injury because of exit speed without the use of landing cushions (which are unsatisfactory in cold weather). One foot of horizontal run is required for a 15-foot-long slide. One additional foot of horizontal run will be provided for each additional 5 feet of slide length. The juncture of the two sections must be well rounded. The metal sheets constructing the slide must overlap in the direction of travel. 
-

○

II-6 


\section{CHAPTER II}

\section{Building and Equipment Maintenance}

\subsection{Cleaning}

a. Structures containing explosives shall be kept clean and orderly.

b. Explosives and explosives dust shall not be allowed to accumulate on structural members, radiators, heating coils, utility lines, equipment, or electrical fixtures.

c. In order to maintain safe conditions, there shall be a regular cleaning program for building interiors to prevent explosives dust and waste accumulation. This program should not be conducted in any bay where a hazardous operation is being conducted.

d. In buildings containing explosives, hot water or water-steam mix should be used wherever practical for cleaning floors. Sweeping compounds that are nonabrasive and compatible with the explosives involved may be used when the use of water-steam mix or hot water is not practical. Such compounds may be combustible but must not be volatile (closed-cup flash point must not be lower than $110^{\circ} \mathrm{C}$ ). Sweeping compounds containing wax shall not be used on conductive flooring. Where nitrated organic explosives (which may form sensitive explosive compounds with some alkalies) are involved, the use of cleaning agents containing those alkalies is prohibited.

e. Before beginning explosives decontamination activities that involve the use of large amounts of organic solvents (generally over 1 liter), provisions must be made for (1) adequate ventilation or respiratory protection, (2) fire protection, and (3) adequate protective clothing.

\subsection{Maintenance and Repair}

a. Records shall be maintained for inspection, repair, and servicing of process and handling equipment and fire protection systems.

b. Maintenance operations involving major repairs, changes, or the use of hazardous equipment should not be performed within bays (rooms) while explosives are present. Before these operations, explosives should be removed and the area prepared.
An approval procedure shall be established to ensure that the area has been inspected and is safe for these operations.

c. Maintenance or construction operations performed by non-DOE facility personnel shall be at least intraline distance from any explosives operation and should be at least intraline distance from any building containing explosives. (Intraline distance separation may be satisfied by providing equivalent protection.) Transportation of explosives is permitted on roadways at less than intraline distance.

d. New equipment or equipment subjected to major repair or modification shall be test-operated, and handling equipment shall be tested before being returned to operations. The DOE "Hoisting and Rigging Manual" may be used as a guide.

e. Maintenance work shall only be performed by authorized personnel.

f. Before resuming operations following maintenance, the area shall be cleaned and approved by the operations supervisor.

\subsection{Hot Work Permits}

Where explosives are involved, a written permit shall be required for the temporary use of portable, heat-producing equipment that generates temperatures higher than $109^{\circ} \mathrm{C}$. Explosives decontamination of the immediately affected work areas and explosives removal shall be required before hot work operations. The permit should state the location, time, duration, purpose of use, details of safety, and fire-fighting equipment required. The permit shall be kept at the named location for availability to and checkout by supervisory personnel.

a. Authorization of permits shall be by signature of personnel designated by the local facility management. Designated personnel should be qualified by experience in explosives work, fire prevention, and general safety precautions, particularly with regard to the purging of equipment, presence of flammable mixtures, and the avoidance of electrical and mechanical hazards that could be incident to repair work. 
b. Designated personnel should represent supervision of the location where the work is being performed, supervision of personnel performing the hot work, and a third group independent of the first two (usually the local safety and fire protection group). c. Someone should remain at the site of a cutting or welding job for approximately 30 minutes after the job has been completed for the purpose of extinguishing or reporting any fires that develop. Designated supervision should inspect the job site before job initiation, during the job, and after job completion. 


\section{CHAPTER II}

\section{Remote Operations}

\subsection{Personnel Protection Criteria}

Explosives operations judged to present a high enough level of risk to be performed remotely shall be conducted in facilities where the construction of the operating bay or the control room is capable of affording sufficient protection to personnel to prevent serious injuries. Criteria for the prevention of serious injuries are specified in Chapter VI, paragraph 4.2.1.d.

Prevention of serious injury from a remote operation applies to transient personnel as well as to personnel involved in the operation.

\subsection{Access and Equipment Controls}

Control procedures and equipment shall be used to prevent personnel from entering the hazardous bay or area in which a remote operation is occurring or to prevent the operation from proceeding when personnel enter, as follows: a. Roads shall be blocked at a minimum of the public traffic route distance from buildings where hazardous (remote) operations are being performed. Public traffic route separation may be satisfied by providing equivalent protection.

b. Corridors leading to bays in which hazardous (remote) operations are being performed shall be adcquately marked to warn of the danger. Barriers shall also be set up.

c. Visual methods such as closed circuit television should be used to monitor remote operations and to enable viewing the operating area conditions before entering. Remote audio monitoring and video recording should also be considered.

d. Interlocking of remote operating equipment to access doors should be required for each remote operation.

e. Buildings or bays in which remote operations are performed shall be conspicuously identified by lights or similar warning devices to indicate when operations are under way. 
-

-

II-10 


\section{CHAPTER II}

\section{General Explosives Area Controls}

\subsection{Smoking, Matches, Lighters, Metal Articles}

a. There shall be no smoking in explosives storage, processing, or test areas, except in designated locations.

b. No matches, lighters, other fire-, flame-, or spark-producing devices shall be taken in to an explosives control area except with written authorization. If authorized to be carried, matches shall be contained in a metal carrying device too large to fit in pockets. Kitchen ("strike anywhere") matches shall not be used.

c. In explosives processing areas, metal articles (keys, jewelry, knives, coins, etc.) should not be carried by operating personnel where such items could constitute a hazard if dropped into the process operation.

\subsection{Cooking and Eating}

a. There shall be no consumption of food or beverages in an explosives building, except in designated areas. b. There shall be no personal dishes or utensils in an explosives building, except in designated eating areas.

c. Coffee pots, hot plates, ovens (including microwave), and portable electric heaters shall not be permitted in rooms where:

- Explosives may be present

- Combustible vapors or dust may be present

- Smoking or drinking is prohibited because there are toxic materials present

- Electrical classification of appliances is not compatible with the area.

\subsection{Access to Explosives Areas}

Access control procedures shall be established for entry to all explosives areas. 
-

○

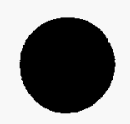

II-12 


\section{CHAPTER II}

\section{Electrical Storms and Lightning Protection}

\subsection{Assessment}

Whenever an electrical storm approaches, personnel shall exit any location wherein a hazard exists due to explosives being initiated by lightning. Determination of the existence of such a hazard shall be based on the assessment of the specific operation and facility or area lightning protection. Locations where evacuation may be necessary are listed below:

- All outdoor operations and operations in buildings that do not afford lightning protection, and locations within inhabited building distance of the hazard. (When an electrical storm is imminent, explosives operations should not be initiated.)

- Explosives-carrying vehicles and railroad cars and locations within magazine distance of the hazard.

- Locations (with or without lightning protection) where operations involving electrostatic-sensitive bulk explosives or electroexplosive devices (EEDs) are being performed.

\subsection{Evacuation}

Evacuated personnel shall proceed to a suitable protective shelter. A suitable shelter is one that will protect personnel fromoverpressures greater than 16 $\mathrm{kPa}(2.3 \mathrm{psi})$, structural collapse, and missiles in the event of explosion of any adjacent facility containing explosives.

\subsection{Shutdown of Operations}

The following guidelines should be used for shutdown of an operation during an electrical storm:

a. Process equipment containing explosives should be stopped as soon as safety permits.

b. When buildings or bays containing explosives are evacuated during periods of electrical storms, operations that cannot be shut down immediately should be manned by the minimum number of personnel required for safe shutdown. When the operation has been brought to a safe condition so that personnel can exit, evacuation of these remaining personnel should proceed. c. Automatic emergency power equipment should be provided if electrical power is critical to an explosives operation during a power shutdown or interruption.

\subsection{Lightning Protection}

It is DOE policy to install lightning protection on all facilities used for storage, processing, and handling of explosives materials where operations cannot be shut down during electrical storms and personnel evacuated. Specific operations shall be assessed for the risk of initiation of process materials by lightning. Assessment shall consider the need for protection factors outlined in NFPA 780, "Lightning Protection Code," Appendix L ("Protection of Structures Housing Explosives"). When risk is high, as in operations with highly sensitive electrostatic materials or components, operations shall only be conducted in lightning-protected facilities. Approved lightning protection systems must conform with the requirements of NFPA 780, Appendix L. Examples of acceptable lightning protection systems can be found in DOD 6055.9-STD, "DOD Ammunition and Explosives Safety Standards," Chapter 7.

a. Visual inspection of lightning protection systems should be conducted every seven months, and shall be conducted at least annually with a report filed following each inspection. Any evidence of corrosion, broken wires/connections or any other problem which would negate the system's usefulness will be noted and repaired.

b. Electrical testing for lightning protection systems should be conducted every 14 months, and shall be conducted at least every 47 months to afford testing during all seasons and immediately following any repairs or modifications. The testing shall be conducted only with instruments designed specifically for earth-ground system testing. The instruments must be able to measure $10 \mathrm{ohms}$ plus or minus 10 percent for ground resistance testing, and $1 \mathrm{ohm}$ plus or minus 10 percent for bonding testing. Electrical resistance readings shall be recorded.

c. Inspection records shall contain the most recent electrical test report and any subsequent visual inspection reports for each building. 


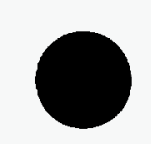

○

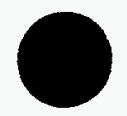

II-14 


\section{CHAPTER II}

\section{Static Electricity}

\subsection{General}

Positive steps must be taken to control or eliminate static electricity in areas where materials are processed or handled that are ignitable by static spark discharge. This includes spark-sensitive explosives, propellants, and pyrotechnics as well as solvent vapors, and flammable gases.

\subsection{Bonding and Grounding of Equipment}

Bonding straps should be used to bridge locations where electrical continuity may be broken by the presence of oil on bearings, paint, or rust at any contact point. Permanent equipment in contact with conductive floors or table tops is not considered to be adequately grounded. Static grounds shall not be made to gas, steam, or air lines, dry pipe sprinkler systems, or air terminals of lightning protection systems. Static grounds can be made to water pipes, ground cones, buried copper plates, driven ground rods, or to down conductors of lightning protection systems. If a structure is equipped with a lightning protection system, all grounds must be interconnected. Wires used as static ground conductors should be at least No. $10 \mathrm{AWG}$ or equivalent.

\subsection{Testing Equipment Grounds}

Grounding systems shall be tested for electrical resistance and continuity when installation has been completed and, in the case of active equipment, at intervals to be locally determined. The ground system shall be visually inspected for continuity (before reactivation of the system) if the equipment has been inactive for more than one month. All exposed explosives or hazardous materials shall be removed before testing. When testing for resistanceto-ground, equipment should be considered as a unit except in the case of a belt-driven machine. In measuring the total resistance-to-ground for belt-driven machinery (to assure compliance with the paragraph below), resistance of the belting is to be excluded.
The maximum resistance-to-ground permitted for different types of equipment is as follows:

Hazardous locations (operations where a static spark discharge may be dangerous). All conductive parts of equipment shall be grounded so that resistance does not exceed $25 \mathrm{ohms}$, unless resistance is not to exceed 10 ohms because of the lightning protection installation. For existing equipment, the rate of static generation should be considered before changes in grounding systems are made. The resistance of conductive rubber hose should not exceed $250,000 \mathrm{ohms}$.

\subsection{Conductive Floors, Shoes, Mats, and Wristbands}

a. Conductive floors and shoes should be used for grounding personnel in operations involving explosives, propellants, pyrotechnics, etc., that are sensitive to initiation by the electrostatic spark discharge from a person. These include lead azide, lead styphnate, mercury fulminate, CP, some propellants, some pyrotechnics, etc. Many flammable liquids and air mixtures can be ignited by static discharge from a person. When personnel come into the proximity of (possible contact with) static-sensitive explosives or vapors, conductive floors shall be installed except where the hazards of dust-air or flammable vapor-air mixtures are eliminated by adequate housekeeping, dust collection, ventilation, or solventrecovery methods. Conductivefloors may also be required where operations are performed involving electro explosive devices that contain a staticsensitive explosive.

b. Conductive floors are not required throughout an entire building or room if the hazard remains localized. In such cases, conductive mats or runners may be used where required. These mats or runners will be subject to all the specifications and test requirements that apply to cond uctive floors. Conductive wristbands may be substituted for conductive mats and footwear at fixed, grounded work stations or outdoor locations. 


\subsection{Conductive Floor and Wristband Specifications}

Conductive floors must be made of nonsparking material such as conductive rubber or conductive flooring composition and shall meet the following requirements:

a. The flooring and its grounding system must provide for electrical resistance not to exceed $1,000,000 \mathrm{ohms}$ (measured as specified in paragraph 7.6).

b. The surface of the installed floor must be free from cracks and reasonably smooth. The material must not slough off, wrinkle, or buckle under operating conditions. Conductive tiles are not recommended for use in areas where contamination can be caused by explosive dust. The large number of joints and the tendency of tiles to loosen provide areas where explosive dust can become lodged that are not easy to clean with normal cleanup procedures.

c. Where conductive floors and shoes are required, resistance between the ground and the wearer shall not exceed $1,000,000 \mathrm{ohms}$, i.e., total resistance of conductive shoes on a person, plus the resistance of floor to ground. (See Figure II-1 for testing method.) Where conductive floors and shoes are required, table tops on which exposed explosives or dusts are encountered should be covered with a properly grounded conductive material meeting the same requirements as those for flooring.

d. Conductive floors must be compatible with the explosive materials to be processed.

e. Conductive wristbands shall not exceed a resistance between the wearer and ground of $1,200,000$ ohms. This resistance shall be measured with a suitably calibrated ohmmeter. Wristbands shall be of a design that maintains electrical contact with the wearer when used.

\subsection{Conductive Floor Tests}

a. Initial tests shall be made of all conductive floors, and subsequent tests shall be made at least semiannually. Test results shall be permanently recorded and a copy filed in a central location. Instruments used in making tests shall be used only when the room is free from exposed explosives and flammable gas mixtures.

b. Maximum floor resistance shall be measured with a suitably calibrated ohmmeter that operates on a normal open circuit output voltage of 500 volts dc and a short circuit current of 2.5 milliamperes with

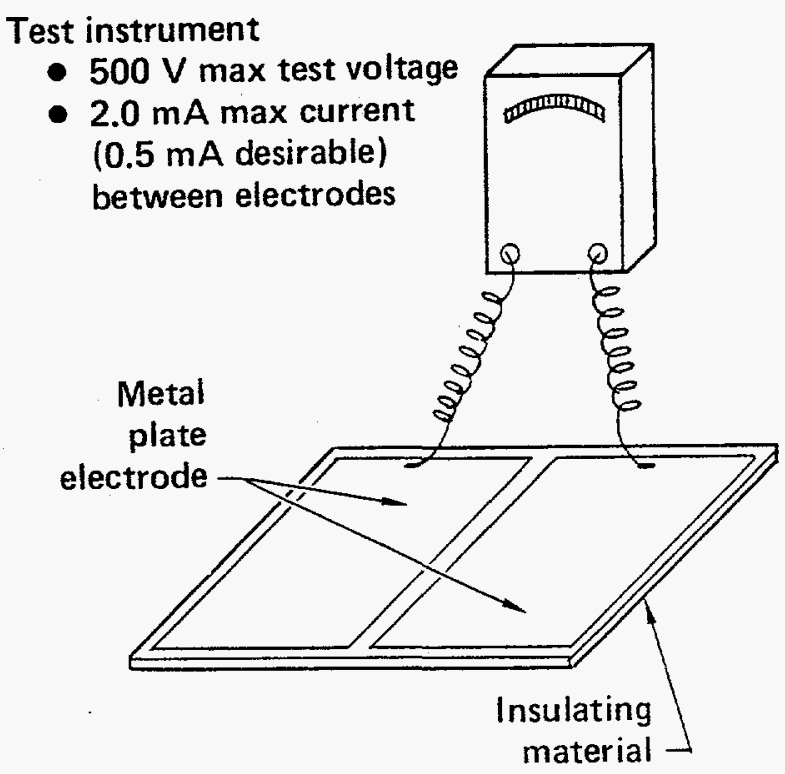
Shoes in series connection
$1,000,000$ Ohms

Figure II-1. Testing shoes on wearer.

an effective internal resistance of approximately $200,000 \mathrm{ohms}$. Minimum floor resistance will be measured with a suitably calibrated ohmmeter appropriate for the task.

c. Each electrode shall weigh 2.3 kilograms and shall have a dry, flat, circular contact area $6-1 / 2 \mathrm{~cm}$ in diameter, which shall comprise a surface of aluminum or tinfoil 1.3 to $2.5 \mathrm{~mm}$ thick, backed by a layer of rubber 0.6 to $0.65 \mathrm{~cm}$ thick and measuring between 40 and 60 durometer hardness as determined with a Shore Type A durometer (ASTM D-2240-68).

d. The floor shall be clean and dry. "Electrode jelly" such as brushless shaving soap or saline solution shall not be used.

e. The resistance of the floor shall be more than $5,000 \mathrm{ohms}$ in areas with 110-volt service and 10,000 ohms in areas with 220-volt service, and less than $1,000,000 \mathrm{ohms}$ in all areas, as measured between a permanent ground connection and anelectrodeplaced at any point on the floor and also as measured between two electrodes placed 3 feet apart at any points on the floor. Measurements shall be made at five or morelocationsineach room. If the resistancechanges appreciably with time during a measurement, the value observed after the voltage has been applied for about five seconds shall be considered as the measured value. 


\subsection{Humidification}

Humidification for preventing static electricity accumulations and subsequent discharges is usually effective if the relative humidity is above 60 percent. However, certain materials such as metallic powders and some pyrotechnic mixtures cannot be exposed to air with 60 percent relative humidity due to the possibility of spontaneous ignition. Where this technique is used to prevent static electricity accu- mulations, a daily preoperational check of the humidity levels will be accomplished before work starts.

\subsection{Ground Fault Circuit Interrupter}

Ground Fault Circuit Interrupter protection should be provided in static grounded areas where personnel may come in contact with ac- powered electrical equipment. 


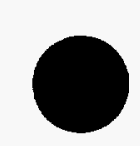

○

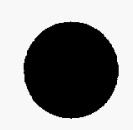

- II-18 


\section{CHAPTER II}

\section{Electrical Equipment and Wiring}

\subsection{Permanent Equipment and Wiring}

The National Electrical Code (NEC) and this section are minimum requirements for DOE facilities containing explosives. All permanent electrical equipment and wiring for those work areas containing explosives hazards shall conform to the standards of NEC hazardous locations Class II or Class I and II (dual rated). For Class II installations, provisions should be made for easy conversion to Class I. The NEC does not specifically address explosives; however, Article 500, "Hazardous (Classified) Locations," does establish requirements for the design and installation of electrical equipment and wiring in locations containing combustible dusts and flammable liquids, vapors, or gases that, in general, are comparably hazardous. Requirements for laboratory operations are contained in Section 21.1.b of this chapter.

\subsection{Hazardous Locations}

National Electrical Code definitions of Class I and Class II hazardous locations are modified as follows for DOE explosives facility applications:

a. Areas containing explosives dusts or ex plosives that may, through handling or processing, produce dust capable of being dispersed in the atmosphere shall be regarded as Class II, Division 1 hazardous locations.

b. Areas that contain exposed explosives but where no dust hazard exists may be regarded as Class II, Division 2 hazardous locations as applied to permanent premises wiring as defined in the NEC.

c. Watertight equipment (that which would pass a NEMA 4 hose test) should be provided in those locations where water/explosives mixtures may come in contact with the electrical equipment and wiring.

d. Areas where explosives are processed and sublimation may occur or where flammable gases or vapors may be present in sufficient quantities to produce explosive or ignitable mixtures shall be regarded as Class I, Division 1 and Class II, Division 1 hazardous locations. e. To ensure assignment to the proper hazardous locations class and group, it is necessary to know the properties of the explosives involved. Minimum requirements include sensitivity to heat and spark, and thermal stability. If the properties of an explosive are such that Class II, Group G equipment provides inadequate surface temperature limits, special protection shall be provided, or the equipment shall be excluded from the hazardous location. This equipment shall not have a surface temperature exceeding the lowest onset of the exotherm of the explosive, as determined by the differential thermal analysis (DTA) test or the differential scanning calorimetry (DSC) test in paragraph 12.1.1.c of this chapter, and Chapter VIII, paragraph 2.2.d. When NEC Class I or II equipment is not available, the substitute equipment should be purged (in accordance with NFPA 496) or sealed to prevent explosives contamination, be determined intrinsically safe by facility management, or administratively controlled. If the equipment is purged, it must be monitored for flow.

f. Wiring from the permanent premises wiring to process instrumentation and equipment should be rated for the actual environment. Nonhazardous location/occupancy ratings may be assigned to areas containing explosives where no dust, vapor, or gas hazards exist and where no exposed explosives are permitted. These areas must be evaluated and documented by facility management as to the improbable initiation of the permitted explosives by the following events:

- Malfunction of the electrical equipment or process instrumentation.

- Breach of containment resulting in exposed explosives or spillage.

- Ignition sources arising from physical damage to the wiring method used (e.g., crushing by forklift or other material handling equipment).

- Exposed electrical conductors or connectors making contact with leg wires or cables of explosive devices during handling.

If the area cannot meet the above criteria or has not been evaluated by facility management, the equipment and instrumentation wiring shall be regarded as NEC Class II. 
g. Procedures shall be established by each DOE facility to control the use and modification of electrical equipment in explosives areas and ensure that uniform standards are adhered to throughout the facility.

\subsection{Electrical Supply Systems}

There may be mutual hazards where explosives facilities are located near electrical supply lines. To protect against these hazards, the National Electrical Safety Code (ANSI C2) and the following requirements apply to all new construction or major modification, and should be considered for existing facilities:

a. Electric lines serving explosive facilities shall be installed underground from a point not less than 50 feet away from such facilities. This also applies to communications and instrumentation lines and security alarm systems.

b. Electric service lines required to be in close proximity to an explosives facility shall be no closer to that facility than the length of the lines between the poles or towers supporting the lines, unless an effective means is provided to assure that broken, energized lines cannot come into contact with, and present a hazard to, the facility or its appurtenances. c. Unmanned electrical substations shall be no closer to explosives facilities than public traffic route distances.

d. Electric transmission lines (carrying $69 \mathrm{kV}$ or more) and the tower or poles supporting them will be located no closer to explosives than-

- Inhabited building distance if the line in question is part of a system serving a large, offsite area

- Public traffic route distance if loss of the line will not create serious social or economic hardships

c. Underground utility separation distance criteria are found in Chapter VI, paragraph 3.2.3.

\subsection{Building Service Entrance}

Electrical service entrance for explosives facilities should be provided with-

- An intermediate, valve-type lightning arrestor on the primary side of the transformer

- Surge arrestors and surge capacitors on the supply side of the main service disconnect

- Interconnected grounding between the lightning arrestor, surge arrestor, surge capacitors, service entrance ground, and building ground. 


\section{CHAPTER II}

\section{Vacuum Equipment}

\subsection{General}

Precautions shall be taken to prevent explosives from entering any vacuum system not specifically designed for the collection of explosives.

\subsection{Labeling}

All vacuum lines used for explosives operations should be labeled to warn maintenance personnel that explosive residues may be present in these lines. One suggested label is:

DANGER, MAY CONTAIN EXPLOSIVES.

\subsection{Disassembly}

Vacuum lines should not be disassembled unless they are flanged or connected by elastomeric tubing.
No explosive-contaminated or potentially contaminated pipe threads shall be disassembled unless performed by remote means. The design or installation of any new vacuum lines shall not employ any demountable, internal screwed or threaded fittings or connections unless welded or fixed permanently in place.

\subsection{Traps or Filters}

Vacuum pumps used to evacuate processes for explosives operations shall be equipped with primary and secondary intake line traps or filters to prevent contamination of the pump with explosives. 
$\bullet$

$\bullet$

II-22 


\section{CHAPTER II}

\section{Explosives Dust Exhaust Ventilation and Collection Systems}

\subsection{General}

Exhaust ventilation should be used to control explosives dust (or other hazardous materials used in or resulting from explosives operations) that may create a hazard to operating personnel or contaminate the operating area. When exhaust ventilation is used to remove explosives dust, an approved dust collection system is required to prevent the release of the dust outside the building.

\subsection{Exhaust Ventilation}

Exhaust ventilation and collection systems for control of explosives dust and materials associated with explosives production shall be designed to meet minimum requirements established in DOE 6430.1A, the ACGIH Ventilation Manual (most current edition), and this manual. The exhaust ventilation system should have sufficient capture and adequate makeup air to reduce exposure to explosives dusts, or materials used in conjunction with explosives, to as low as reasonably achicvable. This is particularly important when toxicity information and occupational exposure limits are not available for the explosives in use.

\subsection{Dust Collection Systems}

a. A "wet collector" that moistens the dust close to the point of origin and keeps it wet until the dust is removed for disposal is preferred. A "drytype collector" is permitted when authorized by a SOP.

b. Dust collectors shall be designed in such a manner that explosive dust is prevented from reaching any mechanical power source of the collection system.

c. All conductive portions of the collection system shall be grounded and bonded.

d. There shall be no screw threads, recesses, or cracks that may be exposed to explosive contamination in a dust collection system.

e. Dust collection lines should be equipped with flanged connectors and inspection ports.

f. Pipes or ducts through which explosives are conveyed shall have long radius bends with a centerline radius at least four times the diameter of ducts or pipes.

g. Dust collectors shall be emptied and cleaned on a regular basis as warranted by system use and must be inspected periodically.

\subsection{Dust Collection Location}

a. Wherever practical, d ry-type explosives dust collection chambers should be located outside operating buildings, in the open, or in buildings exclusively set aside for the purpose.

b. Stationary and portable wet-type collectors may be placed in the explosives operating bays or cubicles provided the quantity of explosives in the collectors does not exceed $2 \mathrm{~kg}$. 


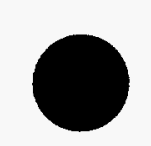

$\bullet$

II-24 


\section{CHAPTER II}

\section{Drains and Sumps}

\subsection{Collection}

a. All drain lines handling explosive wastes shall be provided with sumps or basins of adequate design and capacity for the removal of explosives by settling. The drains shall be of adequate capacity, free of pockets, and have sufficient slope (at least $1 / 4$ inch per foot) to prevent the settling out of explosives in the line until it reaches the sump or settling basin.

b. Drain gutters within buildings may be constructed with a slope of $1 / 8$ inch per foot. However, a satisfactory program of cleaning must be developed to assure that all hazardous material is removed from drain gutters.

c. Sumps must be designed so that suspended and settleable solid explosive material cannot be carried in the wash waters beyond the sumps. The design shall allow sufficient settling time on the basis of the settling rate of the material and the usual flow rate. The sump shall be constructed so that the overflow will not disturb any floating solids. The design must also permit easy removal of collected explosives and retention of those explosives that float on water (until they can be skimmed off). If settling basins are used to supplement sumps, they will be cleaned periodically and a log will be maintained.

d. Explosives collection trays for sumps will be constructed of nonferrous metal. Hoisting equipment used for lifting the trays will be designed to prevent the trays from binding on the sides of the sump. Bolted sump tanks or other types of construction that permit the explosives to settle in obscure or hidden spaces are prohibited. e. Drains between the source of explosive and the sump shall be troughs with rounded bottoms and removable ventilated covers to facilitate inspection for accumulation of explosives. This requirement applies to all new construction and major modifications, and should be considered for existing facilities. Short sections of closed pipe or trough are permitted if they can be visually inspected for blockage or explosives buildup. Explosives or explosivecontaminated waste liquids shall not be run into closed drains and sewers.

f. Drains shall be inspected periodically and necessary steps taken to prevent the buildup of explosive deposits in them.

\subsection{Effluent}

a. Drains containing explosive waste materials must not be connected in a manner to empty such wastes into the normal sewage systems carrying inert or sanitary wastes.

b. Care must be taken to avoid the possibility of deposition of explosives from sump effluent due to drying, temperature changes, or interaction with other industrial contaminations. When explosives that are appreciably soluble in water are handled, sweeping and other dry collecting measures shall be used to keep them out of the drainage system.

c. The combination of sumps, settling ponds, etc. must remove explosives so that outflows meet environmental standards. 


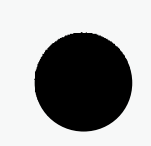

$\bullet$

II-26 


\section{CHAPTER II}

\section{Processing}

\subsection{Heating, Drying, and Thermal Conditioning}

\subsubsection{General}

a. Heating of explosives is potentially dangerous for several reasons:

- Elevated temperature can increase the sensitivity of an explosive to other stimuli such as impact, shock, friction, and static electricity.

- At or above the critical temperature of the system (see definition in Chapter I, Section 5), a runaway chemical decomposition may occur that can produce an explosion or fire.

- Elevated temperature of an explosive in a sealed container can cause gas generation and pressure rupture of the containment at temperatures below the critical temperature.

- Chemically incompatible or reactive materials, which may be present as accidental contaminants, as components of the formulation, or in external contact with the explosive, can intensify the preceding dangers or cause them to occur at lower temperatures.

- Nonuniformheating can causeexcessively hot regions in the explosive. Causes may include inadequate agitation of fluid explosives, nonuniform heaters, and nonuniform heat conduction.

b. The critical temperature is a system property that depends on a combination of the chemical decomposition reactions of the explosive, its mass and shape, the heat transfer and other thermal characteristics of the system, and the confinement or pressure of decomposition products, especially gases. The determination or estimation of the critical temperature can be accomplished by several different methods of thermal analysis, but the process is typically quite complex because of the complexity of chemical reactions that normally occur. For operational safety, a conservative estimate (i.e., lower limit) of the critical temperature for a heating operation shall be made (uncertainties of 10 to $25^{\circ} \mathrm{C}$ being common). Analogy of one explosive or system to another similar system with a reliable thermal analysis may be used to determine safe heating temperatures and heating times (heating limits). c. The DTA, DSC, or other comparable techniques can be used to measure the temperature of the onset of an exothermic reaction in an explosive. The result of this test can be used to rank the thermal stability of explosives and as part of a thermal analysis. Because of the complexity of chemical decomposition, however, the DTA/DSC exotherm has no systematic relationship to the critical temperature and is unreliable for estimating safe heating limits. The exotherm temperature is always considerably above the critical temperature and usually increases with the heating rate of the test. Where the DTA/ DSC exotherm is specified as a standard for control of temperature, the test heating rate shall not exceed $10^{\circ} \mathrm{C}$ per minute. The DTA/DSC shall not be used alone (except as specificd in paragraph 8.2.e) for establishing heating limits.

d. Each facility shall conduct or obtain a thermal analysis of any explosive system before the explosive is heated in a contact operation or in association with hazardous radioactive materials as described in paragraph 13.6.2. A heating limit for the exposive system shall be established from this analysis and should be approved by the EDC. All factors in paragraphs a and $b$ above shall be considered. Any significant change in the geometry or an increase in mass should be considered a new explosive system. For a contact operation, the maximum temperature should be set at least $10^{\circ} \mathrm{C}$ below the critical temperature. For heating explosives in association with hazardous radioactive materials, the maximum temperature should be set at least $20^{\circ} \mathrm{C}$ below the critical temperature. Heating to a temperature greater than the above specifications may be approved by facility management if a documented analysis of the explosive's thermal characteristics indicates that an acceptable time or temperature safety factor is still present for a specific operation. These operations shall be conducted remotely.

e. Heating controls for each operation shall be established and specified in written operating procedures. The specified condition should be set at the lowest temperatures and heating times to do the job efficiently and should not exceed the heating limit for the explosive system. When establishing heating controls, consider the heating limit 
and the accuracy of the estimated critical temperature, the accuracy of the temperature control equipment, and the likelihood of incompatible chemical contamination along with other operational parameters.

\subsubsection{Heating and Drying Equipment}

a. Heat should be supplied by steam, hot water, friction air, or electrically heated transfer fluid. Temperatures shall be limited by redundant, automatic heat controls.

b. In systems heated by steam only, the requirements for redundant, automatic heat controls shall be satisfied if the steam pressure is controlled by a pressure-reducing valve, pressure relief valve, and thermostatic valve on the system.

c. In systems heated by electricity, a manual reset secondary overtemperature system consisting of a controller, failsafe sensor, and an interrupting device shall be provided to interrupt the heat supply source in the event of primary system failure. The secondary interrupter shall be separate from the primary interrupter. The upper limit of the primary controller is determined by the desired operating temperature limit. The secondary (override) controller is set at a higher temperature but should not exceed the maximum temperature determined by the heating limit specified for the explosive system as determined in 12.1.1.d, above.

d. Visual and/or audible airms should be provided to alert operating personnel to abnormal temperature conditions. The heating of explosives should be monitored at all times.

e. The air or gas used to condition exposed explosives shall not be recirculated if directly heated by electrical resistance elements.

f. Drying or heating ovens should be vented to a safe location outdoors. Water wash or filtration of the exhaust may be requi $\mathrm{d}$. If exhaust fans are used, they shall be interlocked with the heat $s$ rce.

\subsubsection{Heating and Drying Operations}

a. Heating and drying shall be performed under the mildest set of conditions that will accomplish the task safely and efficiently. A thermal analysis shall be made and a written procedure prepared consistent with paragraph 12.1.1. The procedure shall include controls on the mass and geometry (thickness of the layer, etc.) of the material that may be heated. b. Except as described in c, below, drying shall be achicved by circulating a warm, dry gas-either air or inert-over or through the material.

c. Small samples may be dried by placement in desiccators or by subjecting them to vacuum. Vacuum drying of larger items should be preceded by drying at atmospheric pressure to remove quantities of moisture or solvent before vacuum is applied to remove the final traces of moisture or solvent. Explosives having a vapor pressure exceeding $1 \times 10^{-4} \mathrm{~mm} \mathrm{Hg}$ at the drying temperature shall not be subjected to vacuum drying. A cold trap shall be used for vacuum drying where the vapor pressure of the explosive is unknown.

d. Formation of a vapor-air mixture within explosive concentration limits shall be avoided. This can be accomplished by providing sufficient airflow to maintain a vapor concentration well below the lower flanmability limit or by use of an inert atmosphere. For inert atmosphere, positive purge shall be used to preclude oxygen leakage into the unit. If vapor concentrations approaching a flammable level are anticipated, they shall be monitored. Airflow shall be controlled to prevent dusting.

e. When heating explosives whose vapor pressure may cause undesired condensation of explosive on parts of the equipment, heating shall be conducted in a manner to control condensation of the explosive materials. This control should be accomplished by heating the exhaust system or by circulating the air at a rate that will keep the explosive concentration below the level at which condensation could occur.

f. The proper operation of heater controls shall be verified on a regular schedule established by site management.

\subsection{Pressing}

Explosive pressing operations are operations in which explosives are subjected to high pressures to achieve a physical change. Pressing of explosives formulations is done routinely to consolidate explosive materials in to configurations required for test assemblies or weapon systems. Two types of pressing operations commonly performed are isostatic/hydrostatic and punch and die. The following safety guidelines apply to these types of pressing operations.

\subsubsection{General}

a. Explosive pressing operations shall be conducted as remote operations. 
b. The correct functioning of press interlock systems shall be verified at regular intervals.

c. Pressing mandrels, punches, and dies used in explosives operations shall be examined regularly during periods of use for evidence of structural failure. Examination shall be performed by suitable nondestructive test methods. Intervals between inspections shall be established by site management for each tooling design before committing the tooling to use. The inspection interval and updating should be dictated by experience with similar tooling designs and configurations. All new or modified mandrels, punches, and dies shall be inspected before their first use. At least one pressing cycle should be completed with mock explosives before proceeding to explosives.

d. Pressure controllers and indicators shall be calibrated periodically to ensure accurate control and monitoring of pressing operations.

e. Press parts that contact explosive materials shall be thoroughly cleaned of residual explosives before they are used with a different explosive formulation.

f. Temperature control for heated presses and dies shall comply with the requirements of paragraphs 12.1.2.a and b.

g. All pressing assemblies shall be designed or procedural controls established so that the extrusion of explosives between two mating metal surfaces will be minimized or eliminated during the pressing operation.

h. Operations with explosive powders should be performed in a manner that reduces the liberation of explosive dust in order to reduce operator exposure and general room contamination. For operations involving large amounts of powders, local exhaust ventilation with a dust collection system should be provided. Respiratory protection to prevent inhalation of explosives dust may be required when adequate ventilation is not available.

\subsubsection{Isostatic/Hydrostatic Pressing}

a. Before an elastomeric container or mandrel constructed of a new material is introduced into a pressing operation (where it will contact explosives), the material shall be evaluated for compatibility with the explosives.

b. All pressing vessels shall be examined for evidence of cracking or other signs of incipient structural failure at regular use intervals by suitable nondestructive test methods. Examination intervals shall be established by local management. c. Before large-scale pressings of new explosives or explosives formulations are made, these materials shall be evaluated for thermal stability (see scaleup procedures, Chapter VIII). "New explosives or explosives formulations" refer to those that are "new" to large-scale pressing. Stability test results shall be used to assist in establishing safe pressing conditions for the specific pressing size.

d. For isostatic pressing, procedural controls shall be established to ensure that:

- An acceptable vacuum on the mandrel assembly can be obtained to prevent adiabatic heating during pressing surization.

- Air is bled out of the press before pres-

e. Consideration should be given to the use of fire-resistant hydraulic fluids. The compatibility of any new fluids must be checked with the explosives used.

\subsubsection{Punch and Die Pressing}

a. All pressing punches and dies shall be visually inspected for damage, deformation, and cleanliness before installation on a press. Any questionable condition(s) shall be resolved before the pressing proceeds to ensure that the operation's safety is not compromised.

b. All punches, dies, and press attachment fixtures shall be designed to minimize the possibility of the punch being misaligned with the die (resulting in gouging of a die surface during pressing). Press setup procedures shall provide for operator verification of proper alignment before pressing.

c. Punches and dies should be maintained in matched sets and shall be controlled by the responsible user or a gaging section capable of performing the necessary measurements. A group other than the user should check critical punch and die dimensions before initial use and at suitable intervals thereafter. Suitable check intervals for each punch and die design should be determined as in 12.2.1.c, above.

\subsection{Extruding}

Extrusion operations involve the flow of plastic explosives material under pressure into a cavity in a component of an assembly. The following general safety guidelines are given for this type of extrusion operation.

a. Extrusion operations shall be conducted remotely. Contact extrusion may be performed only when nonexplosive or mock materials are to be 
extruded or when hand-extruding small quantities with no metal-to-metal contact. Precautions shall be taken to prevent personnel from being injured by the rupture of pressurized equipment.

b. The explosive shall be protected against extrusion beyond the tooling cavity. Precautions shall be taken to prevent foreign material from entering the explosive.

c. New designs and significant design changes in equipment, tooling, or components shall be tested by mock explosives extrusion before actual explosives extrusion.

d. Pressure controllers and indicators shall be periodically calibrated to ensure that proper sealing and extrusion pressures are being maintained.

e. Extrusion press parts shall be thoroughly cleaned of residual explosives remaining from the previous operation before the press is loaded with a different explosive formulation.

f. Hand-loading of extrudable explosives is covered in paragraph 12.8.2.

\subsection{Machining}

Explosives machining is a class of operations that involves cutting of the explosive material, often in conjunction with harder inert materials. There is a possibility that thermal initiation of the explosive substance due to heat buildup from friction at the cutting surface can occur. Precautions must be taken to limit this build up and to facilitate the dissipation of thermal energy.

\subsubsection{Equipment Requirements}

a. Interlocks shall be provided for wet machining operations to ensure coolant flow before machine

operation. The coolant flow shall be monitored and the equipment automatically and safely shut down if loss-of-coolant flow is detected. The interlocks shall be protected by physical means or supervisory control from tampering and unauthorized disabling.

b. The vacuum on vacuum chuck holding fixtures shall be monitored and interlocked with the equipment for automatic shutdown of machining in event of vacuum loss.

c. Tool path controls (stops, limits, design patterns, etc.) shall be provided to prevent the unplanned travel path of a tool or workpiece. Equipment specd and feed rates shall be controlled and limited by positive means or secondary verification.

d. Pressure relief devices should be installed on pneumatically or hydraulically powered equipment when necessary to ensure safe operation. e. Metal chip waste from machining operations should be kept separate from explosives waste. When this is not possible, mixed explosives and metal waste should becompletely segregated from unmixed waste and held for separate disposal.

f. Dull or damaged tools shall not be used. A cutting tool inspection and control program shall be established for explosives machining operations.

g. Consideration will be given to using additional safety control devices (i.e., design patterns, safety templates, chip thickness sensors, tool pressure sensors, etc.), depending on the type of machining operations, size of explosive pieces, types of explosives, etc.

h. The "machining overtest" shall be considered a testing operation (see paragraph 12.4.4.e, below) and shall be exempt from equipment requirements.

\subsubsection{Contact or Remote Operations}

a. The following explosives may be contact machined if a compatible, nontoxic, noncombustible coolant is used. Explosives not listed below shall be machined remotely.

- Amatol

- Baratol

- Boracitol

- Explosive D

- Octol with no more than $75 \%$ HMX

- Pentolite (no more than 50\% PETN)

- RDX/TNT compositions with no more than $75 \%$ RDX. These compositions include-

Composition B

Composition B-3

$75 / 25$ cyclotol.

- TATB and TATB compositions with an inert plastic binder

- TNT

b. Explosive assemblies composed of any combination of explosives listed in the above paragraph and the following nonexplosive materials may be contact machined if a compatible, nontoxic, noncombustible coolant is used. If an assembly contains an explosive not listed in the above paragraph or a nonexplosive material not listed below, the assembly shall be machined remotely.

- Foamed plastics

- Solid plastics

- Adhesives

- Amorphous graphite

- Calcium sulphate casting powder

- Explosives mockup

c. On any explosive, with certain exceptions for IHE and for those explosives being machined by 
fluid jet (see paragraph 12.4.2.e, below), the following operations shall be performed remotely:

- Drilling of holes smaller than $5 \mathrm{~cm}$ in diameter, except for IHE, where drilling of holes smaller than $5 \mathrm{~mm}$ shall be done remotely

- Coring operations, except that contact operations are allowed on those explosives listed in 12.4.2.a above when the requirements of paragraph 12.4.5.b are met and a coolant is used

terface

- Machining of any metal/explosives in-

- Machining IHE subassemblies with Hazard Class/Division 1.1 boosters installed

- Dry machining, except that IHE booster pellets may be contact machined provided a dust collection system (see Section 10 of this chapter) is used

- Machining of explosive in Phase II or earlier stage of scaleup (see Chapter VIII).

d. Machining of primary explosives shall be avoided. Alternative methods, such as forming or pressing to final dimensions, should be used to achieve the desired shape.

e. The machining of IHE, PBX 9404, and LX-10 may be performed contact by high pressure fluid jet. The fluid jet system pressure shall not exceed $20,000 \mathrm{psi}$. The velocity of the fluid jet shall not exceed 520 meters per second (theoretical). The jet nozzle orifice diameter shall not exceed 0.010 inches. The system machining fluid shall be water and shall not contain any abrasives.

f. Concurrent contact machining operations should not be permitted in the same bay. However, concurrent IHE contact machining is permitted when other explosives are not present.

g. Provisions shall be made for visual monitoring of remote machining operations. Consideration should be given to video recording and audio monitoring.

\subsubsection{Setup and Preparation}

The following precautions are provided for preparation and setup before beginning the machining operation:

a. Before setting up the explosive workpiece, the equipment shall be checked for proper function and the absence of interference between stationary and moving parts. For the more complex machining operations, an inert mockup should be used for testing equipment function before the first run.

b. The explosive component to be machined should be inspected for cracks, voids, and high- density foreign objects. The explosive component for contact machining shall be inspected. Radiography can be used for this purpose. The component shall also be checked for proper size.

c. Caution shall be exercised during setup and adjustment to avoid pinching, dropping, or crushing of, or otherwise applying abnormal forces to explosives present. Special care must be given to mounting and centering a part on a vacuum chuck. Special attention must be given to the proper functioning of the vacuum system and its surface holding area.

d. Limits on machine speed, depth of cut, and feed rate shall be set before the machine is activated.

e. Interlocks shall be functional before the machine is used to machine explosives. They should be tested once per shift.

\subsubsection{Operations Guidelines}

a. The minimum tool speed necessary for safe and efficient operation should be maintained. The following maximums shall apply:

(1) The relative velocity between the explosives surface and the cutting tool shall not exceed $65 \mathrm{~m}$ per minute.

(2) Workpieces or cutting tools shall not be rotated at speeds exceeding $525 \mathrm{rpm}$.

(3) The feed rate of the cutting tool or workpiece shall not exceed $1 \mathrm{~mm}$ per revolution.

b. The workpiece, fixture, cutting tools, equipment, floor, troughs, drains, etc., should be cleaned frequently to prevent accumulation of explosive wastes.

(1) Approved measures should be taken to prevent rust and minimize deterioration of precision surfaces.

(2) All tools, equipment, fixtures, and parts should be cleaned before being removed from the work area for storage.

c. For contact machining operations, coolant shall be used to aid in removal of heat and cutting waste. Coolant should be used for remoteoperations when practical.

(1) Coolant should be used on explosives/ inert assemblies. When the explosives portion is included in the cut, coolant shall be used for contact machining. Coolant is not required if the explosives portion of the assembly is contained (no bare explosives) and is not included in the cut, or the machining is conducted remotely.

(2) Spray mist coolant may be used during machining of the explosive-containing assemblies if the explosives portion is not included in the cut. 
d. All visible explosives shall be removed from the machine before maintenance or repairs are performed. No safeguards or interlocks of any kind shall be removed or made ineffective, except by authorized personnel.

e. Before submitting an explosive for contact machining approval, a machining overtest program shall be conducted to identify the machinability and associated hazards. These HE qualification tests should be performed in facilities set aside. for these purposes.

(1) Machining overtests shall be conducted remotely.

(2) Operations performed during sample preparation may include gaging and assembly, but shall not include any contact cutting, scraping, or other material-removing operations on the explosives specimens.

\subsubsection{Specific Machining Operations}

a. Drilling

(1) Drilling operations should be set up to maximize the ease of achieving and maintaining proper alignment and to facilitate removal of explosives chips, fines, and powder.

(2) Length of fluting on the drill bit shall exceed the depth of the hole to be drilled by a minimum of $1.3 \mathrm{~cm}$ or one hole diameter, whichever is greater.

(3) The depth of a hole shall not be extended more than 1-1/2 times the hole diameter (up to a maximum of $2 \mathrm{~cm}$ ) during a single insertion of the drill into the material. After each insertion, it may be advisable to withdraw the drill completely and remove loose explosives from the cavity and drill bit before reinserting.

(4) Coolant flow (when used) shall be directed to the explosives/cutting edge interface. Drill bits having coolant channels to the tip of the drill should be used. Pulsating high-pressure types of coolant supplies are recommended for drills of $6 \mathrm{~mm}$ diameter or less.

b. Coring

(1) Coolant flow (when used) shall be directed at the explosives/cutting edge interface.

(2) The coring will be accomplished in increments if the hole is not positioned to provide continuous breakout. When done in increments, no more than 1-1/2 times the diameter of the hole shall be cored at one time. Before the maximum distance has been cored, the tool shall be totally retracted from the hole and cleaned. The hole shall be flushed with coolant.

\section{c. Sawing}

(1) The feed rate of the saw blade or workpiece shall not exceed $7.5 \mathrm{~cm}$ per minute.

(2) For band saws, coolant flow should be directed onto the saw blade at the cutting interface, guide rollers, and the drive wheel/saw blade interface. For circular saws, the coolant flow should be directed at the explosives/cutting edge interface.

\subsection{Dry Screening}

Screening of dry explosives is often required for size classification or to remove extraneous objects. Use of magnetic separators is often advisable for removal of ferrous materials that may have passed through the screens. The following guidelines shall be observed for screening operations and equipment:

a. Screening operations using mechanical screens shall be performed by remote operations. Equipment shall be designed and operations performed to avoid subjecting explosive materials to pinching, friction, or impact.

b. Screening small samples may be performed as a contact operation where approved by facility management.

c. Equipment shall be electrically bonded and grounded. Resistance-to-ground shall be $10 \mathrm{ohms}$ or less and shall be inspected on a regular basis. Equipment used to transfer electrostatic-sensitive explosives to or from screens shall be conductive and electrically bonded to the screen during transfer.

d. Operations and equipment shall be set up to minimize and control dust generation.

e. The operating area and equipment therein shall be cleaned frequently to avoid accumulation of explosives dust.

f. Precautions shall be taken to prevent metalto-metal rubbing during vibration of the screens. Particular attention shall be paid to frequent inspection of vibrating equipment for development of cracks subject to contamination by explosives.

\subsection{Blending}

a. Dry blending of explosives shall be performed remotely. However, dry, hand blending of small samples may be performed as a contact operation when approved by facility management.

b. Equipment should be designed and operations performed to minimize generation and dispersion of explosives dust.

c. Equipment shall be electrically bonded to provide a continuous path-to-ground. Resistance-toground shall be $10 \mathrm{ohms}$ or less and shall be inspected 
on a regularbasis. Equipment used to transfer electrostatic-sensitive explosives to or from blenders shall be conductive and electrically bonded to the blender during transfer.

\subsection{Melting}

a. The heat for melting explosives shall be supplied by saturated steam, hot water, or other temperature-controlled medium. The steam pressure shall be controlled in accordance with paragraph 12.1.2.b.

b. Temperatures used for contact melting of TNT-based explosives (except those containing PETN, e.g., pentolite) and keeping them molten shall not exceed $121^{\circ} \mathrm{C}$. The temperature limit for TNT explosives containing PETN shall be $109^{\circ} \mathrm{C}$.

c. Feeding of the melt kettle and the melting operation shall be controlled or regulated to prevent the formation of large chunks of explosives.

d. Alarms shall be provided on the melt temperature and on melt kettle agitation when the operation will beleft unattended. Alarms shall sound if the temperature exceeds the specifications of the paragraph $b$, above, or if agitation ceases.

e. Wherever possible, valves, piping, and threaded bolts and fasteners should be eliminated from melted explosives handling systems.

f. Provisions should be made for emergency emptying of melt kettles in the event of temperature control problems or power failures.

g. Melt kettle construction materials shall be corrosion resistant. Construction shall not contain blind holes, threads, or cracks in areas exposed to melted explosives. Welds shall be inspected and found free of cracks and porosity.

\subsection{Assembly and Disassembly}

During assembly and disassembly operations, hand tools and electrical and pneumatic tools that may subject the explosives to abnormal frictional forces, pinching, or excessive pressure, or cause significant deformation, shall not be used. They may, however, be used on nonexplosive components.

\subsubsection{Assembly Operations}

During assembly operations, theoperator should be alert for mismating parts and misalignment of components. Hard surfaces contacting explosives shall be precisely machined to mate with the explosives or lined with cushioning material, or other methods shall be used to keep sharp corners or projections from being forced into explosives.

\subsubsection{Loading Assemblies with Plastic or} Extrudable Explosives

a. The workability and plasticity of plastic and extrudable explosives improves with an increase in temperature. Plastic explosive Compositions C-3 and $\mathrm{C}-4$ may be softened by warming to between 21 and $38^{\circ} \mathrm{C}$ before working. Extrudable explosives LX-13 and Extex should be kept as cool as practical to prevent premature curing.

b. Contamination of these explosives with abrasive or foreign substances shall be avoided.

c. The assembly shall be loaded with small increments of the explosive and may be tamped with suitable nonmetallic tools to eliminate air voids.

\subsubsection{Disassembly Operations}

a. Before beginning disassembly, the condition of the device shall be assessed to determine if it can be safcly handled.

b. The disassembly operation shall be planned before actual disassembly. Possible problem areas caused by method of construction or physical condition shall be considered. A safety procedure for all disassembly should be written and reviewed.

c. Pressurized units shall be thoroughly depressurized before beginning disassembly if disassembly would normally cause release of the pressure or if there is a credible hazard of the pressure causing components to fly apart.

d. If approved for use, compressed air shall be applied cautiously during disassembly operations to avoid causing components to fly apart. This may require remote operation. Use hydraulic pressure if possible.

\subsubsection{Personnel Protection for Disassembly Operations}

a. The operator and all other personnel shall be provided complete protection from disassembly operations involving conditions that are known or expected to require the use of abnormal force. This requires either remote operation or the use of an operational shield. The shielding shall be designed to protect personnel at any other operation or location from blast and missiles arising from a possible explosion.

b. When disassembly is required to be performed with the operator protected by an operational shield, disassembly shall be defined as complete separation (threads or other connections) of component parts. For example, parts shall not beloosened while the operator is properly 
protected and then separated without the same protection.

\subsection{Inspection}

This section deals with the following types of explosives inspection operations: (1) inspection of incoming explosives raw materials and pressed explosives billets for foreign bodies or cracks that could cause operating or safety problems in processing operations; and (2) measurement of physical parameters of explosives pieces and assemblies.

a. To enhance the safety of process operations, positive steps shall be taken to assure that explosives used are properly identified and that foreign material is kept from entering the operation via the explosives raw materials or via materials in process (i.e., pressed explosives billets). Some of the means by which this can be accomplished include:

- Screening

- Visual inspection

- Magnetic separation

- Radiographic inspection

- Chemical analysis.

b. In the design and operation of explosives inspection equipment, the following principles shall be followed:

(1) Pinch points shall be eliminated or steps taken to preclude explosives contamination of pinch points.

(2) Threaded fasteners or threads of measuring equipment shall be protected from explosives contamination. Care shall be taken to prevent any parts of the measuring or handling equipment from becoming loose and getting into the explosives.

(3) Where inspection fixtures are used, they shall be designed to hold the explosives piece or assembly securely to prevent toppling, rolling, or dropping during measurement operations. This is especially critical if the explosives assembly is in motion (i.e., spinning, vibrating, etc.) during measurement.

\subsection{Synthesis}

Synthesis and other chemical processing of new explosives compounds are ongoing activities at DOE weapons facilities. Synthesis operations are conducted both on laboratory and pilot scales, and new operations and materials will be approved by the Explosive Development Committee (EDC, Chapter VIII). In the laboratory, the new material will initially be prepared on a small scale and character- ized as to sensitivity, physical, and explosive propertics. Also, the laboratory will develop processing techniques for the material. If the explosive is of continuing interest as a result of the laboratory studies, it may be advanced to the Pilot Plant where processing techniques will be refined and scaled up. The Pilot Plant will produce sufficient material for larger scale physical, explosive, and sensitivity characterizations.

\subsubsection{Laboratory-Scale Synthesis}

a. Before initiation of work, the professional staff member who is directing or conducting the synthesis work shall analyze each experiment involving explosives or potential explosives for type and magnitude of hazards. He shall be responsible for planning the proper selection of conditions, quantity of explosives, and safety devices to be employed.

b. Experiments should be designed to minimize the amounts of explosives involved and to use the mildest conditions that will yield the desired information.

c. New explosives materials shall be afforded extra protection against impact, pinching, friction, pressure, sparks, contamination, and deterioration. If it is necessary to subject explosives to any of these conditions, theoperation shall beconducted remotely or adequate personnel shielding shall be provided.

\subsubsection{Pilot- or Processing-Scale Synthesis}

a. When operations are conducted using flammable or toxic liquids or gases, local ventilation shall be provided to preclude the formation of hazardous vapor concentrations in the work area.

b. Alarms should be provided for coolant flow to the reactor, for reaction vessel agitation, and for reactor temperature. These alarms should be energized whenever coolant supply or agitation is critical to prevent a runaway reaction. Also, if agitation is critical, the reactor should be equipped with at least two sources of power to maintain agitation in the event of failure. For example, a reactor mightemploy an air or inert gas bubble tube as a backup for a mechanical agitator.

c. The reaction vessel should be equipped with an emergency system. Upon activation, it will automatically cool the vessel or open or close a vessel dump valve as required by the process.

d. The buildingexhaust ventilation system shall be operating during all synthesis operations involving flammable liquids. 
e. An alarm or monitor should be provided for the critical exhaust ventilation system to warn operating personnel if air flow rates drop below a predetermined level.

f. Emergency plans shall be established for the synthesis area, specifying action to be taken in the event an alarm sounds.

g. Before operating, all equipment shall be set up and checked for proper function. Any new equipment, and that which is not used frequently, shall be tested in a "dry run" before being used with any hazardous material.

h. Inspection and maintenance of all explosives synthesis process equipment shall be performed on a routine basis. Equipment found to have any defects that could affect safe operations shall be tagged to prevent its use until repairs are completed.

i. Before any process operation is started, the transfer lines to be used should be properly labeled and their function specified in the operating procedure.

j. Transfer hoses and portable equipment not involved in the process shall be removed from the work area and stored in their proper places.

k. All control valves shall be correctly identified according to function.

1. Safety equipment and clothing shall be worn as defined in the individual operating procedures.

m. Agitator blades on reactors and mixers shall be inspected for proper clearance at regular intervals. This is to ensure that there are no pinch points or metal-to-metal contact. The inspection schedule shall be set up and approved by local facility management.

n. Explosives warning signs shall be conspicuously displayed on any processing vessel in which explosive materials are to be left overnight.

o. Any vessel that can be sealed and that can operate above atmospheric pressure shall be equipped with overpressure protection.

p. All closed vessels should be purged with inert gas before introducing flammable liquids.

q. Inert gas pressure should be used for transferring flammable liquids when gravity flow or pumping are not practical.

\subsection{Formulation}

Formulation operations considered in this section are those involving the combining of compounds or mixtures when one or more of the ingredients being combined is an explosive. This combining of ingredients is commonly accomplished at DOE explosives- handling facilities to obtain some desired physical property, combination of properties, or reaction parameter(s).

\subsubsection{General}

a. Explosives may be loaded contact (operator attended) into mixers, mills, and deaerators. However, the starting, operating, and stopping of such equipment with explosives present shall be accomplished remotely. Exception: mixing-type operations involving a low energy transfer may be allowed as a contact operation. Examples: slurry coating and melt agitation.

b. Equipment used for explosives formulation shall be checked for proper operation before adding explosives. In particular, equipment shall be examined for proper clearances and for metal-to-metal rubbing of moving parts potentially contacting explosives. Bearings should be sealed to preclude contamination with explosives.

c. Fast-action deluge systems shall be considered for equipment (e.g., mixers, mills, and deacrators) used for easily ignitable explosives formulations.

d. Hot or cold water or steam can be applied to mixers and mills, but heating fluid temperatures shall not exceed known safe operating temperatures for the particular explosive(s) involved. In the case of roll milling, allowance shall also be made for viscous shear heating of the explosives during working. Heated systems shall comply with the requirements of paragraphs 12.1.2.a and b.

\subsubsection{Mixing}

a. Mixer seals and gaskets shall be checked on a regular schedule and cleaned or replaced as required.

b. Checks should be made to ensure that maximum particle sizes of ingredients or hard agglomerates of proposed mixes are less than the blade-toblade or blade-to-bowl clearances.

c. Initial cleaning with solvents used for dissolving or suspending the explosives residues shall be done remotely (other than melt-mix or slurry coating vessels).

d. Explosive powders and plastic-bonded explosives formulations may be mixed wet in a contact operation. This can be accomplished if the wet mixture cannot be initiated with energy sources available and if the viscosity is kept low and the possibility of isolated portions of the mix becoming dry is precluded. 


\subsubsection{Ball or Jar Milling}

a. Balls that are porous or contain cavities shall not be permitted in mills for grinding explosives.

b. Grinding media contaminated with explosives slurry shall be protected from excessive impact during emptying of the mill.

c. After grinding, a careful inspection shall be made to ensure that the explosive is free of grinding media. Dispose of any explosives contaminated with broken media.

d. After separation of the explosive, the grinding media shall be thoroughly cleaned and inspected before reuse or disposal.

\subsubsection{Roll Milling}

a. Positive stops should be installed on roll mills to prevent rolls from rubbing each other.

b. Before a milling operation is started on a roll mill, the contact of the scraper blade with the roll should be adjusted to the minimum pressure necessary to perform the operation.

c. Roll gaps should be set as wide as possible while still allowing adequate working of the material. Minimum gap setting shall be $0.1 \mathrm{~mm}$.

d. Roll rpm should be held at the minimum required to process the material adequately.

e. All roll mills that may be contact operated (e.g., with nonexplosive materials) shall be equipped with emergency stop devices (breaker bar, chain) within easy reach of the operator.

\subsection{Concurrent Contact Operations}

Arranging explosives operations so that cach operation is performed in a separate location to preclude any adverse operation interaction is preferred. Since such an arrangement is frequently impractical, concurrent operations may be permitted if the following conditions exist:

a. Potential equipment-operator interactions between the two operations have been analyzed and the risk is not appreciably greater than that for both operations considered separately.

b. Explosive materials in either operation are not exposed to stress conditions such as elevated temperature (melting or heat conditioning), elevated pressures (pressing or extruding), or deformation/ shear (machining or cutting).

c. Mixing of materials in the concurrent operations will not create compatibility problems.

d. Each operator is aware at all times of concurrent operations in his or her area.

\subsection{Contamination Prevention}

a. When two or more incompatible explosives or materials are handled on a line or within a building or room, precautions shall be taken to avoid mutual contamination. This includes vacuum systems and explosives scrap collection. Inadvertent mixing of incompatible explosives materials can be hazardous not only to manufacturing facilities and personnel but also to the user if such materials are loaded into explosives devices.

b. When two or more explosives are used in a line or within a building and mixing is not intended, the materials shall be segregated in separate locations. The containers shall be clearly marked with the weight and contents identification. Care shall be exercised to properly segregate material in service magazines as well as in operating buildings.

c. When a different explosive is to be used in process equipment, the equipment shall be thoroughly cleaned, and excess explosive from the previous job should be removed from the bay. This eliminates the hazards caused by mixing materials.

d. In any explosives operation, all permanent service lines shall be labeled as to contents. All valves and switches on service lines whose operation can result in a hazardous situation shall be labeled as to function. 


\section{CHAPTER II}

\section{Testing}

\subsection{General}

This section covers the following types of testing operations: explosives test shots, gun firings (both small arms and larger caliber), and environmental, physical-property, and sensitivity testing of explosives specimens.

\subsection{Test Planning}

\subsubsection{Hazards Analysis}

Every proposed testing program shall be examined for all foreseeable hazards involved in the test. This shall be done with a knowledge of the construction and operation of all standard and nonstandard equipment to be used, as well as the type of explosives involved. When a specific hazard can be foreseen, alternative means for attaining the test objective without the hazard shall be adopted, or adequate precautions shall be taken to protect personnel from the hazard. If the nature of a proposed test is such that hazardous conditions of abnormally long duration may exist following the test, the procedure shall require a suitable waiting period before personnel leave their shelter. Possible hazardous conditions include dispersed pieces of burning explosives, cookoff of explosives or propellant, slow pressure buildup in a closed vessel, etc.

\subsubsection{Firing Areas}

A secured firing area (danger zone) shall be established for each test to assure that personnel are not exposed to hazardous blast overpressure, firebrands, fragments, or projectiles from an explosives shot or gun firing. In the case of large-scale tests that have potential for propelling missiles off Government land, a formal risk analysis of worst case conditions for each different test type shall be performed. Such analysis shall address both the probability of a hazard occurring and the potential severity of the hazard with respect to injury and property damage.

\subsection{Test Firing}

\subsubsection{General Range Standards}

Procedures shall be established at each DOE explosives test site to ensure that no site personnel or transients are exposed to firebrands, fragments, or excessive blast overpressure from a test shot. In establishing these procedures, the following guidelines shall be considered:

a. Personnel access to each test site shall be controlled during actual testing operations. If unattended roadblocks, gates or doors are used to prevent personnel from entering the danger zone during a test, they should be interlocked or locked with specially controlled keys.

b. All firing site personnel and visitors shall be accounted for and in a safe place before test firing.

c. A visual inspection of the danger zone shall be performed immediately before each test shot or series of shots as applicable, to ensure that no transients are present.

d. The danger zone shall be free of service personnel (such as telephone repairmen, surveyors, road maintenance crews, etc.) during test operations. The control point shall notify service personnel of the specific requirements under which they may safely work when testing is not in progress. In addition, the control point shall notify firing site personnel of the presence and location of service personnel in their areas.

e. Clearance for a test or test series shall be coordinated with all test sites and other areas potentially affected. A warning shall be provided to every affected area immediately before each firing.

f. Detonation of very large explosive shots, numerous smaller shots, or gun firings may result in hearing damage and may exceed the DOE allowable limits for impulse noise. Make a noise evaluation of these activities to ensure that adequate hearing protection is provided to those involved.

g. During test operations, all personnel assigned to the test area shall be continuously alert for movement of personnel, vehicles, and aircraft. 
h. Test firings often create hazardous conditions for aircraft operating in the airspace near the danger zone. If this airspace is periodically subject to air traffic, precautions shall be taken to ensure that the airspace will be clear of traffic at the time of firing.

i. Each firing site shall establish personnel limits based on the number of people actually needed to conduct an operation and the number of transients that should be present. These personnel limits shall be enforced by the responsible person at the firing site.

j. Testing of explosives can result in personnel exposure to toxic decomposition products such as carbon monoxide, hydrogen chloride, hydrogen fluoride, hydrogen cyanide, and nitrogen oxides. It is good practice to allow the detonation cloud to disperse before leaving protective bunkers. Fragment danger zone distances are normally adequate to allow cloud dispersal and protect outside personnel from excessive exposure.

\subsubsection{Test Setup}

In setting up a test, all work should be done that can be done before receipt of the explosives. Such work includes the following items:

a. All firing site safety devices shall be checked at regular intervals. Such safety devices include warning lights, door and gate firing circuit interlocks, emergency firing circuit cutoff switches, grounding, etc. (including those that are remote from the firing bunker).

b. All firing pad and shot stand setup work that requires power tools or other potential sparkproducing devices should be completed. The firing pad shall be cleared of all unnecessary gear. Special precautions and procedures will be developed and implemented if power tools or other spark-producing devices are needed after the explosive has been received at the firing pad.

c. If a special structure is required, as much work as possible should be accomplished on the structure, including assembly of all materials.

d. When possible, all diagnostic equipment shall be set up, checked, and dry runs performed.

\subsubsection{Pin Switches and Other Noninitiating Circuits}

Whenever pin switches and other noninitiating circuits are to be checked (such as for charging current or leakage) and are in contact or close proximity to explosives, the check should be performed remotely. Other noninitiatingelectrical circuits include strain gages, pressure transducers, thermocouples, etc., that may be affixed to or close to the explosives within an assembly. If a continuity-only (resistance) check is desired, this may be accomplished as a contact operation with an electrical instrument approved for use with the particular explosive device. When low-firing-current actuators are involved, it may be advisable to conduct these tests remotely. (See paragraph 13.8 of this section.)

\subsubsection{Lightning Storms}

All operations in open, test-firing areas shall be discontinued during lightning storms when explosives are present. Completion of a test after receipt of a lightning alert may be allowed only if test preparation has progressed to the extent that discontinuance of testing would represent a greater personnel exposure than completion of testing.

\subsubsection{Low-Energy Electroexplosive Devices (EEDs)}

When using hot-wire or low-energy electroexplosive devices (EEDs) for a test firing, apply the following requirements:

a. Procedures shall be established to ensure that RF, FM, and TV transmitters having sufficient output energy to cause initiation of an EED at the test site are either restricted to a safe distance from the site or not operated. Tables II-1, II-2, and II-3 specify minimum safe distances for the various types of transmitters at several output power levels.

Table II-1. Minimum safe distances between RF transmitters and electric blasting operations.

\begin{tabular}{ccc}
\hline & \multicolumn{2}{c}{ Minimum safe distances (feet) } \\
\cline { 2 - 3 } $\begin{array}{c}\text { Transmitter } \\
\text { power (watts) }\end{array}$ & $\begin{array}{c}\text { Commercial AM } \\
\text { Broad cast transmitters }\end{array}$ & $\begin{array}{c}\text { HF transmitters other } \\
\text { than AM Broadcast }\end{array}$ \\
\hline 100 & 750 & 750 \\
500 & 750 & 1,700 \\
1,000 & 750 & 2,400 \\
4,000 & 750 & 4,800 \\
5,000 & 850 & 5,500 \\
10,000 & 1,300 & 7,600 \\
25,000 & 2,000 & 12,000 \\
$50,000^{2}$ & 2,800 & 17,000 \\
100,000 & 3,900 & 24,000 \\
$500,000^{b}$ & 8,800 & 55,000 \\
\hline
\end{tabular}

2 Present maximum power of U.S. broadcast transmitters in commercial AM Broadcast Frequency Range ( 0.535 to $1.605 \mathrm{MHz})$. b Present maximum for International Broadcast. 
Table II-2. Minimum safe distances between TV and FM broadcasting transmitters and electric operations.

\begin{tabular}{rccr}
\hline & \multicolumn{3}{c}{ Minimum safe distances (feet) } \\
\cline { 2 - 4 } $\begin{array}{c}\text { Effective radiative } \\
\text { power (watts) }\end{array}$ & $\begin{array}{c}\text { Channels } \\
2-6 \text { \& FM }\end{array}$ & $\begin{array}{c}\text { Channels } \\
7-13\end{array}$ & UHF \\
\hline up to 1,000 & 1,000 & 750 & 600 \\
10,000 & 1,800 & 1,300 & 600 \\
$100,000^{\circ}$ & 3,200 & 2,300 & 1,100 \\
$316,000^{b}$ & 4,300 & 3,000 & 1,450 \\
$1,000,000$ & 5,800 & 4,000 & 2,000 \\
$5,000,000^{\circ}$ & 9,000 & 6,200 & 3,500 \\
$10,000,000$ & 10,200 & 7,400 & 6,000 \\
$100,000,000$ & - & - & - \\
\hline
\end{tabular}

- Present maximum power, Channel 2 to 6 and FM.

' Present maximum power, Channel 7 to 13.

- Present maximum power, Channel 14 to 83.

Table II-3. Minimum safe distances between mobile RF transmitters and electric blasting operations.

\begin{tabular}{|c|c|c|c|c|c|}
\hline \multirow{2}{*}{$\begin{array}{c}\text { Transmitter } \\
\text { power (watts) }\end{array}$} & \multicolumn{5}{|c|}{ Minimum safe distances (feet) } \\
\hline & MF & $\mathrm{HF}^{2}$ & $\operatorname{VHF}(1)^{a}$ & $\operatorname{VHF}(2)^{2}$ & $U \mathrm{HF}^{2}$ \\
\hline $5^{b}$ & - & - & - & 一 & 一 \\
\hline 10 & 40 & 100 & 40 & 15 & 10 \\
\hline 50 & 90 & 220 & 90 & 35 & 20 \\
\hline 100 & 125 & 310 & 130 & 50 & 30 \\
\hline $180^{\circ}$ & - & - & - & 65 & 40 \\
\hline 250 & 200 & 490 & 205 & 75 & 45 \\
\hline $500^{d}$ & - & - & 209 & - & - \\
\hline $600^{\circ}$ & 300 & 760 & 315 & 115 & 70 \\
\hline $1,000^{f}$ & 400 & 980 & 410 & 150 & 90 \\
\hline $10,000^{8}$ & 1,200 & - & 1,300 & - & 一 \\
\hline MF & \multicolumn{3}{|c|}{1.6 to $3.4 \mathrm{MHz}$} & \multicolumn{2}{|l|}{ Industrial } \\
\hline HF & \multicolumn{3}{|c|}{28 to $29.7 \mathrm{MHz}$} & \multicolumn{2}{|l|}{ Amateur } \\
\hline VHF(1) & \multicolumn{3}{|c|}{35 to $44 \mathrm{MHz}$} & \multicolumn{2}{|l|}{ Public use } \\
\hline & \multicolumn{3}{|c|}{50 to $54 \mathrm{MHz}$} & \multicolumn{2}{|l|}{ Amateur } \\
\hline VHF(2) & \multicolumn{3}{|c|}{144 to $148 \mathrm{MHz}$} & \multicolumn{2}{|l|}{ Amateur } \\
\hline & \multicolumn{3}{|c|}{150.8 to $161.6 \mathrm{MHz}$} & \multicolumn{2}{|l|}{ Public use } \\
\hline UHF & \multicolumn{3}{|c|}{450 to $460 \mathrm{MHz}$} & \multicolumn{2}{|l|}{ Public use } \\
\hline
\end{tabular}

b Citizens band radio (walkie-talkie), 26.96 to $27.23 \mathrm{MHz}$ and cellular telephones, 3 watts power, 825 to $845 \mathrm{MHz}$; minimum safe distance; five feet.

c Maximum power for 2-way mobile un its in VHF, 150.8- to 161.6$\mathrm{MHz}$ range, and for 2-way mobile and fixed-station units in $\mathrm{UHF}, 450-$ to $460-\mathrm{MHz}$ range.

Maximum power for major VHF 2-way mobile and fixedstation units in 35- to 44-MHz range.

eMaximum power for 2-way fixed-station units in VHF, 150.8- to 161.6-MHz range.

' Maximum power for amateur radio mobile units.

8 Maximum power for some base stations in $42-$ to $44-\mathrm{MHz}$ band and 1.6- to 1.8-MHz band. b. Blasting caps and other low-firing-current igniters or detonators shall be kept separate from explosives atall times, exceptduringactual test charge assembly and setup.

c. The entire wiring system of the explosive charge and of any low-firing-current initiators shall be kept insulated at all times from every possible source of extraneous current except for weapon components that have an exposed electrical ground by design. Connections that are made using weapon wiring connectors and/or cables are acceptable without further modification. Shunts shall be left on all low-energy initiators or lead wires until actual connections are to be made. Connections shall be taped or otherwise insulated.

d. Test units containing low-firing-current actuators or detonators shall be clearly marked. No contact operations involving electrical testing shall be permitted on this type of unit unless an electrical meter for the specific application is used.

\subsubsection{Explosives Storage in Firing Areas}

Explosives or ammunition storage at a firing area shall be located such that ignition, explosion, or detonation is improbable in case of a fire, unplanned explosion, or detonation in the area.

\subsubsection{Warning Signals}

Each DOE explosives testing facility shall use standard audible signals to warn personnel of any impending firing in a test area. Signals shall be established by each facility and approved by facility management.

\subsubsection{Grass Fires}

Evaluation shall be made before a test shot at outside firing pads to determine the necessity to control any grass fires that may be initiated by the test.

\subsubsection{Firing Leads}

All detonator lead wires shall be electrically insulated. Firing leads or cables of low-energy detonators for explosiveassemblies shall be kept properly shorted during setup on the firing point.

\subsubsection{Unattended Test Assemblies}

If necessary, a test assembly may be left unattended on the firing pad during off-shift hours under the following minimum conditions:

a. If explosives are present, appropriate safety warning signs shall be displayed at all entrances to the firing pad. 
b. Protective services and fire department personnel shall be notified of the explosives location. This location must be in a controlled access or secured area.

c. If low-energy detonators are present on the assembly, their leads or cables shall be shorted.

\subsubsection{Postfiring Controls}

a. If the firing appears to be normal, a suitable waiting period shall be observed before test personnel leave the protective shelter. The waiting period shall be sufficient to assure adequate dissipation of smoke and dust and shall be specified by the facility or test procedure. In some cases, it may be helpful to develop and analyze the diagnostic film for misfires.

b. During the waiting period, all power to the firing units shall be turned off or disconnected. Whenever possible, detonator cables should be disconnected from the firing units and shunted and grounded, and the firing unit capacitor grounded.

c. After the waiting period, one qualified operator or technician shall inspect the firing pad in person or by remote TV to determine the results of the shot before other personnel leave the shelter.

d. If the inspecting operator is certain that safe conditions exist, the lead operator shall signal "all clear."

e. After any test misfire, suspected misfire, or partial detonation, the firing area shall be inspected for unreacted explosives after the minimum waiting period. (See Section 13.7, "Test Failures and Misfires," in this chapter.)

f. Recovered explosives from a test shot shall be considered as potentially contaminated and/or partially reacted material and stored in Group $\mathrm{L}$ storage facilities (see Section 17.4 of this chapter) or stored separately pending disposition.

\subsubsection{Contamination of Firing Areas}

Most test firing areas are subject to explosives contamination due to incomplete detonations or to detonation failures when the explosives are subjected to varying forms of energy input. Most, but not all, of this contamination will be cleaned up in the postshot inspection of the test sites. The following steps shall be taken to reduce the hazards from residual explosives contamination:

a. The contamination zone for each firing area shall be established and permanently annotated on facility site plans.

b. Personnel access to explosives contaminated areas shall be controlled. c. No work shall be permitted in the area by service personnel without the permission of testingarea management and only when supervised by a person approved by management.

\subsubsection{Test Range Firing Circuit Criteria}

The following criteria are guidelines for the design of electrical circuits that are used to arm and initiate squibs, igniters, detonators, and similar EEDs during test firing activities:

a. The fire control circuit shall include both an ARM switch and a FIRE switch. In the case of lowfiring-current initiators, the safe mode of the arming circuit should not only interrupt the firing circuit, but also short-circuit and ground theEED terminals. Manual shorting and grounding is permitted.

b. Every electrical ARM and FIRE circuit on a test range shall include an interlock device consisting of a safety plug or a key-operated switch to prevent inadvertent energization.

c. The safety plug design and configuration shall be unique for its application and use to prevent unauthorized or accidental activation of a firing circuit. Key-operated switches for ARM and FIRE circuits shall be designed to lock in the safe (off) position when the control key is removed. Duplicate keys or safety plugs shall not be permitted in any one test area.

d. During shot-preparation operations, the key or safety plug for a firing site shall be in the control of the lead operator at all times.

e. All FIRE control circuits in test operation areas shall be properly documented for operational control purposes. Documentation shall include complete wiring diagrams, electrical schematics, and cable function lists. All changes or modifications to FIRE control circuits shall be reviewed for safety and approved by other appropriate departments before being incorporated into the circuits.

f. Each FIRE control circuit shall be adequately isolated from all other circuits. A shielded, twisted pair of wires with an outer insulating jacket or coaxial cable should be employed for each circuit.

g. All programmers (sequential timers) used in firing circuits shall be "failsafe." That is, failure of a component or circuit must not energize the firing circuit.

h. Test current from the electrical instruments used to perform resistance checks shall not exceed 10 percent of the no-fire rating of the EED in the circuit.

i. Firing circuits shall be clearly marked or otherwise identified in a distinctive manner, and 
shall be installed so as to prevent their inadvertent energization by other circuits.

\subsection{Test Firing in Tanks or Chambers}

Small quantities of explosives may be detonated in cubicles or in pressure vessels. The following requirements apply to such vessels:

a. The firing vessel and flanges shall be capable of withstanding and confining the effects of the explosion and properly safeguarding personnel.

b. The firing circuit should be interlocked with the vessel access door latch in such a manner that the door must be closed and latched before the explosive can be fired.

c. Inspections of the vessel by qualified engineering personnel shall be made periodically to ensure that structural integrity is maintained after repeated detonations.

d. Test firing is often conducted inside large containment vessels that allow personnel entry but provide a confined working space and limited egress. The requirements for ventilating and evaluating the atmosphere of the tank or chamber before personnel entry must be included in the SOP.

\subsection{Gun Firings}

a. No work, adjustment, or observation shall be permitted on any gun while a live round is in the firing chamber. The only exception is to check azimuth and elevation.

b. Precautions shall be taken to protect against errors in assembly or preparation of equipment and ammunition that may create hazards to personnel or equipment. In particular, the following areas shall be checked: mechanisms

- Adequate filling of hydraulic recoil

- Safe function of the firing mechanism. (Firing mechanisms shall be tested before use, particularly in the case of electric firing mechanisms, to ensure that mere insertion of the round or closing of the breech will not result in firing.)

- Absence of obstructions in the bore.

c. With the exception of manually fired small arms, test weapons should be equipped for remote control of the safety and for remote cocking. The safety shall not be advanced to the fire position and the weapon shall not be cocked until all personnel are in a safe location. d. Guns used to fire projectiles at explosives targets shall meet the following criteria:

(1) The gun shall be rigidly mounted in such a way that the impact area is defined and controlled.

(2) The target shall have an adequate backstop.

(3) Provision should be made for remotely moving the gun, remotely removing the propelling charge, or removing the explosives from the line of fire in the event of a gun misfire.

(4) Provisions shall be made for the collection and removal of undetonated explosives from the chamber or area.

e. When hydrogen gas is used in the firing of a light gas gun, the operation shall be remote while hydrogen is present in the gun pressure tanks or in the gun barrel and catch tank after firing. The hydrogen shall be purged from the entire system with inert gas and the atmosphere checked before personnel are allowed to reenter the gun bay.

\subsection{Ballistic, Environmental, Physical Property, and Sensitivity Testing}

\subsubsection{Checkout of Dynamic Engineering Test} Equipment for Explosive Assemblies

a. In order to minimize the possibility of an incident during dynamic testing of explosive assemblies, load-bearing members of the test equipment or the explosive assembly should be proof-tested and examined if -

(1) The test equipment is new or has undergone a design modification

(2) Existing test equipment is to be used under unusually severe test conditions (i.e., conditions of velocity, vibration, pressure, load, etc.)

(3) A new or modified explosive assembly is to be tested that affects the loading characteristics of the equipment.

b. Proof-testing of the explosive assembly or test equipment should be conducted before running tests involving actual systems with explosives.

c. As a minimum, proof-testing should consist of the following sequence of checkouts:

(1) Check out load-bearing members (i.e., lifting devices, hold-down mechanisms, fixtures, vehicle cases) to at least 125 percent of rated load using simulated loads (see Section 14.4 of this chapter). 
(2) "Dry run" tests of actual systems with mock materials in place of explosives and hazardous radioactive materials.

d. In the event of a part failure in either of the two checkout tests given above, no tests involving explosives or radioactive material shall be run until additional checkout tests have demonstrated that the failure cause has been eliminated.

\subsubsection{Testing of Explosives and Hazardous Radioactive Materials}

Explosives and hazardous radioactive materials (i.e., plutonium, enriched uranium, etc--depleted uranium and natural thorium are not considered hazardous radioactive materials for this purpose) shall not be included in the same test or operation if the test or operation is not contained and involves-

a. Application of high-energy stimuli (i.e., high shock, impact, or friction levels) to the explosive.

b. Heating the explosive to within $10^{\circ} \mathrm{C}$ of the heating limit determined for the explosive system without hazardous radioactive materials consistent with paragraph 12.1.1.d.

c. Intimate contact of incompatible material with the explosive as determined by compatibility testing.

d. Unacceptably high risk of accidental application of stimuli listed in $a, b$, or $c$ above.

\subsubsection{Heating of Explosives Test Specimens}

a. Heating of an explosive shall be preceded by a thermal analysis and preparation of a written procedure consistent with paragraph 12.1.1. See paragraph 12.1.2 for requirements on heating equipment.

b. Contact operations on explosives specimens undergoing thermal conditioning may be permitted if (1) the specimen will not be subjected to excessive friction, impact, or spark stimuli during normal operations or during a credible accident scenario, and (2) the explosive involved has satisfied appropriate scaleup sensitivity and stability criteria (see Chapter VIII) and has sufficient handling history to reveal any special characteristics affecting its safe use.

c. If an explosives test specimen in a contact operation is discovered to have exceeded the established heating limit for the explosive system, the test shall be terminated and the specimen cooled to ambient temperature. A procedure should be prepared and approved for the required corrective action (i.e., disassembly or disposal).

\subsubsection{Instrumentation}

a. Instrumentation directly applied to explosives in a test specimen shall be physically disconnected, isolated, or grounded before personnel may enter the test cell. Only those instrumentation channels that contain devices that limit the current below the level capable of initiating the explosive are exempt.

b. Environmental control transducer leads, not attached to the test specimen and permanently installed in an approved control system, do not need to be grounded or disconnected.

\subsubsection{Explosives Limits}

Explosives specimens shall not be permitted to accumulate in a test cell beyond the number required to sustain the test. For short-term testing (less than one day), specimens present shall not exceed a 4 -hour supply.

\subsubsection{Drop Testing}

After an explosives drop test, personnel shall wait a minimum of 5 minutes before leaving the control bunker to inspect the test pad. If smoke or flame is observed at the drop test area, entry shall not be permitted until at least 30 minutes after all visual signs have disappeared.

\subsection{Test Failures and Misfires}

\subsubsection{Explosives Misfire}

a. If no audible detonation is heard after once pulsing the firing circuit, the firing circuitry and detonator(s) may be checked for continuity. This checking shall be accomplished from within the control bunker or from a protected location. If the firing circuits and detonator(s) appear operative, one or more attempt to fire may be made.

b. If the shot still does not fire, the following precautions shall be taken:

(1) Disconnect and deenergize all electrical power sources connected to the shot.

(2) Ensure that all personnel in the danger zone are aware that a misfire has occurred and that they must remain under cover until notified otherwise.

(3) Before any personnel are permitted to leave the cover of the bunker, a preestablished waiting period shall be observed. It is advisable in most situations to establish this waiting period at $30 \mathrm{~min}$ utes minimum. 
(4) A carefully prepared review of the situation, in consultation with another knowledgeable person, should be initiated.

(5) Before other personnel are permitted to leave cover of the bunker and after an agreement has been reached, one qualified person should carefully approach and examine the setup to verify that it is safe.

\subsubsection{Misfire of a Remotely Fired Gun}

a. When a misfire occurs, several more attempts to fire the gun may be made. If these subsequent attempts are also unsuccessful, the following precautions should be taken:

(1) Disconnectallelectrical circuitry to thegun to ensure that the firing system cannot be energized.

(2) If the gun is light-gas driven, ensure that it is in a safe condition by venting all pressure in the gun breech before approaching the gun. To reduce the risk of a gas explosion in the case where the driving gas is flammable, the gun breech shall be purged with inert gas after venting.

(3) An appropriate waiting period shall be observed beforeapproach to thegun is permitted. In no case shall the waiting period be less than 10 minutes.

(4) If there is any indication that powder is burning when the gun is approached, personnel shall return to a safe area and observe an additional waiting period of at least 20 minutes.

(5) The gun shall not be approached within the known recoil distance behind the breech or from the front. Approach to and work on the gun shall be from the sides.

(6) If the gun is a separate loading type (i.e., propellant charge is loaded separate from projectiles), the propellant igniter shall be disconnected from the firing mechanism and removed from the gun before any other gun operations.

(7) If possible, the powderchamber of thegun shall bechecked for the presence of pressureand vented to the atmosphere before opening the chamber.

b. If an unforeseen failure situation arises (e.g., the explosive projectile is stuck in the bore), an emergency procedure shall be prepared and followed to resolve the situation.

\subsection{Electrical Instruments for Use with Explosives Systems (except those covered by DOE Order 5610.11)}

\subsubsection{Classification}

Test instruments shall be assigned to categories on the basis of electrical characteristics that affect their safe use with explosives systems. Specifically, the instrument categories shall be established so that each category can be safely applied to one or more of the following classes of explosives systems: (1) lowenergy or hot-wire initiators (blasting caps, actuators, squibs, etc.); (2) high energy initiators (exploding bridgewires, slappers, etc.); and (3) noninitiating electrical circuits.

Test instruments that do not meet the safety criteria may only be used on an explosive system if the activity is considered a remote operation and adequate personnel shielding or separation distance is provided.

\subsubsection{Certification}

a. Each DOE facility engaged in the use of electrical test instruments on explosives systems shall establish a formal system for the purpose of reviewing and certifying these instruments. Procedures for marking instruments to show their approved use and restrictions on their use should also be established.

b. Every individual test instrument designated for use on explosives systems shall be certified and prominently labeled with its approved use and with a warning if there is a restriction on its use.

c. Inspection and calibration of certified instruments shall be required at prescribed intervals or whenever the instrument is opened for servicing or repair. Access to internal circuitry of certified instruments shall be controlled to prevent unauthorized repairs, maintenance, or alteration.

d. Records of all instrument types certified shall be maintained by each DOE facility using electrical instruments to test explosives systems. These records should include type, manufacturer, model, electrical specifications, wiring diagrams, and failure mode analyses. The Explosives Safety Committee chairperson shall be notified in writing by DOE facilities when they approve new electrical instruments for use with initiating systems. The chairperson shall disseminate this information to all committee members.

\subsubsection{Electrical Instruments for Use with Initiating Electrical Circuits}

Instruments in this category are used with electrical initiation circuits connected to electroexplosive devices. Instruments may be further categorized for use with either low-energy initiators or high-energy initiators. All test instruments used for this purpose shall be current-limited. Before being used on initiating circuits, every individual instrument wiring diagram and internal circuitry design shall be analyzed, examined, and certified for the following:

a. The output current through a resistance, equivalent to that of the minimum resistance initiator of the class, should not exceed $1 \%$ and shall 
not exceed $10 \%$ of the no-fire rating for the most sensitive initiator of the class. The current-limiting features of the test instrument shall be internal to the instrument and shall not depend on test circuit load characteristics.

b. The internal circuitry shall ensure isolation features that require, as a minimum, two independent failure modes before the specified output current can be exceeded.

c. Acomprehensive (point-to-point, if possible) wiring check should be made to ensure that the wiring corresponds to the diagram and that all components are functioning properly and within specifications.

\subsubsection{Electrical Instruments for Use with Noninitiating Electrical Circuits}

Instruments in this category are used with electrical circuits connected to strain gages, pin switches, pressure transducers, thermocouples, electrical components, etc. that are affixed to or within an assembly with explosives. These instruments shall meet the following requirements:

a. Each specific use of the instrument shall be analyzed to ensure that there is no credible scenario whereby the normal test energy from the instrument can ignite explosives charges or initiators in the test. Guidance on operational requirements is contained in paragraphs 13.3.3 and 13.6.4.

b. Where an instrument is used to make measurements on sensors directly applied to explosives, e.g., bonded strain gages or pin switches, the instrument shall be certified and have met the requirements of paragraph 13.8.3.

c. Instruments used with noninitiating electrical circuits shall be prominently marked with the restrictions on use. Many of these instruments do not meet the requirements for use with initiating systems and must be marked to prevent their use on this type of circuit. 


\section{CHAPTER II}

\section{Materials Handling}

\subsection{General}

a. The distance that explosive materials can fall, if accidentally dropped during handling, shall be maintained at a minimum.

b. Hard surfaces and edges of equipment that could be struck by accidentally dropped, consolidated explosives should be padded with cushioning mats or coverings whenever possible and needed. (Protective padding includes both sheet material on work surfaces and on equipment and approved floor coverings.)

c. Explosives handling shall be permitted only where handling areas are free of obstructions and where the walkway surfaces provide positive footing with no slipping or tripping hazards (e.g., explosives shall not be handled on walkways coated with snow or ice).

d. Explosives and materials that are not compatible shall not be handled together.

e. Detonators, actuators, EEDs, and other items that would normally be shipped as a Class C explosives, should be kept in nonpropagating trays or containers unless handled individually.

f. Dry explosive materials that generate dust shall be transported in closed containers.

g. Containers of explosives or explosive assemblies shall be labeled for contents identification during handling, storage, and transportation.

h. Any explosives items that cannot be identified and labeled shall be submitted for disposal.

\subsection{Manual Handling of Bare Consolidated Explosives}

a. Manual handling shall be minimized as follows:

(1) One person may lift or carry up to $25 \mathrm{~kg}$ of explosive (if it can be securely gripped).

(2) Two people may lift or carry $50 \mathrm{~kg}$ of explosive (if manual lifting and handling tooling is provided).

(3) Any explosive item over $50 \mathrm{~kg}$ in weight or which cannot be securely gripped should not be manually handled. b. Explosives should not be carried up or down stairs except when in protective containers.

c. Operations shall be arranged to minimize the handling distance in all manual explosives handling situations.

\subsection{Carts or Hand Trucks}

a. Explosives that cannot be manually handled shall be hand led only on suitable carts or hand trucks. Carts used for bare explosives handling shall be provided with a padded surface to support the explosives. These carts shall be equipped with either a lip, sides of sufficient height, or tiedown straps to prevent the explosives from sliding or rolling off the cart. The cart-explosive load combination shall have a center of gravity low enough to prevent tipping in the event of a sudden stop caused by a wheel contacting an obstruction.

b. Explosives handling carts or hand trucks should be provided with brakes. Carts containing explosives shall be positively secured (e.g., setting wheel brakes or chocking) when the cart is stationary.

\subsection{Mechanical Handling Equipment}

a. All items of mechanical handling equipment (i.e., cranes, hoists, slings, etc.) used to lift and move explosives or explosive containing assemblies shall be initially proof-tested, periodically inspected, and maintained in first-class working condition. The DOE Hoisting and Rigging Manual may be used as a guide for testing, inspection, and maintenance.

b. Equipment for vacuum lifting of consolidated explosives must comply with the following requirements:

(1) The lifting equipment shall be designed so that jerks or other irregular motions in the hoisting apparatus or bumping of other equipment will not dislodge explosives from the vacuum head.

(2) Equipment shall be designed to monitor the available vacuum and to control loss of vacuum in the event of a power failure or vacuum-source failure. 
(3) Any handling where a loss of vacuum would allow the explosive to drop an excessive distance shall incorporate some safety device (collar, net, strap) to prevent dropping. "Excessive distance" shall be defined as a distance greater than the minimum drop height giving drop-skid initiation for the explosive being handled. "Initiation" in the dropskid test is used here to refer to any indication of sample decomposition. An alternative method of protection can be the use of a cushioning surface under and over all items that may be struck by the falling explosives. 


\section{CHAPTER II}

\section{Materials Receipt}

The following guidelines shall apply to the inspection, receipt, and unloading of explosives materials:

\subsection{Motor Vehicles}

a. Incoming motor vehicles loaded with explosives shall be carefully inspected by a competent person using an approved checklist at a designated inspection station.

(1) When an inspection reveals that an incoming tractor is in an unsatisfactory condition, the tractor should be disconnected from the trailer at the inspection station and moved to a position where it will not endanger any other explosives.

(2) When inspection reveals that a trailer or its load is in an unsatisfactory condition, the trailer shall be moved to a location that is at least inhabitedbuilding distance for the particular material involved from inert and administration areas, hazardous locations, and the facility boundary. At this location, correction of unsatisfactory conditions shall be accomplished before moving the vehicle to its destination within the facility. When moving from the inspection station to the isolated locations, the route should be as far away as possible from built-up areas and areas where personnel concentrations are high.

(3) Vehicles that cannot be immediately dispatched to points where they are to be unloaded may be moved to a holding yard that shall be sited in accordance with Chapter VI, paragraph 3.2.2.

(4) Incoming or outgoing explosives loaded trailers that cannot be exchanged directly between the carrier and DOE facilities may be moved to an interchange yard. Quantity-distance provisions do not apply if the trailers are moved expeditiously.

b. Vehicles shall not be backed up to a dock where explosives are resting and could be damaged if the dock were struck.

c. The building doors at the receiving facility should be closed while the motor vehicle is in motion or the engine is running.

d. Once the vehicle is in position, the engine shall be shut off, the brakes set, and the whecls chocked. e. After unloading, the vehicle shall be inspected for loose explosives materials, and any spilled material shall be cleaned up after the inspection. If a spill involves liquid explosives or explosives in solution, the spill shall be reported immediately to the building supervisor and appropriate cleanup procedures shall be used.

\subsection{Railcars}

Railcars containing explosives and ammunition entering a DOE facility must be inspected. This inspection comprises the examination of the outside and underside of each car for damage such as defective brakes, couplings, wheel flanges, etc.; for unauthorized and suspicious articles; and for correctness of the individual car numbers and seal numbers against bills of lading.

a. Cars of ammunition or explosives showing a defect that could affect the facility or contents of the car should be removed to the suspect car spur for additional inspection (ChapterVI, paragraph 3.2.2.b).

b. Cars that satisfactorily pass the inspection outlined above may be considered reasonably safe, but care must be exercised in breaking car seals and opening car doors because of possible damage or shifting lading, leaking containers, etc. Interior inspection should be accomplished after the cars have been spotted at the unloading point.

\subsection{Damaged Shipments}

a. Explosives shipments shall be inspected for damage before storage.

b. Contents of a damaged or broken container shall be removed to another container. Any spilled materials shall be cleaned up before continuing with loading or unloading.

c. Any shipment received in damaged condition as a result of inadequate or improper blocking and bracing or as a result of not being loaded in accordance with appropriate DOT requirements shall not be reshipped until the damage is corrected. 



\section{CHAPTER II}

\section{Transportation}

\subsection{Equipment}

\subsubsection{General}

a. Explosivesshipped on common carriers shall be packaged and shipped in accordance with DOT regulations.

b. Explosive-containing items transported by weapons couriers in a Safe Secure Trailer (SST) or Safe Secure Railcar (SSR) are exempt from the equipment requirements given below.

c. Security and authorized emergency vehicles carrying approved quantities of explosives in support of approved contingency plans are not considered "in transportation," as defined by 49 CFR Part 171.8.

\subsubsection{Motor Vehicles}

a. Motor vehicle shipments on public highways are governed by DOT regulations. All motor vehicle shipments from a DOE installation shall comply in full with the applicable portions of DOT, and with state and municipal regulations, except as provided for in these regulations. Any motor vehicle that may be loaded with explosives (Hazard Class/ Division 1.1, 1.2, and 1.3) and is designated for movement over public highways must be inspected and approved by a qualified inspector for compliance with an approved checklist. After loading, the lading must be inspected and approved. Driver selection, training, etc., for intraplant shipping and for operation of government-owned trucks on public highways shall be in accordance with pertinent requirements of 49 CFR, Parts 390-397.

b. Before motor vehicles loaded with explosive materials leave a DOE facility, drivers shall be informed as to the nature of their cargo and methods of fighting fires involving the vehicle or its cargo.

c. Cargo-type trucks and truck-tractor drawn semitrailers are the preferred types of equipment for transporting explosives. Flat-bed semitrailers or trailers may also be used to transport large items in special containers for such movement. For transfer movement within facilities, open body vehicles (other than flat-bed types) must have sides and tailgates or rear doors that are strong and securcly fastened so that explosives are safely retained. Vehicles (including flat-bed types) partly or completely loaded shall have the lading blocked, braced, chocked, tied down, or otherwise secured to prevent shifting during transit.

d. All DOE explosives-carrying vehicles for onsite transportation should be equipped with the following:

- Explosives placards plainly visible from all directions (except for vehicles transporting Hazard Class/Division 1.4 items)

- Tiedown bolts, rings, and straps with which to securely fasten the explosives items and which are adequate for the load

- On trucks, a cargo area with no sharp projections. (Nonsparking lining is desirable when hauling explosives in transfer containers that are not DOT approved.)

- Chock blocks

- A quick-disconnect switch on the battery if explosives are left on the vehicle overnight

- Rear-view mirrors on both sides of the vehicle

- Two fire extinguishers with a minimum rating of $2 \mathrm{~A}: 10 \mathrm{BC}$, one of which should be mounted outside the vehicle. Vehicles for transportation of Hazard Class/Division 1.4 explosives need just one extinguisher.

e. Precautions must be taken to avoid ignition of explosives material by the exhausts of motor vehicles. When a motor vehicle approaches within 25 feet of the doors of a structure through which a shipment is to be moved, the doors must be kept closed until the motor has been turned off unless the exhaust system is equipped with a spark arrestor or no exposed explosives are present. Exposed explosives exclude finished items and explosives packaged for shipment in DOT or DOT equivalent containers. No explosives shall be loaded into or unloaded from motor vehicles while their motors are running except when required to provide power to vehicle accessories used in loading or unloading and the vehicle exhaust is equipped with a spark arrestor.

(1) Security patrol and response vehicles are authorized to transport the minimum quantity of munitions needed to support approved contingency plans and to execute their security duties. Whenever possible, support munitions required for defense against hostile forces should be prepositioned in readilyaccessible magazines. Security vehiclesarmed 
with a combination of up to 25 pounds net explosives weight of Hazard Class/Division 1.1 and 1.2 munitions shall be exempt from explosives quantitydistance requirements when executing approved contingency plans or security duties. Vehicles so armed will not be used for administrative purposes and will be separated from inhabited facilities and property lines by a minimum of 125 feet when temporarily out of security service, and shall be downloaded into properly sited magazines or approved facilities when parked for periods in excess of 4 hours. Operation of explosives loaded vehicles will be restricted to on site locations and transported explosives must be secured within the vehicle. Smoking in explosives loaded vehicles is prohibited. These vehicles shall be downloaded into properly sited magazines or approved facilities prior to repair or maintenance, except under emergency response conditions.

(2) Security force personnel shall be allowed to transport on their person Hazard Class/Division 1.1 and 1.2 munitions issued to them for personal use in the execution of approved contingency plans and security duties without regard to explosives quantity-distance requirements. Appropriate safety precautions for the handling of ammunition shall be observed and the munitions shall be placed in an approved location if temporarily removed from the uniform/load bearing equipment worn to carry such items.

\subsubsection{Railcars}

a. A railcar must not be loaded with any Hazard Class/Division 1.1 and 1.2 explosives unless it has been thoroughly inspected by a qualified employee of the carrier who certifies that the railcar's condition conforms to DOT regulations. After a certified car has been furnished by the carrier, the shipper or an authorized employee of the shipper must, before starting to load any such car, inspect the interior thereof and, after loading, certify its proper condition. A certificate will be completed and signed where applicable. Shipments of Hazard Class/ Division 1.3 explosives may be loaded in a closed car or container car in good condition (i.e., sparks cannot enter the car and the roof does not have unprotected decayed wood that constitutes a fire hazard). Wooden-floored cars must be equipped with spark shields. Such cars do not require a car certificate, but they must have a placard in accordance with DOT regulations.

b. The railcar certificate, printed on strong tag board measuring 7 by 7 inches or 6 by 8 inches, must be duly executed in triplicate. The original copy must be filed by the carrier in a separate fileat the forwarding station, and the other two must be attached to the car, one to each outer side on a fixed placard board or as otherwise provided.

\subsubsection{Materials Handling Equipment}

a. Gasoline-powered materials-handling equipment (forklifts, etc.) may be used only in areas where all explosives are properly packaged and only if equipped in the following manner.

- Backfire deflectors shall be securely attached on the throat of the carburetor and shall be the oil-bath or screen type (certain types of air cleaners will serve the purpose).

- A tight-fitting cap, properly vented, shall be in place on the gasoline fill pipe at all times (except during refueling).

- A flame arrestor shall be installed in the fill pipe.

- If necessary, a deflector plate shall be installed to prevent any gasoline tank overflow from reaching the motor or the exhaust pipe.

- On gravity feed systems or on pump systems where siphoning might occur, a shut off valve shall be installed at the fuel tank or in the feed line to permit shutting off the flow of gasoline in the event of an emergency or a break in the fuel line or carburetor.

- Provisions shall be made to prevent vibrational rupture of the fuel lines.

b. Diesel-powered equipment may be used if all the precautions for gasoline-powered equipment (as specified above) are followed.

c. Battery-powered equipment for handling explosive material shall comply with the criteria listed below.

(1) Battery-powered equipment and its use in hazardous locations shall comply with OSHA standards. All equipment shall be appropriately labeled for ready identification.

(2) Types E, EE, ES, and EX-rated, batterypowered equipment are satisfactory for handling all classes of properly packaged ammunition and explosives. Types EE and ES battery-powered equipment may be used for handling packaged explosives or explosive components in corridors or ramps connecting hazardous operations, provided the ramps and corridors are not Class I or II, Division 1, hazardous locations (NEC). Type EEequipment is authorized for use in Class II, Division 2, Group G hazardous locations, and Type ES equipment may be authorized on approval of facility management (see NFPA 505 , Powered Industrial Trucks). 
(3) Type EX equipment is the only equipment approved for use in specifically named Class I, Division 1, Group D or Class II, Division 1, Group G hazardous locations. At this time, EX equipment does not carry a dual rating and shall only be used in hazardous areas for which it is specifically rated.

\subsection{General Operation Guidelines}

a. Explosives-containing items transported by weapons couriers in SSTs or SSRs are exempt from the operation guidelines given below.

b. Drivers shall be given special training that emphasizes caution, road courtesy, and defensive driving.

c. The operator of an explosives-carrying vehicle shall have proper training in the general safety precautions for explosives handling.

d. Congested areas should be avoided.

e. Road vehicles shall stop at all railroad crossings.

f. No personnel shall ride in the cargo arca. There shall not be any loose items (e.g., handling gear) in the cargo compartment.

g. No smoking is allowed in a vehicle containing explosives. (Matches, lighters, or other firc-, flame-, or spark-producing devices shall not be in the vehicle or carried by personnel in the vehicle.)

$h$. The vehicle shall be subjected to regular maintenance checks.

i. Before shipment, explosives materials being transported by commercial carrier shall be classified by testing or analogy in accordance with DOT regulations.

j. Other than when opened for inspection, containers of explosives shall not be opened or repaired on any transportation vehicle.

k. Except for emergency situations, fueling or maintenance of vehicles containing explosives is forbidden.

1. Each facility shall have a special set of traffic rules governing the operation of explosives-carrying vehicles and the operation of other onsite vehicles in the vicinity of explosives-carrying vehicles.

$\mathrm{m}$. Industrial trucks shall not be used in locations where high concentrations of dusts or sublimation of explosives may result in contaminated surfaces (e.g., screening buildings, pouring bays, melt-pour units, drilling bays, consolidating bays, and explosive washout facilities).

\subsection{Emergency Conditions}

a. Explosives should not be transported when hazardous conditions (such as storms, icy roads, or poor visibility) prevail. An emergency plan shall be prepared to provide instruction and guidelines in the event any of these conditions arises while an explosives carrying vehicle is in transit. The plan should address the following items:

- Parking the vehicle

- Safeguarding the vehiclefrom other traffic

- Notifying appropriate authorities of the emergency situation

- Leaving the vehicle unattended.

b. A plan shall be prepared to provide for an explosives-carrying vehicle that has a mechanical breakdown. Theplan shall address the following items:

- Removing the vehicle from the road as far as practical

- Posting emergency reflectors, signals, etc. (carrying flares on the vehicle is not permitted)

- Reporting the problem

- Maintaining surveillance of the vehicle

- If necessary, removing the vehicle load to facilitate repair of the vehicle.

c. If an explosives-carrying vehicle is involved in an accident, the following steps should be taken:

(1) Inspect the load for evidence of fire.

(2) If there is a fire, but the explosives material is not presently nor imminently involved, attempt to prevent the fire from spreading to the load. The fire may be fought using the vehicle's fire extinguishers. If explosives items are removed from the vehicle, ensure their security.

(3) If there is a fire that presently or imminently involves the explosives load, evacuate all personnel to a preestablished safe distance. Block or divert other traffic from the vicinity of the accident. Evacuate any potentially affected area residents.

(4) Unless the explosive cargo is imminently involved in fire, direct the operator to stay with the vehicle until proper disposition of the cargo is accomplished.

(5) Immediately notify the fire department or fire brigade of the accident and inform them of the general type and approximate quantity of explosives involved.

(6) Inform proper authorities of the accident. 


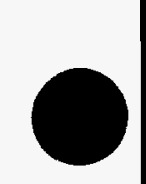

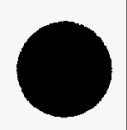

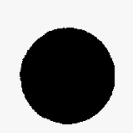

II-52 


\section{CHAPTER II}

\section{Explosives Storage}

\subsection{Storage Magazine Facilities}

a. Placard(s) shall be posted on or near each door of the magazine, specifying explosive and personnel limits and general safety precautions that should be observed during work in the magazine.

b. Vegetation around storage magazines should be controlled to minimize potential damage to the magazine (see Chapter VI, paragraph 5.1).

c. At least two fire extinguishers, minimum rating $2 \mathrm{~A}: 10 \mathrm{BC}$ and winterized where necessary, should be provided and maintained for immediate use by personnel working around a magazine. These extinguishers may be permanently located in the area or available on an explosives transportation vehicle. The extinguishers are for the purpose of fighting small external fires or magazine fires where explosives are not involved.

d. Suitably rated telephone or other forms of emergency communication equipment should be provided in magazine storage areas. All communications equipment located outdoors should be protected from the weather.

e. Temperature Control

(1) In general, storage magazines should not be provided with heat. An exception shall be made in the case where heating may be necessary to prevent damage caused by sudden changes in temperature or where dimensional changes of components are undesirable.

(2) Magazines requiring heat should be heated with steam, hot water, or electrically heated hot water. Some magazines with tight temperature controls may require both heating and air conditioning. Electrical systems with forced air through ducts may be allowed if the systems are located exterior to any explosive hazard.

(3) Heating coils shall be arranged so that explosives material cannot come in contact with the coils. They shall be equipped with covers designed to prevent the storage of materials on top of the coils.

(4) In all magazines where heat is supplied, maximum/minimum temperature monitors should be provided.

\subsection{Storage Magazine Operations}

a. Explosives items should be properly packaged when stored (see paragraph 17.5).

b. Explosives may be stored on magazine shelves where provided, but should not be placed more than 2 meters off the floor.

c. Explosives and explosives containers in storage shall be safely and securely positioned. If explosives containers must be stacked, they shall be placed in stable arrays.

d. Permissible loading of all shelving should be determined for all magazines containing explosives. If there is a possibility of overloading, the loading conditions shall be posted.

e. Materials shall not be left suspended by booms, cranes, or hoists in any explosives storage facility.

f. Explosives in storage should be segregated by lot designation. Stacks of explosives should be arranged so there is free air circulation to all parts of the stack.

g. Aisles shall be sufficient in width to accommodate inspection, inventory, sampling, and materials handling operations on the stored explosives containers.

h. A crew shall not be permitted to work in a position that requires passing the work aisle or the position of a second crew to reach the exit. Unobstructed aisles shall be maintained to permit rapid exit of personnel.

i. Each crew working in a magazine must have its own exit route that does not interfere with exit routes for other crews.

j. Magazines shall be locked at all times except when permissible operations are in progress or when a magazine is opened for ventilation. Personnel shall be present while the magazine is open for ventilation. All exit doors shall be unlocked and open when personnel are working in the magazine.

k. An inventory of each magazine shall betaken at least annually to determine the total weight of explosives present (to assure this weight conforms to allowable quantity-distance constraints) and to remove and destroy materials that are not properly identified or labeled. 
1. The liquid level in storage containers for wet explosives shall be checked and replenished if necessary at least once a year, and a log of the checks shall be maintained.

m. Empty containers, tools, conveyors, lift trucks, skids, and other similar equipment should not be stored in a magazine containing explosives.

n. Combustible materials such as excess dunnage, packing material, and boxes shall not be stored in a magazine containing explosives. Flammable liquids shall not be stored or used in explosives magazines unless the liquid is an explosive, is needed as an explosives-wetting agent, or is an integral part of an explosives device.

o. Operations in and around magazines shall be prohibited when an electrical storm is in progress and minimized when it is evident that such a storm is approaching. Explosives-handling operations shall not be performed when magazine entranceways are ice-covered or, for any other reason, do not provide adequate footing.

p. Unless excepted, no operation in which hazardous materials are involved shall be permitted in any magazine. The following exceptions are recognized:

(1) Those operations incident to storage or removal from storage

(2) Inspection and surveillance sampling of compatibility Group D and bulk propellants of Group C materials (see paragraph 17.4.c and Table II-4), provided that each storage container sampled is in good condition (i.e., the container is not leaking, no evidence exists of explosives contamination at the closure or of seal failure, and the closure is mechanically sound and free of excessive corrosion, etc.). Only one container of explosives shall be opened at one time in a magazine.

(3) Liquid addition to adjust the liquid composition level in which a Group D explosive is stored. (Water and alcohol mixtures may be used as the liquid. If only water is added to the explosive, the water should be distilled or deionized. Bacteria present in untreated water may produce gassing during storage.)

\subsection{Storage Review Program}

Each facility shall have a program to review the explosive materials stored at that facility. In recognition of the fact that explosives may degrade during prolonged storage and the hazards of handling or using degraded explosive may increase significantly, the following procedure is provided as an example: a. A storage review date should be assigned to every bulk explosive placed in storage. The storage review date should be shown on or adjacent to the identification tag or sticker attached to every container or package of explosive in storage or should be listed in the inventory records.

b. Storage review intervals should be based, whenever possible, on stability data. A safe storage interval should be considered as that time period, at maximum anticipated storage temperature, during which an explosive material can be conservatively expected to show an acceptable level of decomposition.

c. A storage review committee should be designated or created by facility management to establish and approve storage review intervals for all explosives stored at the DOE facility. Also, the committee should prescribe for each explosive appropriate tests to permit an evaluation of the safety of handling and processing the material once it has exceeded its storage review interval. These tests may be referred to as "stability tests," although sensitivity, or other types of testing, may be included in the material evaluation program. In some cases, the revicw committee may simply require periodic stability testing of the material rather than establish a storage review interval (i.e., nitrocellulose, single and double base propellants, etc.).

d. To store a new explosive, to increase (or decrease) the review interval for a previously approved material, or to use different stability test data for an explosive, the following procedure should be observed:

(1) A responsible person should communicate the request to the storage-review committee.

(2) If the request concerns storage of a new explosive, the individual should recommend a storage-review interval and stability-evaluation testing.

(3) Supporting data should be supplied with the recommended review interval and with the proposed stability tests for the explosive.

(4) The storage review committee should review the request and supporting data and then prescribe a storage review interval and/or stability tests.

e. A new explosive should be assigned an interim storage review and stability test interval before Phase II scaleup (see Chapter VIII).

f. The following general guidelines are offered to assist the storage-review committee in establishing review intervals in cases where there is insufficient stability information to predict storage life: 
(1) If there is no available information on a new material relative to storage stability, a review interval of 90 days or less should be assigned.

(2) A new formulation should be assigned a storage review interval not exceeding that of its least stable component.

(3) If the compound or formulation is new to DOE but DOD agencies have extensive experience with it, the DOD information should be used conservatively.

(4) If a manufacturer has an assigned shelf life for a formulation or ingredient, a review interval that exceeds the recommended shelf life should not be assigned unless additional DOE tests indicate such storage is warranted.

g. A storage review interval of up to 20 years should be permissible for an explosive if a conservative evaluation of stability data indicates that such an interval is justified.

\subsection{Storage Compatibility}

a. Explosives shall not be stored with materials or items that increase the risk of initiation or decomposition of the explosives. Examples are mixed storage of explosives with flammable or combustible materials, acids, or corrosives.

b. Different types of explosives may be stored in the same magazine if they are compatible. Explosives shall be assigned to a storage compatibility group when they can be stored together without significantly increasing either the probability of an accident or, for a given quantity of explosive, the magnitude of the effects of such an accident.

c. Each type of explosive shall be assigned to an appropriate storage compatibility group (A through $G, L$, and S) for the purpose of storage at DOE facilities. The nine groups are defined in the following paragraphs. These definitions and the Table II-5 Storage Compatibility Mixing Chart are in accordance with the principles and tables in DOD 6055.9 STD, "DOD Ammunition and Explosives Safety Standards." Table II-4 presents some examples of commonly used materials that are assigned to each storage compatibility group. This list does not enumerate all materials that may be included in each group.

(1) Group A-Initiating explosives. Bulk initiating explosives that have the necessary sensitivity to friction, heat, or shock to make them suitable for use as initiating elements in an explosives train. Examples are lead azide, lead styphnate, mercury fulminate, and tetracene.
(2) Group B-Detonators and similar initiating devices not containing two or more independent safety features. Items containing initiating explosives that are designed to initiate or continue the functioning of an explosives train. Examples are detonators (all types, excluding EBWs and Slappers), blasting caps, small arms primers, and fuzes.

(3) Group C-Bulk propellants, propellant charges, and devices containing propellant with or without their own means of initiation.* Items that will deflagrate, explode, or detonate upon initiation. Examples are single-, double-, triple-base, and composite propellants, rocket motors (solid propellant), and ammunition with inert projectiles.

(4) Group D-High explosives (HE) and devices containing explosives without their own means of initiation." This group shall include explosives and ammunition that can be expected to explode or detonate when any given item or component thereof is initiated.

(5) Group E-Explosives devices without their own means of initiation* and with propelling charge (other than one containing a flammable or hypergolic liquid). Examples are artillery ammunition and rockets.

(6) Group F-Explosives devices with their own means of initiation and with or without propelling charge.*

(7) Group G-Pyrotechnic materials and devices containing pyrotechnic materials. Examples are devices that when functioning, result in an incendiary, illumination, lachrymatory, smoke, or sound effect.

(8) Group L-Explosives or ammunition not included in other compatibility groups. This group shall include explosives or ammunition having characteristics which do not permit storage with other similar or dissimilar materials. Examples are damaged or suspect explosives devices or containers, explosives which have undergone severe testing, fucl/air explosive devices, and water-activated devices. Also included are experimental explosives, explosives of temporary interest, newly synthesized compounds, new mixtures and salvaged explosives until they have been established to be compatible with the original materials. Types presenting similar hazards may be stored together.

(9) Group S-Explosives, explosive devices, or ammunition presenting no significant hazard. Explosives or ammunition so designed or packed

* See definitions of Initiation, Chapter I, Section 5, p. I-5. 
Table II-4. Storage compatibility groups for explosives and explosive-containing devices.

Group A-Initiating explosives

CP (5-Cyanotetrazolpentaamine Cobalt III Perchlorate)

HMX (Cyclotetramethylene tetranitramine) (dry)

Lead azide

Lead styphnate

Mercury fulminate

Nitrocellulose (dry)

PETN (Pentaerythritol tetranitrate) (dry)

RDX (Cyclotrimethylene trinitramine) (dry)

TATNB (Triazidotrinitrobenzene)

Tetracene

Group B-Detonators and similar initiating devices

Blasting caps

Detonators excluding EBWs and slappers

Explosive bolts

Fragmenting actuators

Igniters

MDF (mild detonating fuze) detonator assemblies

Pressure cartridges

Primers

Squibs

Group C-Bulk propellant, propellant charges, and devices containing propellants with or without their own means of initiation

Smokeless powder

Pistol and rifle powder

Rocket-motor solid propellants

Group D-High explosives (HE) and devices containing explosives without their own means of initiation

Ammonium picrate

Baratol

Black Powder

Boracitol

Compositions A, B, and C (all types)

Cyclotols (not to exceed a maximum of $85 \%$ RDX)

DATB (diaminotrinitrobenzene)

Detasheet

Detonating cord (primacord or mild detonating fuze)

bis-Dinitropropyl adipate

bis-Dinitropropyl glutarate

bis-Dinilropropyl maleate

Dinitropropane

Dinitropropanol

Dinitropropyl acrylate monomer (DNPA)

Dinitropropyl acrylate polymer (PDNPA)

EBW and slapper detonators

Elastomeric plastic bonded explosives

Explosive D

HMX (Cyclotetramethylene tetranitramine) (wet)

HMX/wax (formulated with at least $1 \%$ wax)

HNS (Hexanitrostilbene)

Linear-shaped charge

Methyl dinitropentanoate

Nitrocellulose (wet)

Nitroguanidine

Octol

Pentolite

PETN (Pentaerythritol tetranitrate) (wet)

PETN/extrudable binder
Plastic Bonded Explosives, PBX (a Group D explosive

formulated with a desensitizing plastic binder)

Potassium picrate

RDX (Cyclotrimethylene trinitramine) (wet)

TATB (Triamino trinitrobenzene)

TATB/DATB mixtures

Tetryl

TNT (Trinitrotoluene)

Group E-Explosives devices without their own means of initiation and with propelling charge

Artillery ammunition

Rockets (e.g., M66 LAW)

Group F-Explosives devices with their own means of initiation and with or without propelling charge

Group G-Pyrotechnic material and devices that produce an incendiary, illumination, lachrymatory, smoke, or sound effect Smoke pots (when in lots of 50 or more)

Flares

Incendiary ammunition

Group $L-$ Explosives or ammunition not included in other compatibility groups

Damaged or suspect explosives devices or containers

Explosives that have undergone severe testing

Experimental explosives, explosives of temporary interest, newly synthesized compounds, new mixtures, and some salvaged explosives

Group S-Explosives, explosives devices, or ammunition presenting no significant hazard

Propellant cartridge actuated devices (which yield a nonfragmenting, nonflame-producing controlled

reaction). Examples include the following:

Cable cutters

Cartridge actuated valves

Linear actuators (e.g., dimple, piston, bellows motors)

Safety fuze

Small arms ammunition

Smoke pots or similar smoke devices (when in lots of less than 50)

Thermal batteries

Materials and systems that need not be stored or labeled as explosives unless they are near other explosives that could initiate them

When near explosives, these materials become Group D unless otherwise indicated.

FEFO/SOL ( $35 \mathrm{wt} \%$ or less FEFO in ethyl acetate) FEFO/solution

Group D explosives in inert solvents (explosive concentration not exceeding $25 \mathrm{wt} \%$ )

Nitrates; treat as Group $C$ when with other explosives Perchlorates; treat as Group $C$ when with other explosives

Picric acid (containing at least $10 \mathrm{wt} \%$ water and in less than $11 \mathrm{~kg}$ lots)

Small arms ammunition classified for shipment by DOT as ORM-D (Other Regulated Material Class D) rather than Hazard Class/Division 1.4 explosives. Normally consists of ammunition not exceeding $\mathbf{5 0}$ caliber for hand guns and rifles and 8 gauge for shotguns. 
that, when in storage, all hazardous explosive effects are confined and self-contained within the item or package. An incident may destroy all items in a single pack, but must not be communicated to other packs.

d. Newly synthesized compoundsand mixtures shall bestored in Group L storagefacilities. After more complete evaluation, those compounds or mixtures of continuing interest shall be assigned by the Explosives Development Committee (see Chapter VIII, Section 1.1) to the appropriate compatibility group, and stored according to the following considerations:

(1) The material's sensitivity to initiating stimuli (i.e., friction, impact, spark, shock, and thermal) is similar to that of other explosives in the group.

(2) The material's reactions and the effects of these reactions, in the event of application of initiating stimuli, are similar to other members of the group.

(3) The material is chemically compatible with other members of the group. Sensitivity and compatibility testing is described in Chapter VIII.

e. Mixing of storage compatibility groups may be permitted as indicated in Table II-5. Items from Storage Compatibility Groups B, C, D, E, F, G, and S may be combined in storage if the net quantity of explosives in the items (or in bulk) does not exceed 1,000 pounds and if the items are in approved containers. Each article of Storage Compatibility Groups $B$ and $F$ shall be segregated in storage from those of other compatibility groups by means that will prevent propagation of those articles. In addition, samples of explosives up to $2 \mathrm{~kg}$ total, may be stored in the same cubicle without regard to the above compatibility groupings if the cubicle walls are designed to prevent propagation and the cubicle is designated for one of the following groups of explosives:

High explosives

Propellants

Detonators, actuators, and similar devices

Primary and static-sensitive explosives

\subsection{Containers (On-Site)}

a. Explosives containers shall be designed and constructed so they will not leak and will protect their contents from excessive movement, external stimuli, contamination, or spillage during handling, transportation (including transportation to disposal sites), and storage. Container closures shall prevent spilling or leakage of contents if the container is overturned. Screw-type container closures should not be used. b. Explosives containers should be constructed of, or lined with, nonabsorbent materials that are compatible with the explosive contents. Use of glass containers is discouraged, except for small samples, and shall be used only when theexplosive reacts with other materials or when a high degree of purity is required.

c. Metal containers for materials that are potential dust producers shall be constructed with out seams or rivet heads. Seams or rivet heads can provide locations for dust accumulation.

d. Containers for cast or pressed explosives pieces that are larger than 0.3 meter at their greatest dimension or weigh more than $5 \mathrm{~kg}$ loaded should be provided with handles or some other type of handhold. If the loaded container weighs more than $50 \mathrm{~kg}$, provisions should be made to allow handling by mechanical handling equipment.

c. All explosives containers shall be labeled.

f. Whenever possible, explosive pellets and items containing small quantities of explosives (e.g., detonators) shall be packaged in containers constructed so the functioning of one item will not propagate to the remaining items in the container. When a nonpropagating array is not possible, the pellets or detonators shall be stored inside a closed container and shall be labeled to indicate the total weight of the explosive contents.

g. Container closures shall be the type that will not apply excessive pinching or rubbing forces to explosives during closing and opening. The closures and surfaces of container openings shall be kept thoroughly clean of explosives contamination to minimize any hazard during closing and opening.

h. Explosives and ammunition in damaged containers shall not be stored in a magazine with other explosives and ammunition. Damaged containers shall be repaired, or the contents transferred to new or undamaged containers, or the container plus contents moved to a Group L storage magazine.

i. Open containers and containers with covers not securely fastened shall not be stored in magazines. Containers that have been opened shall be properly reclosed before being returned to storage.

\subsection{Storage in Buildings Other Than Storage Magazines}

\subsubsection{Packing and Shipping Buildings}

In buildings specifically designated for packing and shipping, explosives may be stored subject to the following rules: 
Table II-5. Storage compatibility mixing chart.

\begin{tabular}{|c|c|c|c|c|c|c|c|c|c|}
\hline Groups & $\mathbf{A}$ & B & C & D & $\mathrm{E}$ & F & G & $\mathbf{L}$ & S \\
\hline $\mathbf{A}$ & $x$ & z & & & & & & & \\
\hline B & $\mathbf{z}$ & $x$ & $\mathbf{z}$ & $z$ & $\mathbf{z}$ & $\mathbf{z}$ & $\mathbf{z}$ & & $x$ \\
\hline C & & $\mathbf{z}$ & $\mathrm{x}$ & $x$ & $\mathbf{x}$ & $\mathbf{z}$ & $\mathbf{z}$ & & $\mathbf{x}$ \\
\hline $\mathrm{D}$ & & $\mathbf{z}$ & $x$ & $x$ & $x$ & $\mathbf{z}$ & $\mathrm{z}$ & & $x$ \\
\hline E & & $\mathbf{z}$ & $x$ & $x$ & $x$ & $z$ & $\mathrm{z}$ & & $x$ \\
\hline $\mathbf{F}$ & & $\mathbf{z}$ & z & z & z & $x$ & z & & $x$ \\
\hline $\mathbf{G}$ & & $\mathbf{z}$ & $\mathbf{z}$ & $\mathbf{z}$ & $\mathbf{z}$ & $\mathbf{z}$ & $\mathbf{x}$ & & $x$ \\
\hline $\mathbf{L}$ & & & & & & & & $x$ & \\
\hline $\mathbf{S}$ & & $x$ & $x$ & $x$ & $\mathbf{x}$ & $x$ & $\mathbf{x}$ & & $x$ \\
\hline
\end{tabular}

NOTES:

- An " $x$ " in a block of the above chart indicates that these groups may be combined in storage. Otherwise, mixing is either prohibited or restricted according to the following paragraphs.

- A " $z$ " in a block of the above chart indicates that when warranted by operational considerations or magazine unavailability, and when safety is not sacrificed, these groups may be combined in storage. Combinations that violate the principles of paragraph $17.4 \mathrm{~b}$ in Chapter II require justification by an exemption.

- No mark in a block indicates that combined storage is not permitted.

- Refer to DOE DNA TP-20-7 for warhead storage compatibility and hazard class.

a. Incoming shipments shall not be allowed to accumulate and shall be distributed as soon after receipt as practical.

b. Items for outgoing shipments should not be accumulated before receipt of orders covering each specific shipment.

c. Separate rooms shall be provided for the temporary storage of explosives awaiting shipment and for their preparation for shipment (i.e., assembling, crating, marking, etc.). The rooms shall be divided by walls or separated from each other so an explosion in the preparation area will not propagate to the temporary storage area.

d. The combined total amount of explosives permitted in shipping/receiving buildings, plat forms, and transportation vehicles shall be based on quantity-distance constraints. If there is an adequate barricade (sufficient to prevent sympathetic detonation) between transportation vehicles and the adjoining building or platform, the quantities on each side of the barricade may be considered individually to determine quantity-distance requirements.

e. If required by operational necessity, ex plosives and pyrotechnics which are part of the work in process within the building may be stored during non-operational hours in operating buildings provided: (1) explosives limits are not exceeded, (2) containers of bulk explosives or pyrotechnics are properly secured and covered and (3) processing equipment, such as hoppers and pipelines, is empty.

\subsubsection{Service Magazines}

The guidelines presented above in paragraphs 17.1 through 17.5 for storage magazines shall also apply to service magazines, except as modified below:

a. An explosives item should be stored for no longer than necessary in a service magazine (with a maximum of 180 days).

b. The inventory of each service magazine should be reviewed every three months. Any material that has been in the service magazine for a period approaching 180 days and is not expected to be used immediately should be disposed of or removed to an appropriate storage magazine.

c. When practical, explosives stored in service magazines shall be in containers. Unpackaged explosives-containing devices and unsealed bulkexplosives containers may be present in a service magazine. However, these items and unsealed containers shall be stored in a manner that renders them stable and unlikely to be dropped or spilled.

d. Minimum/maximum temperaturemonitors are not normally required for service magazines. 


\subsubsection{Warehouses}

a. Hazard Class 1.4 materials (see Chapter VI, Section 3.1) packaged as Hazard Class/Division 1.4, Storage Compatibility Group S, may be stored in warehouses if they are placed in segregated and specifically designated areas.

b. Articles in Hazard Class/Division 1.4 and Storage Compatibility Group $S$ are considered inert for storage purposes and not subject to quantitydistance requirements as long as they are stored with inert items or other $1.4 \mathrm{Sitems}$ only. This applies only if Hazard Class/Division 1.4 and Storage Compatibility Group $S$ articles remain in their original packaging container or are proven to be self-contained. When stored with items in a Storage Compatibility Group other than S, normal quantity-distance requirements must be observed.

\subsubsection{Prepositioned Storage of Security Response Munitions}

a. When required for defense against hostile forces, and in support of response and contingency plans, limited quantities of authorized response force munitions may be prepositioned at locations other than bulk-storage magazine areas. Compliance with Quantity-Distance and compatibility criteria is not required during the heightened security condition. Munitions will be kept in their original shipping containers unless operational necessity dictates otherwise.

b. Personnel charged with the responsibility of overseeing storage of munitions at guard stations and contingency deployment sites shall be trained in explosives storage and transportation, as required in Chapter V of this Manual.

c. In the event Hazard Class/Division 1.2 is stored inside or at less-than-inhabited building distance from inhabited buildings, fragment barriers will be provided. Any of the following are minimally acceptable fragment barriers: $1 / 4$ in. of mild steel plate; one layer of sand bags; 12 in. of loose sand or dirt, or other equivalent protection. 


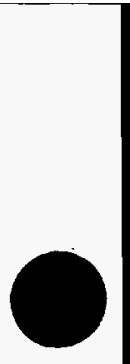

○

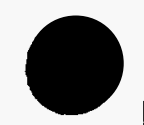

II-60 


\section{CHAPTER II}

\section{Decontamination and Cleaning}

\subsection{General}

a. Operating procedures shall be prepared to specifically cover decontamination procedures. These procedures should cover methods, inspection, marking, control, dismantling, maintenance, final disposition, etc.

b. Hot water or steam may be used to clean up explosives or remove explosives contamination from equipment. Solvents that have been tested for and are compatible with explosives can be used if necessary. Controls for their use must be specified in operating procedures. Only clean cloth rags, paper wipes, and approved non-metallic brushes or scrapers should be used in conjunction with hot water, steam and solvents, to clean or remove explosives material from equipment, work surfaces, and floors.

c. The disposal of waste generated during decontamination shall be coordinated with site environmental/waste management personnel.

\subsection{Cleaning Contaminated Equipment}

a. Items to be cleaned should be positioned so that water and residue will drain directly into an approved collection system. See Sections 19 and 20 for Waste Collection and Waste Disposal.

b. Personnel protective equipment as required shall be used by personnel performing decontamination of facilities and equipment. Emergency shower and eyewash shall be provided where needed.

c. Exhaust ventilation may be required to remove toxic explosives fumes or vapors and/or steam from the decontamination area.

\subsection{Cleaning Screw Threads}

a. To avoid the necessity of cleaning explosives from threads, explosives processing techniques shall be designed to avoid the deposition of explosives on threaded fasteners. When it is necessary to use screw threads, some type of covering or protection (i.e., RTV cement) over the exposed threads should be provided.

b. Threads should be cleaned by judicious use of approved nonmetal "picks," solvent, or hot water, or steam. Soaking in solvents and the application of a penetrating oil may be useful.

c. After decontamination of threads of screws, bolts, pipe, etc., it may still be advisable to provide operator protection to facilitate their disassembly.

\subsection{Final Decontamination and Disposal of Equipment}

a. If the item to be decontaminated has only smooth, flat surfaces (i.e., no cracks, seams, voids, or other places where explosive residue may be inaccessible), hot water, steam, or solvents may be employed to effect total decontamination. Any explosives contamination of concern will be visible to the unaided eye and will have dimensions (length, width, and depth).

b. If the item to be decontaminated has tight places where explosives may remain lodged following normal cleaning procedures, the item shall be subjected to final decontamination techniques. To facilitate cleanup, some items may have to be partially disassembled during the decontamination operation.

(1) Final decontamination by thermal techniques shall be done by subjecting the item to sustained heating at a temperature at least $60^{\circ} \mathrm{C}$ higher than required for decomposition of the most thermally stable explosive substance present. The item shall be kept at that temperature for a sufficient period of time to ensure that all parts have reached the temperatureand all explosives material is decomposed. This is usually done by placing the item(s) to be decontaminated in a hot fire. This operation shall be conducted remotely or with operator protection.

(2) Final decontamination may also be accomplished by immersing the item in a chemical cleaning agent. The period of immersion shall be of sufficient duration to ensure that all explosive material is chemically decomposed. The chemical cleaning agent shall be one which is approved for use by the Department of Army TM9-1300-214. Chemical cleaning agents for decontamination or destruction of explosives should not be used for more than about one ounce (or about 28 grams) of explosives. Reference U.S. Department of the Arm TM9-1300-214 for decontaminating chemicals for explosives and for color tests for identification of energetic materials. 
(3) Before subjecting the item to final decontamination by thermal or chemical techniques, as much explosive as possible shall be removed by the approved means (hot water, steam, and approved solvents in conjunction with cloth or paper wipes and non-metallic brushes or scrapers).

\subsection{Inspection}

After decontamination procedures are complete and before transfer to a nonexplosive area, the item shall be inspected. The degree of decontamination shall be determined/documented and the item shall be labeled to indicate its decontaminated state. Inspection should be accomplished by representatives of at least two departments, such as the operating department and the safety department.

\subsection{Identification and Control of Decontaminated Items}

a. Decontaminated items shall be marked to indicate the degree of decontamination and stored separately from non-contaminated items until final disposition is made.

b. Degrees of decontamination shall be designated and items shall be tagged and/or marked with this designation.

c. Guidelines for establishing a system for designationdegrees of decontamination are provided below:

(1) $X$ - A single $X$ indicates the facilities or equipment have been partially decontaminated. Further decontamination processes are required before facilities or equipment are moved or any maintenance, repair, etc. is performed. This degree would generally be applied to facilities or equipment that have been subjected to routine decontamination performed by an operator on a piece of equipment, room, bay, or building at the close of the workday.

(2) $X X X$ - Three Xs indicate the equipment or facilities have been examined and decontaminated by approved procedures and no contamination can be detected by appropriate instrumentation, test solutions, or by visual inspection on easily accessible surfaces or in concealed housings, etc. and are considered safe for the intended use. Items decontaminated to this degree cannot be furnished to qualified, $\mathrm{DOE}, \mathrm{DoD}$, or Industry users or be subjected directly to open flame (cutting, welding, high temperature heading devices), or operations which generate extreme heat, such as drilling and machining unless the following two conditions are met:

(a) It is determined that decontamination to the XXXXX level will destroy the uscfulness of the item; and,

(b) Decontamination to a degree less than $X X X X X$ in combination with administrative and technical safeguards will eliminate risk of injury. As a minimum, an approved SOP (setting forth the specific operational limitations, precautions to be observed, and monitoring necessary to assure safety) will be available and decontamination will be performed under the direction of the inspector(s) who will certify decontamination.

(3) $X X X X X$-Five $X$ sindicate the equipment or facilities have been completely decontaminated, are free of hazard and may be released for general use or to the general public.

(4) O-A (Zero) indicates the item, although located in a contaminated area, was never directly exposed to contamination.

d. Reference U.S. Department of the Army TB700-4, "Decontamination of Facilities and Equipment" for decontamination methods and marking.

\subsection{Decontamination of Real Estate}

For decontamination oi real estate reference DoD 6055.9-STD.

\subsection{Decontamination and Cleaning References}

In addition to this manual, the following are reference sources for decontamination and cleaning.

DoD 6055.9-STD, "Department of Defense Ammunition and Explosives Safety Standard," Assistant Secretary of Defense (Force Management and Personnel), Chairman Department of Defense Explosives Safety Board, 2461 Eisenhower Avenue, Alexandria, VA 22331.

Department of the Army Technical Bulletin TB700-4, "Decontamination of Facilities and Equipment," Army AG Publications Center, St. Louis, MO.

Department of the Army Technical Manual TM91300-214, "Military Explosives," Army AG Publications Center, St. Louis, Mo., U.S. Government Printing Office: 1986 0-169-377. 


\section{CHAPTER II}

\section{Waste Collection}

\subsection{General}

a. Provision shall be made for removal of explosives waste from any area in which explosive waste is generated. Removal of explosives waste may be accomplished by collecting dust/fines in a wet or dry vacuum system, collecting dust/fines or chips in a slurry of water or nonflammable solvent, or by collecting solid waste in receptacles (See also Chapter II, Sections 9, 10, and 11).

b. Explosives waste shall be collected and maintained separately from conventional waste.

c. Mixing of incompatible explosives shall be avoided. Receptacles shall be clearly labeled to indicate the type of waste permissible.

\subsection{Solid Wastes}

a. Each explosives area in which solid explosives wastes are generated that are not removed by vacuum or liquid systems shall be equipped with a seamless or lined receptacle in which explosives wastes can be collected. The receptacle should never be more than half full.

b. Explosives waste shall be removed from the collection point on a regular basis, frequently enough to keep the aggregate explosives levels within the explosive weight limits.

c. Rubbish not contaminated by explosives or containing noncombustible materials shall not be placed in an explosives waste receptacle.

d. Rubbish contaminated by explosives shall be placed in separate waste containers and also segregated as combustibles and noncombustibles.

e. Before being transported, explosives waste shall be packaged to prevent spillage, leakage, or exposure to initiation stimuli. Incompatible materials shall not be packaged together. All packages of explosives waste shall be clearly labeled to indicate the nature and approximate quantity of contents.

\subsection{Vacuum Collection of Explosives Dusts}

a. Explosives dusts should be collected by a vacuum system, preferably the wet type. When using a wet system, the dust should be maintained in a wet form using a wetting agent that is kept close to the point of origin; the dust should also be kept wet in the collection system until removed for disposal. Water-soluble explosives such as Explosive D should be collected dry.

b. Storage compatibility Group A explosives may be collected by a vacuum system, provided they are maintained in a wet form using a wetting agent that is kept close to the point of intake. Use of a vacuum system for collecting these more sensitive materials should be confined to operations involving small quantities of explosives.

c. Dry-type dust collection chambers, except portable units, should be located in the open and outside operating buildings, or may be inside if adequate shiclding is provided. The quantity of explosives collected shall not exceed the capacity of the shiclding to protect operating personnel. This limit shall be determined by the degree of barricading and the appropriate intraline distance.

d. If dry dust collection outside the building is not practical, a separate room or shielded area within the building shall be designated for this purpose. This room or shielded area shall not contain other operations, nor shall it be used as a communicating corridor or passageway between other operating locations within the building when explosives are being collected.

e. Stationary and portable wet-type collectors may be placed in the explosives operating bays or cubicles if the quantity of explosives in the collectors does not exceed $2 \mathrm{~kg}$. If placed in separate cubicles, the explosive weight limits may be increased by an amount determined by the extent of the cubicle walls' capabilities to serve as operational shields.

f. Collection systems and chambers shall be designed to prevent pinching explosives between metal parts. See Chapter II, Sections 9 and 10 for additional design information.

g. Two collection chambers shall be installed in scries ahead of the pump or exhauster to prevent explosives dust from entering the vacuum producer in dry vacuum collection systems. In addition, nonsparking fans and dust-tight motors shall be used.

h. Dry-type portable vacuum collectors shall not be located in a bay or cubicle where explosives are present or in enclosed ramps, but may be positioned outside the building or in a separate cubicle. The building or cubicle walls shall provide 
adequate shielding for at least $2 \mathrm{~kg}$ of explosives and the explosives limits shall be defined by shielding and quantity-distance constraints.

i. Explosives dust shall be removed periodically from the collection chamber to eliminate unnecessary and hazardous explosives concentrations. The entire system should be cleaned periodically, dismantling the parts if necessary. A cleaning schedule for the collection chamber and the entire system shall be established using the operating hours as a basis.

j. The entire explosives-dust collecting system shall be electrically bonded and grounded with resistance-to-ground not exceeding $10 \mathrm{ohms}$. Thegrounds shall be tested periodically.

\subsection{Explosives Slurries}

a. Machine tools shall be fitted with wet boxes to catch and direct water and explosives fines to an explosives waste gutter system.

b. Wastewater that might contain explosives materials shall be kept from contaminating potable water or conventional wastewater systems.

c. Settling tanks shall be regularly inspected to monitor the accumulation of waste. Records shall be kept of waste removals.

d. If pumping is involved in removing the settled explosives from a slurry settling tank, the operation shall be arranged to preclude exposure of the explosive material to any pinching in the operation. e. Explosives materials in the settling basins shall be kept wet until removed and the materials shall be maintained wet until spread out for disposal. Explosives materials containing powdered metals shall be kept sufficiently wet to prevent a dangerous temperature rise resulting from a reaction of the metal with water. The possibility of hydrogen generation in this situation must be anticipated.

\subsection{Metal Scrap}

a. Metal scrap shall be inspected to detect explosives-contaminated items and shall be certified by qualified responsible personnel to be free from explosives before disposition.

b. If the scrap is found to be contaminated with explosives, it shall be decontaminated in accordance with final decontamination procedures (see Section 18.4).

\subsection{Explosives Recovery and Reuse}

a. Salvaged explosives materials shall be thoroughly inspected by operating supervisors and reused, screened, reprocessed, or destroyed as the situation warrants.

b. Salvaged explosives materials shall beclassified as Storage Compatibility Group L until they have been established to be compatible with the original material. 


\section{CHAPTER II}

\section{Waste Disposal}

\subsection{Preparation for Open Burning}

a. Preparations for burning explosives waste on a pad or in a pit, or for placing explosives waste shall not begin until 24 hours after the previous burn at the same burning point. The only exception is if the burning area has been thoroughly soaked with water and inspected by qualified personnel to assure the safety of personnel during subsequent burning operations. In any case, the burning point shall be inspected for residual embers or hot spots before loading with explosives.

b. Before beginning preparations, firing controls shall be disconnected from the power source and the circuit shunted and grounded.

c. Incompatible explosives materials shall not be in the same pit or on the same pad at the same time.

d. Containers of explosives materials shall not be opened less than 3 meters from each other.

e. Empty explosives waste containers that are to be reused shall be situated an adequate distance from the burning point to prevent charring or damage during the destruction operation.

f. A layer of excelsior or similar material should be placed on the bottom of the pit or pad for placement of the explosives waste.

g. Explosives in powdered, granular, or slurry form should be placed in a layer not more than $8 \mathrm{~cm}$ thick. Water-wet initiating explosives (storage compatibility Group A) shall not be allowed to become completely dry.

h. Wood, heating oil, and TNT may be used as an aid to ensure complete combustion of the explosives waste material.

i. The ignition train should be set up to burn upwind.

j. The firing circuit shall require a key for completion. Only one copy of the firing key shall exist; and it shall be in the lead operator's possession.

k. Radio transmitters in the control shelter and vehicles at the burning site shall be turned off during setup and firing to protect against radio frequency currents.

1. Precautions shall be taken to ensure that the firing system will not be unintentionally activated by extraneous electrical currents from any source. m. Priming of the burn shall be accomplished after all other preparation work is complete and with a minimum number of personnel present.

n. Ignition shall be accomplished remotely.

\subsection{Destruction by Burning or Flashing}

a. Explosives waste may be destroyed by burning (remotely) if it can be done with little chance of detonation. Explosives-contaminated waste may be burned remotely in a wire cage.

b. An open furnace or burning area for explosives should be used for destruction of wet-machining cuttings and classified parts. The furnace or burning area may also be used for flashing casings after washout of an explosive charge.

c. Explosives should not be burned in closed containers or casings, nor in large pieces likely to detonate. Special attention should be given to the placement and orientation of large items and those in closed containers or casings. Approved incinerators may be used to destroy small devices such as detonators, actuators, etc.

d. Concurrent burning operations shall not be conducted within 45 meters of each other.

e. When several pads are burned, the downwind pad shall be ignited first, followed by the others in succession to the upwind pad.

\subsection{Ignition System Malfunctions}

a. If the ignition system fails to fire, check the circuit's continuity and refire if no open circuits are detected.

b. If the squibs did fire but failed to ignite the ignition train, survey the area by remote means, and wait at least 30 minutes. If it then appears safe to emerge from the control shelter, disconnect, shunt, and ground the firing circuit, and inspect the squibs, firing system, or ignition train.

\subsection{Postburn Operations}

a. No entry shall be allowed into the pit area until at least 8 hours have elapsed following an open burn. 
b. The squib firing lines shall be disconnected, shunted, and grounded before the burn area is entered.

c. Unburned or partially burned explosives materials remaining in the pit shall not be raked or otherwise disturbed. The burning operation shall be repeated to destroy any remaining explosives waste.

d. At least 24 hours shall elapse before ashes are collected and the pit prepared for another burn.

\subsection{Disposal Area}

a. Explosives wastedestructionoperations shall be separated from magazines, inhabited buildings, public traffic routes, and occupied operating buildings to ensure that personnel and facilities are not exposed to hazardous blast overpressure, fire brands, fragments, or projectiles from burning or detonation of explosives.

(1) Destruction by open burning or flashing shall not be performed within $730 \mathrm{~m}$, unless carried out in pits or with other aids for limiting the range of fragments and debris in event of an accidental detonation. In no case may the pit be located at less than $204 \mathrm{~m}$ for weights of $45 \mathrm{~kg}$ or less and $381 \mathrm{~m}$ for weights exceeding $45 \mathrm{~kg}$. Sites should be located in relation to the direction of the prevailing winds so that sparks will not be blown toward explosives locations.

(2) The size of the danger zone for destruction by open detonation shall be determined by the formula $D(m)=131 Q^{1 / 3}\left[D(f t)=328 \mathrm{~W}^{1 / 3}\right]$. The minimum separation distance shall be:

Non-fragmenting Explosive

Materials

$381 \mathrm{~m}$

Fragmenting Explosive

Materials

Bombs/Projectiles with

5 in. caliber or greater

$762 \mathrm{~m}$

$1220 \mathrm{~m}$

If known, the maximum fragment (debris) throw distances with an applicable safety factor may be used to replace the $762 \mathrm{~m}$ and $1220 \mathrm{~m}$ minimum separation distances but not below $381 \mathrm{~m}$.

(3) Self-contained destruction facilities fully analyzed for the intended net explosives weight (NEW) are exempt from the above requirements.

b. The maximum quantity of explosives that may be destroyed at one time shall be determined by starting with a small quantity, gradually increasing until an optimum amount, consistent with safe and efficient operation, is achieved.

c. Explosives waste and ordinary rubbish shall not be destroyed in the same destruction area at the same time. d. When destruction operations are being carried out, the area within 60 meters of the destruction point shall be keptclear of dry grass, leaves, and other extraneous combustible material. This clearance may be reduced to fire brand distance if aids for limiting the range of fragments and debris are provided for all the destruction points used within the disposal area.

e. Explosives waste awaiting destruction shall be stored at least intraline distance from the explosives being destroyed.

f. Provisions for emergency firefighting shall be readily available at the waste disposal area.

\subsection{Destruction by Detonation}

a. Cased explosives should be removed from the case and burned or the cased item destroyed by detonation. Detonators, primary explosives, and other explosives that mightdetonate if burned should also be destroyed by detonation.

b. The detonation should be initiated by a highenergy detonator (e.g., an EBW).

\subsection{Use of Solvents}

a. Small quantities of explosives and explosive detonators may be prepared for destruction by solvent immersion.

b. The items to be destroyed shall be soaked in a suitable, compatible solvent until all the explosives material is dissolved. Saturated solvent solutions shall not be reused.

c. The solvent-explosives mixture shall be destroyed by burning.

\subsection{Burial}

a. Burial as a means for disposing of explosives-contaminated equipment is the least desirable method of disposal and should be used only if other methodsare impractical, unsafe, or impossible. Waste material that is technically contaminated with explosives and cannot be disposed of by burning or other means may be buried if there is no conflict with prevailing environmental regulations.

b. Visible explosives material shall be removed before burial.

c. Burial sites shall be appropriately marked and protected from unauthorized personnel. The location of the burial sites shall be noted on facility drawings.

d. Records shall be kept of the burial sites that identify the types and quantities of materials buried. 


\section{CHAPTER II}

\section{Laboratory Operations}

\subsection{General}

a. The safety guidelines presented in this section are applicable to general laboratory operations involving explosive materials. Laboratory operations shall be conducted in such a manner so as to maintain employee exposures to hazardous chemicalsat or below the permissible exposure limits (PELs) and in compliance with the facility chemical hygiene plan.

b. Laboratory work involving explosives materials shall be performed only in accordance with the provisions of written operating procedures (seeChapter VII). Laboratory operations shall comply with the requirements of NFPA 45, "Fire Protection for Laboratories Using Chemicals," including the requirements for electrical equipment and wiring.

c. The quantity of explosives present in the laboratory shall be the minimum required for the experiment and in all cases shall be at or below assigned limits. Explosives not being worked on shall be stored in closed containers.

d. There shall be no explosives other than those in process left in the laboratory during nonworking hours. They must be secured in an approved storage container or in a service magazine (see paragraph 17.6.1.e).

e. Smoking and open flames shall be prohibited in laboratories where explosives or flammable solvent vapors are or may be present.

f. Disposal of explosives through laboratory drains shall be forbidden unless the drain plumbing has no traps and is designed to handle explosives (i.e., is provided with a sump or other device for the collection of solids). Even if a drain is designed to handle explosives, deliberate disposal of explosives in these drains should be avoided. These drains should be used only for the purpose of cleaning up explosives spills. Special care should be exercised to prevent entrance of compounds into drains that may react with iron or rust to form sensitive salts (e.g., picrates and picric acid).

g. Solvents or other substances that are flammable shall be protected against electrical sparks, heat, and open flames.

h. Suitable guards shall be provided for all glass or fragile equipment that must withstand reduced or elevated pressure.

\subsection{Safety Shields}

a. If a laboratory operation involves an explosion hazard, personnel should be protected by safety shields or the operation should be performed by remote control. Table II- 6 lists shields that have been tested and found acceptable for the indicated quantities of explosive. The shields of this table were not tested for metalfragmentpenetration (unlessspecificallyindicated) and thus may not offer effective protection when the explosive is closely confined in a heavy-walled metal container. ("Heavy-walled" is defined here as wall thickness to diameter ratio greater than 0.01 .)

Table II-6. Safety shields for explosives laboratory operations.*

\begin{tabular}{|c|c|c|}
\hline Shield & $\begin{array}{c}\text { Minimum } \\
\text { distance from } \\
\text { explosive, } \mathrm{cm}\end{array}$ & $\begin{array}{l}\text { Explosives } \\
\text { limit }\end{array}$ \\
\hline $\begin{array}{l}\text { Leather gloves, jackets } \\
\text { or coats, and plastic } \\
\text { face shields }\end{array}$ & - & $50 \mathrm{mg}$ \\
\hline $3 \mathrm{~mm}$ tempered glass & 8 & $50 \mathrm{mg}$ \\
\hline $\begin{array}{l}7 \mathrm{~mm} \text { Lucite/equivalent } \\
\text { material }\end{array}$ & 15 & $2-1 / 2 \mathrm{~g}$ \\
\hline $\begin{array}{l}20 \mathrm{~mm} \text { Lucite/equivalent } \\
\text { material }\end{array}$ & 15 & $10 \mathrm{~g}$ \\
\hline $\begin{array}{l}15 \mathrm{~mm} \text { laminated resistant } \\
\text { glass }\end{array}$ & 20 & $20 \mathrm{~g}$ \\
\hline $25.4 \mathrm{~mm}$ Lexan/Lexguard & 30 & $50 \mathrm{~g}$ \\
\hline $\begin{array}{l}2 \text { units each of } 25.4-\mathrm{mm} \\
\text { plate glass laminated with } \\
\text { 12.4-mm polycarbonate } \\
\text { with a } 9.5-\mathrm{mm} \text { air gap } \\
\text { between units (glass sides } \\
\text { facing the explosive) }\end{array}$ & 30 & $\begin{array}{c}50 \mathrm{~g} \\
\text { (steel confined) }\end{array}$ \\
\hline
\end{tabular}

" The material of choice for a transparent safety shield is either polycarbonate or laminated safety glass. When designing and or replacing a safety shield with a polycarbonate, it should be UV stabilized, treated for abrasion resistance, and have met Mil Spec P-46144C. When designing and/or replacing a safety shield with laminated glass, it should be coated with a 0.1-mm fragment resistant film on the viewer's side to minimize spalling. The shield, shield frame, and anchoring system shall be designed to resist maximum credible overpressure and fragments. 
b. If an experiment presents a metal-fragment hazard (as opposed to a glass fragment hazard) and the experiment cannot be conducted remotely, the proposed shield should be tested and approved under conditions simulating an explosion in the experimental setup but with at least $125 \%$ of the anticipated explosive content.

c. The shield shall be anchored to the hood frame or bench top when it is being used for protection against more than 5 grams of TNT equivalent.

d. Other shields may be used after successfully passing a test of $125 \%$ of the rated explosive charge and being approved.

e. For confined areas, a blast vent having less strength than the shield should be provided.

f. When explosives operations require personnel to reach around a shield to manipulate equipment, exposure shall be minimized.

\subsection{Heating Operations}

a. During synthesis, formulation, or experimental work, heat may be applied to initiate or maintain reaction, to increase solubility, etc., if the principles below are followed:

(1) Heat shall be applied indirectly using steam, a water bath, oil bath, or an approved laboratory electrical heating device such as a mantle.

(2) Utmost caution shall be exercised to ensure that reactive material does not come in dircct contact with the heating elements.

(3) If an experiment must be conducted behind a shield, any heating device shall be mounted so that temperature can be controlled from the operator side of the shield. The heating device should be mounted so it can be quickly separated from the reaction vessel without operator exposure. Consideration should be given during design of the experiment to providing emergency cooling for the reaction vessel or its contents.

(4) Heating of explosives with devices without proper controls shall be monitored at all times, and if the operator must leave for any reason, the heating device should be turned off. Heating systems that will be operated unattended shall have dual controls, an override shutoff, or some other protection against failure of the primary heating control. Systems capable of total containment of the effects of an explosion may be exempted from this requirement. b. Periodic checks should be made to ensure that an experiment is proceeding satisfactorily and that the apparatus is not boiling dry, malfunctioning, or the like. In the case of remotely controlled operations, provisions shall be made for such observation, using such equipment as mirrors, TV monitors, etc.

\subsection{Laboratory Setups}

Good workmanship and laboratory practice shall be exercised in making and operating laboratory setups. In particular, cognizance must be taken of the following points:

a. Equipment and apparatus shall be clean, in good condition, and in good working order.

b. Allglasswareand apparatus shall beinspected for cracks, defects, etc., before use. Defective or damaged equipment shall be removed from service.

c. Setups shall be geometrically and structurally stable.

d. Work areas should be as neat and uncluttered as circumstances will permit.

\subsection{Low Concentration of Explosives in Solution}

a. After explosives are in dilute solution (less than $33 \%$ explosives by weight), the primary hazard shall be considered as that associated with the solvent and not with the explosive.

b. Until the explosive is in solution, or if for any reason the explosive recrystallizes or precipitates out of solution, the safety guidelines for pure explosives shall apply.

\subsection{Explosives Sample Control}

a. Samples shall be delivered to the laboratory only at specific designated locations.

b. Each sample shall be properly identified and labeled.

c. Upon completion of the required tests or analyses, the sample should be removed from the laboratory.

d. All samples of new experimental explosive matcrial submitted to a labora tory for analysis should be accompanied by an information sheet giving available safety information. 


\section{CHAPTER II}

\section{Emergency Control}

\subsection{Placarding and Fire Symbols}

Buildings and areas shall be placarded to provide warning of potential hazards from explosives and information crucial to dealing with emergency situations. This includes the use of appropriate fire symbols as specified in DOD6055.9-STD or the NFPA 704 Standard, provided placarding is applied consistently throughout the entire facility.

\subsection{Explosives Emergency Control Plans}

a. Each installation shall have a written plan, prepared specifically for that installation (it may be necessary to break it down for each operating area), for the control of emergencies involving explosives. The explosives emergency control plan may be part of the overall emergency control plan for the facility. All facility personnel shall be trained in the content of the plan applicable to their area. The plan shall be available to all personnel for ready reference.

b. Emergency situations that should be covered, as applicable to the facility, are as follows:

1. Fires and explosions

2. Floods
3. Extreme weather conditions

4. Conditions resulting in environmental disturbances

5. Civil disturbance

6. Threats and bomb scares

7. Enemy attack

8. Any other emergencies which require rapid mobilization of personnel and equipment to minimize death and injury to personnel or to prevent the spread of damage and destruction.

c. Subjects that should be addressed by the plan include:

1. Reporting an emergency

2. Decision to activate the emergency plan

3. Authority and responsibility for administration and execution of the plan

4. Mobilization of personnel to combat the emergency or disaster

5. Role of operating personnel in combatting the emergency

6. Procedures for combatting the emergency or disaster

7. Accounting for and evacuation of personnel

8. Plant and document security. 
$\bullet$

$\bullet$ 


\title{
CHAPTER III
}

\section{EXPLOSIVES AND PERSONNEL LIMITS AND CONTROL}

\author{
1. Explosives Limits
}

The quantity of explosives at an operating location shall be the minimum necessary to carry out the operation in a safe and efficient manner. When practical, this quantity shall be subdivided and adequately separated to prevent propagation of detonation. Supplies exceeding this minimum quantity shall be removed from the operating area.
In no case shall the quantity of explosives permitted in an operating building exceed the maximum permitted by the quantity-distancecriteria. Quantitydistance criteria and guidelines for application of these criteria are presented in Chapter VI of this manual.

\section{Personnel Limits}

The number of personnel at an operating location shall be the minimum consistent with safe and efficient operation. In establishing personnel limits, the following principles shall be followed.

a. Jobs not necessary to the performance of a hazardous explosives operation should not be performed in the same location as the hazardous operation. Personnel not needed for the hazardous operations will not be allowed in hazardous locations.

b. Personnel limits shall allow for necessary casuals. c. Sufficient personnel shall be available to perform a hazardous operation safely and, in the event of accident, to obtain help and aid the injured.

d. No person shall work alone performing explosives activities that have a high risk of serious injury. Prompt and easy communications with other employees shall be provided. Facility management shall specify which explosives activities may be performed alone.

\section{Limit Control}

\subsection{Posting and Recording}

All rooms, bays, and buildings containing explosives shall have posted in a conspicuous place a standardized placard stating the maximum amount of explosives and the maximum number of workers and casuals permitted in the control unit at any one time.

Maximum explosives and personnel limits for all buildings and bays for each explosives area shall be recorded and maintained on file.

\subsection{Limit Review and Approvals}

Management personnel with authority and jurisdiction over an operating bay or building shall periodically review explosives and personnel limits for each location and recommend changes as required. If the use of a location changes, personnel and explosives weight limits shall be reviewed at the time of use change and limits reestablished as required.

Changes in explosives and personnel limits shall be reviewed and approved in the same manner as operating procedures (see Chapter VII).

A procedure shall be established for the approval of temporary changes in explosives and personnel limits for an operating location.

\subsection{Personnel Controls}

A system shall be established to control the presence of personnel within explosive operating areas. 


\section{IHE Limits}

When no other explosives are present, IHE weight limitations shall be based on separation distances for Hazard Class 1.3 explosives (see Chapter VI, Section 3.1) or equivalent protection provided by facility design features. The quantity of IHE at an operating location shall be the minimum necessary to carry out the operation in a safe and efficient manner. This quantity should not exceed an 8-hour supply.

IHE limits for pressing should be the same as those established for other explosives pressing operations. 


\section{CHAPTER IV}

\section{PERSONAL PROTECTIVE CLOTHING AND EQUIPMENT}

\section{Clothing and Personal Equipment}

\subsection{Clothing}

Each operation shall be analyzed to determine when personnel working with explosives and toxic materials must wear approved coveralls or laboratory coats to prevent contact with these materials and to prevent contaminating personal apparel. Flame-retardant coveralls may be desired for certain explosives operations where the possibility of a flash fire exists. These coveralls shall not have cuffs and should not have metallic fasteners. Written procedures shall include protective clothing and equipment requirements.

Cotton (or other antistatic material) outer and undergarments, including socks, should be worn where generation of static electricity would create a hazard.

\subsection{Footwear}

Personnel working in a building or area where electrostatic-sensitive explosive powders or materials are handled shall wear conductive, nonsparking footwear. Exception: personnel working on electrical or electronic equipment shall not wear conductive footwear unless protected by insulated mats, ground fault circuit interrupters (GFCI), etc. Personnel working in other areas where explosives contamination may be present shall wear nonsparking footwear or bootie shoe coverings.

\subsection{Respirators}

Appropriate, approved respiratory protection shall be used when exhaust ventilation is not available, or does not adequately control airborne particulates, gases, or vapors liberated during explosives operations. The employee must have current approval to wear respiratory protection (medical exam, respirator fitting, and training).

\subsection{Eye Protection}

Suitable eye protection devices must be worn by all personnel when working or visiting in eye hazard areas, particularly when electroexplosive devices are handled. The type of explosive operation shall be evaluated for eye hazard risks. Contact lenses shall not be considered as an appropriate eye protection.

\subsection{Gloves}

Skin contact with some explosives, and with some materials used in conjunction with explosives, can result in dermatitis or absorption across the skin barrier. Each type of operation using these materials must be evaluated for the potential skin contact hazard and the need for the proper type of glove.

\section{Maintenance and Testing}

\subsection{Equipment Maintenance and Inspection}

Personal protective equipment shall be properly maintained; the operator's life may depend on the proper functioning of the equipment. An appropriate inspection schedule shall be established.

\subsection{Conductivity Testing}

When conductive footwear is required, the conductivity shall be tested initially and regularly thereafter to ensure continued conductivity from person to ground. 


\subsection{Cleaning and Disinfecting}

Provision shall be made for the laundering and disinfecting of protective garments and devices. Attention to cleaning and disinfecting is especially important for equipment worn about the face. Because laundering affects the flame-retardant properties of fabric, flame-retardant coveralls should be tested to establish the maximum number of laundering cycles permitted.

\subsection{Contaminated Clothing}

If clothing becomes contaminated, as much contaminant as possible should be removed by wiping or dusting; compressed air shall not be used for this purpose. If obvious contamination remains, clothing shall be changed. 


\section{CHAPTER V}

\section{TRAINING}

\section{General}

Before being assigned to any explosives operation or operating any explosives-carrying vehicle, personnel shall be properly trained. The training for explosives work, which serves to assist in conducting work safely and developing safety awareness, shall include the following:

- Develop and maintain a safe attitude towards work with explosives
- Define and understand the potential hazards involved

- Teach correct skills for safe performance of the task

- Prepare personnel for unexpected hazardous conditions

- Ensure that personnel read and understand the appropriate operating procedures.

\section{Supervisory Responsibility}

The supervisor shall be responsible for the following:

- Determining the training required for the worker (or researcher)

- Verifying that the worker is adequately trained to perform the task safely and efficiently
- Ensuring that the worker can perform required emergency duties

- Providing on-the-job training for the worker

- Continually updating worker training.

\section{Training and Qualification Programs}

Each organization shall have a training and qualification program. Following is an example:

a. After successfully completing training for an assignment, the worker should be qualified for that task for a specific period of time. Maintenance of qualification should be governed by the following items:

(1) At the end of the initial qualification period, qualification may be extended for subsequent specific time periods if-

- The worker has successfully performed the task during the preceding six months and has read and understands the current operating procedures, or

- The worker receives refresher training and is again determined to be qualified by his supervisor.

(2) Retraining in the specific area of weakness should be required of workers who do not demonstrate job proficiency or who subsequently violate safe practices.

(3) If an operating procedure is modified substantially, all personnel using that procedure should be retrained in the use of the new procedure.

(4) A person should not be permitted to continue working with explosives if the supervisor, with counsel from medical personnel, determines that person is unable to perform the task safely. Possible reasons include the following:

- Physical injury or illness

- Disease

- Mental or emotional disturbances.

(5) Records should be maintained for each worker, including:

- Description and dates of training received

- Description and dates of refresher training

- Reading and understanding standard operating procedures

- Attendance at safety meetings and participation on safety committees

- Qualification review by supervisor.

(6) The supervisor may temporarily authorize an employee who has not completed the 
required training to perform the task if the following conditions are satisfied:

- The supervisor determines that the employee has a working knowledge adequate to perform the task safely qualified person.

- The work is directly supervised by a

b. Employee hazardous materials information and training programs are required for personnel working with explosives and hazardous materials used in conjunction with explosives operation. Training should include-
- Information on the physical and health hazards

- The purpose and proper use of engineering controls, work practice controls and protective equipment

- Labeling systems and Material Safety Data Sheet terms

- Detection methods for the presence or release of a hazardous material in the work area. 


\section{CHAPTER VI}

\section{QUANTITY-DISTANCE AND \\ LEVEL-OF-PROTECTION CRITERIA \\ FOR EXPLOSIVES ACTIVITIES}

\section{General}

This chapter establishes quantity-distance and level of protection criteria to be applied to all DOE operations involving high explosives. The purpose of these criteria is to provide specific levels of protection from the effects of potential fires and explosions for personnel and property within and outside of DOE installations.
The cardinal principle to be observed at any location or in any operation involving explosives, ammunition, severe fire hazards, or toxic materials is to limit the exposure to a minimum number of personnel, for a minimum time, and to a minimum amount of the hazardous material consistent with safe and efficient operation.

\section{Applicability of Criteria}

\subsection{Specific Applications}

The criteria presented in this chapter shall be followed in:

a. Establishing maximum explosives limits for explosives facilities and operations

b. The planning of explosives activities to be performed in existing facilities

c. The design and siting of new explosives facilities and operations as well as the siting of other facilities and operations in the explosives area.

\subsection{Explosives Limits}

When defining working explosives limits, those limits shall never exceed the minimum required for efficient, safe operation. (See Chapter III.)

\subsection{Areas Where Criteria Are Not Applicable}

The quantity-distance and level-of-protection criteria in Section 4 of this chapter are not applicable to portable buildings used at specified nuclear test shot locations.

\section{Quantity-Distance Criteria}

Quantity-distance criteria must account for the types and severity of hazards presented by each explosive material, the construction and orientation of facilities to which the criteria are applied, and the degree of protection desired for facilities and personnel adjacent to the explosives operations. The hazard classification system recommended by the United Nations Organization (UNO) defines types and severities of hazards for explosives. The guidelines presented below specify minimum degrees of protec- tion for various categories of facilities. These guidelines also describe how the quantity-distance tables are to be applied to facilities of various construction and orientation with respect to adjacent facilities.

\subsection{Hazard Classes and Class Division}

Explosives shall be classified on the basis of their reactions to specific initiating influences. The hazard classification system recommended by the UNO shall 
be used for DOE explosives classification. The UNO system consists of nine classes for dangerous goods, with explosives included in Class 1 . The explosives hazard class is further subdivided into "divisions," which are based on the character and predominance of the associated hazards and on the potential for causing personnel casualties or property damage. The six divisions of Class 1 are as follows:

\begin{tabular}{cl}
$\begin{array}{c}\text { Hazard Class and } \\
\text { division designators }\end{array}$ & \multicolumn{1}{c}{ Hazards } \\
\hline 1.1 & $\begin{array}{l}\text { Mass explosion } \\
\text { Non-mass explosion, } \\
\text { fragment producing } \\
\text { Mass fire, minor blast, } \\
\text { or fragment } \\
\text { Moderate fire, no blast } \\
\text { or fragment } \\
\text { Explosive substance, } \\
\text { very insensitive (with a } \\
\text { mass explosion hazard) } \\
\text { Explosive article, } \\
\text { extremely insensitive }\end{array}$ \\
1.4 & \\
1.5 &
\end{tabular}

When required to properly describe the hazard, a numerical figure in parenthesis shall be placed to the left of the division designators 1.1 through 1.3 (e.g., (18) 1.1, (08) 1.2, and (06) 1.3; this number is used to indicate the minimum separation distance (in hundreds of feet) for specified levels of protection from explosive items for inhabited buildings, public traffic routes, and personnel in the open. A minimum distance number shall be used for all items in Class 1, Division 2, as shown in the applicable tables. Figure VI-1 illustrates the use of the UNO hazards classification system. Also, this figure lists the storage compatibility groupopposite each hazard class. Thelisted compatibility group is typical for the expected compatibility to hazard class relationships. Note however, that the two classification systems apply to different concerns.

- Compatibility groupings define which explosives may be safely stored together without increasing the risk of initiation.

- Hazard classifications indicate the initiation effects of the various explosives.

Classification tests (described by TB 700-2, "Explosives Hazard Classification procedures") and/or

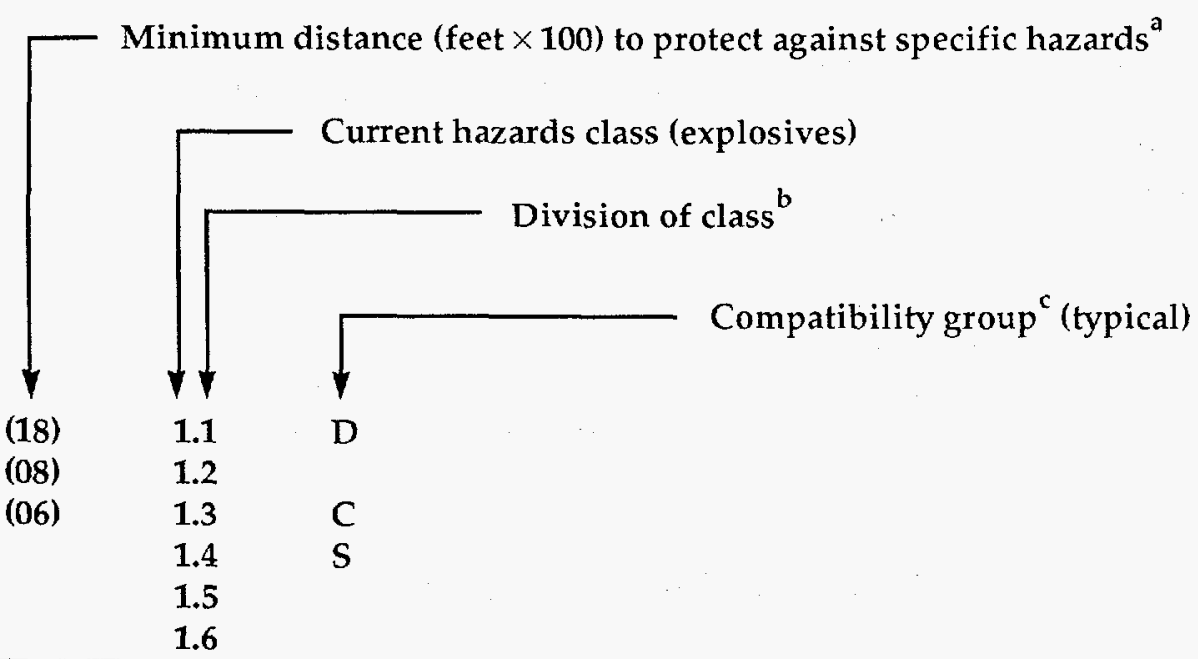

a Varies with type of explosive.

b

Class divisions:
1.1 Mass explosion
1.2 Non-mass explosion, fragment producing
1.3 Mass fire, minor blast or fragment
1.4 Moderate fire, no blast or fragment
1.5 Explosive substance, very insensitive (with a mass explosion hazard)
1.6 Explosive article, extremely insensitive

${ }^{c}$ Chapter II, Section 17.4.

Figure VI-1. Application of Hazard Classification System. 
additional tests (as desired), including United Nations ST/SG/AC. $10 / 1$ and ST/SG/AC/10/11, shall be used in the assignment of energetic materials to the appropriate compatibility group and hazard division. These tests may be supplemented by other tests to characterize material hazards more fully if material properties or anticipated material environment are expected to significantly influence the explosive classification.

While DOT Hazard classifications require the use of the Bureau of Explosives' (BOE) Impact Apparatus in determining impact sensitivity, other impact apparatus may be used, providing:

a. Test results for at least two reference explosives are compared to results for the reference explosives on the BOE Impact Apparatus.

b. A minimum of ten trials each are run for the reference explosives and the explosives being classified.

\subsection{Establishing Quantity of Explosives and Distances}

\subsubsection{General}

The principles and tables presented in DOD 6055.9-STD, "DOD Ammunition and Explosives Safety Standards," shall be used to determine the following:

a. The total quantities of explosives in adjacent magazines, operating buildings, or other explosives facilities that must be applied to quantity distance tables.

b. The levels of protection required for different types of facilities-where the requirements of DOD 6055.9-STD differ from the rules of Section 4 below, Section 4 shall take precedence.

c. The minimum separation distances required for the facilities - this separation is based on the desired level of protection and total quantities of explosives.

d. The total quantity of explosives is determined by defining and examining the maximum credible event (MCE). If an explosives event occurs, the maximum credible explosives event is the largest credible amount of explosives which could be involved in the event (not necessarily the total quantity of explosives present).

\subsubsection{Use of Metric System}

Throughout DOD 6055.9-STD, the net explosive weight (NEW) is used to calculate distance by means of a formula of the type $D=K W^{1 / 3}$, when $D$ is the distance in feet, $\mathrm{K}$ is a factor depending upon the risk assumed or permitted, and W is the NEW in pounds.
When metric units are used, the symbol $Q$ denotes net explosive quantity (NEQ) expressed in kilograms. In the formula $\mathrm{D}=\mathrm{KQ}^{1 / 3}$, the distance $\mathrm{D}$ is expressed in meters. Thus, the respective units of $K$ are $\mathrm{ft} / \mathrm{lb}^{1 / 3}$ and $\mathrm{m} / \mathrm{kg}^{1 / 3}$ in the two systems. The value of $\mathrm{K}$ in English units is approximately 2.5 times its value in metric units (e.g., if $D(m)=6 Q^{1 / 3}$, then $D(f t)=15 W^{1 / 3}$.

\subsubsection{Railcars and Transport Vehicles}

Explosives-loaded railcars, motor vehicles, or any other transport vehicles in holding yards are considered as aboveground magazines for quantitydistance purposes. These railcars, motor vehicles, or other transport vehicles shall be kept in groups, and each group shall be limited to a maximum of 250,000 pounds of high explosives.

a. When a railcar receiving yard or point is provided for the interchange of cars containing explosives between the common carrier and the facility rail system, quantity-distance provisions do not apply, provided that the cars are moved expeditiously to a suitable location.

b. When inspection of a railcar of explosives indicates that it may be in a hazardous condition, the railcar should be moved at once to a suspect car spur track or an isolated section of track. This spur or section of track should be accessible directly from the inspection point. The distance between the spur or track and facility boundaries, classification yards, inhabited buildings, administration areas, operating buildings, magazines, inert storage locations, and public traffic routes should be the inhabited building distance, which is based on the maximum quantity of explosives that the facility can receive in one railcar. Only one car is permitted at this location at any time.

c. Incoming explosives-laden motor vehicles shall be inspected at a station located remotely from hazardous and populated areas.

\subsubsection{Utilities Installations}

Permanent DOE-controlled underground utilities installations (excluding building service lines) should be separated from explosives locations containing Hazard Class/Division 1.1 materials according to Table VI-1. Utilities installations (aboveground and underground) that are privately owned or operated shall be separated from explosives locations by at least public traffic route distances. If these installations include structures, they should be separated from explosives facilities by inhabited building distance. 
Table VI-1. Quantity-distance separation for protection of underground service installations.

\begin{tabular}{ccc}
\hline $\begin{array}{c}\text { Quantity of explosives } \\
\text { (maximum pounds) }\end{array}$ & \multicolumn{2}{c}{ Distance } \\
\cline { 2 - 3 } & Meters & Feet \\
\hline 100 & 26 & 80 \\
200 & 26 & 80 \\
500 & 26 & 80 \\
1,000 & 26 & 80 \\
2,000 & 26 & 80 \\
5,000 & 26 & 80 \\
10,000 & 26 & 80 \\
20,000 & 28 & 85 \\
50,000 & 36 & 110 \\
100,000 & 46 & 140 \\
250,000 & 62 & 190 \\
\hline
\end{tabular}

Note: If the potential donor building is designed to contain the effects of an explosion, the formula $\mathrm{D}=3.0 \mathrm{~W}^{1 / 3}$ can be used to determine separation distances for less than 20,000 pounds.

\section{Level of Protection Criteria}

\subsection{Hazard Classes}

The level of protection required for any specific explosives activity shall be based on the hazard class (accident potential) for the explosives activity involved. These four hazard classes are defined for explosives activities as follows:

a. Class I. Class I consists of those explosives activities involving a high accident potential; any personnel exposure is unacceptable for Class I activities, and they thus require remote operations. In general, Class I would include activities where energies that may interface with the explosives are approaching the upper safety limits, or the loss of control of the interfacing energy is likely to exceed the safety limits for the explosives involved. This category includes those research and development activities where the safety implications have not been fully characterized. Examples of Class I activities are screening, blending, pressing, extrusion, drilling of holes, dry machining, machining explosives and metal in combination, new explosives development and processes, and explosives disposal.

b. Class II. Class II consists of those explosives activities that involve a moderate accident potential because of the explosives type, the condition of the explosives, or the nature of the operations involved. This category consists of activities where the accident potential is greater than for Class III, but the exposure of personnel performing contact operations is acceptable. Class II includes activities where the energies that do or may interface with the explosives are normally well within the safety boundaries for the explosives involved, but where the loss of control of these energies might approach the safety limits of the explosives. Examples of Class II activities are weighing, some wet machining, assembly and disassembly, and environmental testing.

c. Class III. Class III consists of those explosives activities that represent a low accident potential. Class II includes explosivesactivitiesduring storage and operations incidental to storage or removal from storage.

d. Class IV. Class IV consists of those explosives activities with IHE or IHE subassemblies. Although mass detonating, this explosive type is so insensitive that a negligible probability exists for accidental initiation or transition from burning to detonation. IHE explosions will be limited to pressure ruptures of containers heated in a fire. Although the fire hazards of IHE or IHE subassemblies are not as great as those of other explosives, they are classified as hazard class/division 1.3 (mass fire) to be consistent with DOD 6055.9 STD. Most processing and storage activities with IHE and IHE 
subassemblies are Class IV. However, the following examples of explosives activities with IHE and IHE subassemblies will remain Class I:

- Pressing

- Some machining (see Chapter II, paragraph 12.4.2.c)

- Dry blending

- Dry milling

- Dry screening.

\subsection{Required Level of Protection}

Each bay (i.e., storage, handling, or processing building) housing an explosives activity shall have levels of protection that are based on the hazard class determined for the activity. The levels of protection may be accomplished by equipment design, structural design, operation separation, or provision of operational shields. The levels of protection required for each hazard class are as follows and shall be required for all new facilities or redesign of any existing facilities where changes in activities will result in a change to a more hazardous class.

\subsubsection{Explosives Bay}

a. Class IV. Bays for Class IV (negligible probability of accidental initiation) activities shall provide protection from fire hazards effects. This protection may be achieved by hazard class/division 1.3 aboveground-magazine distance separation or by a design that contains the effects of an accident. Because accidental detonation is not considered credible, Class IV bays shall be sited and designed as acceptors rather than donors for the effects of blast overpressure, structural collapse and missiles (hazardous fragments).

b. Class III. Bays for Class III (low accident potential) activities shall provide protection from explosion propagation from bay to bay within buildings and between buildings that are located at intraline or magazine distance. If intermediate storage of explosives is within an operating building containing Class II or Class I operations, the intermediate storage or staging bay will require Class II level of protection. Minimum separation distances may be reduced when explosives bays are designed to adequately contain the effects of an accident (blast pressures and missiles).

c. Class II. Bays for Class II (moderate accident potential) activities shall, in addition to complying with the requirements for Class III bays, include design to prevent fatalities and severe injury to personnel in all occupied areas other than the bay of occurrence. (For the purpose of this Class II Category, access ramps and plant roads are not considered occupied areas.) Prevention of fatalities and severe injuries is satisfied where personnel in occupied areas other than the bay of occurrence will not be exposed to the following:

- Overpressures greater than $100 \mathrm{kPa}$ (15 psi) maximal effective pressure.*

- Structural collapse resulting from overpressure or debris impact-structural collapse is the failure of a structural component as a direct result of loss of structural integrity of the facility being subjected to various loadings (judged in accordance with the ability of the structure to remain intact so that explosion propagation, fatalities, or severe injuries will not occur).

- Missiles (hazardous fragments) generated in acceptor-occupied areas-hazardous fragments that can cause fatalities and severe injuries are defined as those having greater than $58 \mathrm{ft}-\mathrm{lb}$ impact energy.

d. Class I. Bays for Class I (high accident potential) activities shall, in addition to complying with the requirements for Class II bays, provide protection to prevent serious injuries to all personnel, including personnel performing the activity, personnel in other occupied areas, and all transient personnel. This protection may be achieved by controlling blast and debris through suppression, containment, or establishment of an exclusion area with positive access control. Prevention of serious injuries is satisfied where personnel will not be exposed to:

- Overpressuresgreater than $34-\mathrm{kPa}(5 \mathrm{psi})$ maximal effective pressure, ${ }^{*}$ and should not exceed $16 \mathrm{kPa}(2.3 \mathrm{psi})$ peak positive incident pressure. ${ }^{+}$

- Structural collapse of the building from overpressure or debris impact-structural collapse is the failure of a structural component as a direct result of loss of structural integrity of the facility being subjected to various loadings (judged in accordance with the ability of the structure to remain intact so that explosion propagation and serious injury to personnel will not occur.)

- Missiles (hazardous fragments)-hazardous fragments that can cause serious injuries

\footnotetext{
* These values are requirements of DOE Order 6430.1 and are taken from Chapter 3, Section III. of TM5-1300. The threshold pressure for eardrum rupture is $34 \mathrm{kPa}$, and one-half of the threshold pressure for lung damage is $100 \mathrm{kPa}$.

+ This value is specified in DOD 6055.9-STD as required protection for all personnel exposed to remote operations ( $16 \mathrm{kPa}$ is also the overpressure for public-traffic-route distance).
} 
are defined as those having greater than $11 \mathrm{ft}-\mathrm{lb}$ impact energy.

- Thermal fluxes greater than $0.3 \mathrm{cal} / \mathrm{sq}$ $\mathrm{cm} / \mathrm{sec}^{*}$

\subsubsection{Bays for Joint Explosives-Plutonium Activities}

Bays for joint explosives-plutonium activities shall comply with the requirements of 4.2.1, above, for the class of explosives activity involved and DOE DNA TP-20-7. In addition, because of the plutonium contamination potential, they shall comply with the following:

a. Bays for Uncased Explosives-Plutonium Activities. Where it is necessary to store, handle, or process uncased explosives components in the same bay with plutonium, the enclosing structure and its associated ventilation, electrical, fire protection, and utility system shall be designed to assure that, in the event all the explosives present should detonate, radiation exposures shall comply with DOE 6430.1A ("General Design Criteria Manual," paragraph 3.i.(5), Chapter I) from the standpoint of hypothesized accidental releases. The quantity of plutonium allowed in such a bay will be governed by the safety analysis report. Activities may be performed in Class IV bays if only IHE, IHE subassemblies, or IHE weapons are present; however, the quantity of plutonium allowed will be governed by criticality considerations.

b. Bays for Cased Explosives-Plutonium Activities. Where it is necessary to handle or process cased high explosive components that contain plutonium, the enclosing structure shall be designed as a Class II explosives bay. Storage shall conform to Class III requirements. The limit of plutonium shall be 25 kilograms per bay. The plutonium limits for magazines are specified in DOE-DNA TP 20-7. Activities may be performed in Class IV bays if only IHE, IHE subassemblies, or IHE weapons are present; however, the quantity of plutonium allowed will be governed by criticality considerations.

\section{Fire Protection}

\subsection{Vegetation Control}

Vegetation around storage magazines and explosives operating facilities should be controlled to minimize potential damage to the magazine or facility from grass, brush, or forest fires, or from erosion. A firebreak at least 15 meters wide and free from combustible material should be maintained around each aboveground magazine or facility processing or containing explosives. If the aboveground magazine or explosive facility exterior is fire resistant, the firebreak need not be devoid of vegetation, but the growth must be controlled by mowing to prevent rapid transmission of fire to the magazine or facility. The maintenance of firebreaks around earthcovered magazines and the cutting of grass covering these structures are not normally required, except around ventilators to prevent transmission of a fire into a structure.

\subsection{Fire Protection Criteria}

These fire protection criteria shall be required for all new facilities or for redesign of any existing facilities where changes in activities will result in a change to a more hazardous class. a. Automatic fire suppression systems shall be installed in all buildings containing high explosives and plutonium, with the exception of storage magazines.

b. For buildings containing explosives, but no plutonium, the need for fire suppression systems shall be determined by the facility management, on the basis of maximum fire loss criteria and program mission interruptions and delays as outlined in the DOE Orders 5480.7 and $6430.1 \mathrm{~A}$.

c. Where fire suppression is required, each explosives bay shall have an individual feed with its controls protected (located so as to remain operable in the event of a detonation in any bay) outside the bay.

d. Transmitted firealarms shall distinguish between explosives and nonexplosives areas through the use of annunciator panels at safe locations; small non-HE areas are exempt from having separately transmitted alarms.

* This value is specified in DOD 6055.9 STD, Chapter 4, Paragraph D, as required protection for all personnel assigned to perform remote operations. 


\section{Explosives Facility Siting and Design Criteria References}

In addition to this manual, the following are resource documents for the siting and design of explosives facilities:

- DOE Order 6430.1A, "Department of Energy General Design Criteria Manual," Office of Project and Facilities Management, U.S. Department of Energy, Washington, D.C. 20545.

- TM5-1300, NAVFAC P-397, AFM 88-22, "Structures to Resist the Effects of Accidental Explosions," Departments of the Army, the Navy, and the Air Force, Chairman, Department of Defense Explosives Safety Board, 2461 Eisenhower Avenue, Alexandria, VA 22331.

- DOE/TIC-11268, "A Manual for the Prediction of Blast and Fragment Loading of Structures," U.S. Department of Energy, Albuquerque Operations, Amarillo Area Office, Facilities and Maintenance Branch, P.O. Box 30030, Amarillo, TX 79120.

- DOD 6055.9-STD, "Department of Defense Ammunition and Explosives Safety Standards," Assistant Secretary of Defense (Manpower, Installations, and Logistics), Chairman, Department of Defense Explosives Safety Board, 2461 Eisenhower Avenue, Alexandria, VA 22331.
- TR-828, "Blast Environment from Fully and Partially Vented Explosions in Cubicles," W. A. Keenan and J. E. Tancreto, Civil Engineering Laboratory, Naval Construction Battalion Center, Port Hueneme, CA 93043.

- $\mathrm{AD} 411445$, "Industrial Engineering Study to Establish Safety Design Criteria for Use in Engineering of Explosives Facilities and Operations," Process Engineering Branch, APMED Picatinny Arsenal, Dover, NJ; Defense Technical Information Center, Defense Logistics Agency, Cameron Station, Alexandria, VA 22314.

- AFWL-TR-74-102, "The Air Force Manual for Design and Analysis of Hardened Structures," Air Force Weapons Laboratory, Air Force Systems Command, Kirtland Air Force Base, NM 87117; AD B004152, Defense Technical Information Center, Defense Logistics Agency, Cameron Station, Alexandria, VA 22314.

- HNDM-1110-1-2, "Suppressive Shields, Structural Design and Analysis Handbook," U.S. Army Corps of Engineers, Huntsville Division, HNDED-CS, P.O. Box 1600, Huntsville, AL 35807. 
0

0

v1-8 


\section{CHAPTER VII}

\section{OPERATING PROCEDURES}

\section{General}

\subsection{Requirements}

This section establishes requirements for preparing and controlling all procedures used for operationsinvolving explosives at DOE installations. These requirements for procedures minimize the chances of an incident resulting from operations using outdated, inapplicable, or incomplete procedures, or from operations performed in violation of established practices.

This section also specifies that procedures must be generated for all explosives operations because the step-by-step reasoning process that is used in developing the procedure will identify many safetyrelated problem areas that might be overlooked otherwise. In addition, the approval system for new or revised procedures also provides other viewpoints and knowledge that may not be available to the originator and may need incorporation into the procedure.

\subsection{Types of Procedures}

Two general types of operating procedures are described in this chapter: (1) standard operating procedures (SOPs) and (2) nonstandard procedures, which include experimental and special procedures. Standard operating procedures are formalized documents prepared for performance of a task on a routine basis. Experimental and special procedures are documents prepared for performance of a task on a limited basis. For the purpose of this manual, special procedures are those written to correct a problem encountered in an explosive operation.

\section{Guidelines}

The following general guidelines should be used in creating operating procedures:

\subsection{Before Operation}

Before starting any operation involving explosives, operating procedures shall be written and approved.

\subsection{Supervisory Responsibility}

Supervisory personnel shall be responsible for enforcement of the provisions of all procedures that are used in their jurisdiction.

\subsection{Preparation}

a. Procedures shall be prepared by responsible personnel with knowledge of the operations involved. b. All items presented in the procedure and operational steps called out shall be checked for compliance with the standards of this manual.

c. The specific types of equipment and building or area in which the operation is to be conducted should be designated in the procedure, when applicable.

d. In the event similar operations in the same area involve differences in equipment or process, supplemental procedures or sections shall be written.

\subsection{Approval}

All new or revised operating procedures shall be reviewed and approved prior to use. Levels of approval required should be based on the inherent risk in the operation and be established by each operating contractor. Review and approval requirements shall include, as a minimum, line and safety organizations. 


\subsection{Control}

a. Distribution of procedures shall be controlled to make certain that each operating area has the most current revision. Superseded or inactive procedures shall be removed from operating areas. No operation shall be performed with a superseded, inactive, or unapproved procedure.

b. Files of active procedures should be maintained.

\subsection{Audits}

a. An audit system should be established that will evaluate routinely the adequacy, availability, and currency of procedures. Also, audits should include an evaluation of operator knowledge and compliance with procedures.

b. Groups conducting the audits should include personnel from other than the operating department or division using the procedure.

\subsection{Reviews}

a. All active procedures should be reviewed a minimum of once a year by the appropriate departments.

b. If the procedure is no longer completely applicable to the operation or if new safety considerations (i.e., compatibility, toxicity, ignition sources, etc.) have been identified, the procedure shall be revised.

c. If a procedure is not expected to be used during the coming year, it may be placed in an inactive procedure file.

d. Before an inactive procedure can be reactivated, it shall be reviewed and approved. Minimum approval shall be the same as that required for a new or revised procedure (see Section 2.4 above).

\subsection{Content of Standard Operating Procedures}

The following presentation is intended to specify procedures content-not format or organization. Each operating contractor can developits own system for preparing safety procedures.

\subsubsection{General Operating Procedures}

a. Introduction. The introduction to the procedure should include the following:

- A statement of the scope of the procedure, defining what facilities and equipment are covered

- The name of the department and/or individual responsible for the operation

- If the procedure serves as the basis for an exemption or waiver from the standards of this manual, a statement to this effect and a specific reference to the standard involved.

b. Safety and Health. The safety section of the procedure should present the following information or reference a safety manual that specifies the requirements:

- General safety rules to be observed and techniques to be applied that will ensure safety of operations, prevent injury or illness to personnel, and prevent damage to equipment. In particular, this section of the SOP should describe the personnel control features of the facility that protect personnel from exposure to hazardousoperations, toxic materials, or tests

- Personnel number and explosive weight linits

- Additional or specific emergency controls not addressed by the facility emergency plan.

c. Operations. The operations section should consist of general directions for operation of all major items of explosives handling equipment. Particular emphasis should be placed on safety interlocks and controls, and the proper use of these systems.

If operation of a particular item of equipment or of an area requires that no other operation be performed simultaneously in this same work area, this requirement shall be clearly stated in the procedure.

\subsubsection{Unit Operating Procedures}

a. Introduction. The procedure introduction should include the following:

- A statement of the nature of the operation and its objectives

- The name of the department responsible for the operation and the procedure

- A description of the range of work authorized by the procedure

- If the procedure serves as the basis for an exemption or waiver from the standards of this manual, a statement to this effect and a specific reference to the standard involved. 
b. Materials and Equipment. The materials and equipment section should present the following information:

- All significant tools, supplies, chemicals, and equipment necessary to perform the operation should be listed in the SOP or in a separate required document

- Specifications for approved chemicals, supplies, tooling, and equipment should be referenced where applicable

- An explanation of any specific hazard involved in the handling of chemicals or explosives for the operation, or a reference to a document that describes the hazards should be included.

c. Safety. The safety section should present the following information or reference a safety manual that specifies the requirements: operation

- Safety rules that are specific to the

- Protective equipment that must be used during the operation

- Emergency controls applicable to the operation that are not considered in the General Operating Procedures. d. Operations. The operations section should consist of sequential directions written or pictured in clear, concise steps that describe how to perform a particular operation. If a particular operation requires that no other operation be performed simultaneously in the same work area, this requirement shall be clearly stated in the procedure.

\subsection{Content of Special or Experimental Procedures}

a. Introduction. The procedure introduction should state the purpose of the operation.

b. Limits. The limits for the amounts of material, personnel, operating temperature, conditions, time, etc. should be included.

c. Operations. The operations section should consist of sequential directions written in clear, concise steps that describe how to perform a particular operation.

When special or an experimental operation will be conducted a number of times, a standard operating procedure should be written and approved. 
$\bullet$

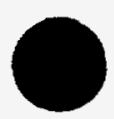

VII-4 


\section{CHAPTER VIII}

\section{FORMULATION SCALEUP}

\section{Explosives Development Program}

\subsection{Explosives Development Committee}

A committee, which will be the approving authority for each phase of an explosives development program, shall be established at each DOE facility engaged in explosives development. This committee will be referred to here as the Explosives Development Committee (EDC), but it may have a different name at each DOE facility. Individuals chosen to serve on the EDC should have considerable experience in explosives handling, processing, chemistry, sensitivity, and safety.

\subsection{Phase-by-Phase Approvals}

The data generated in each phase of a development project involving a new explosive or new explosive formulation shall be reviewed by the EDC and approved prior to starting the next phase.

\subsection{Modified Formulations}

Compositional modifications to previously evaluated explosive formulations shall be approved by the EDC. However, if formulation modifications are minor, the EDC may approve the explosives formulation for a given phase of development without requiring all of the developmental steps and tests.

\subsection{Sensitivity Data from Another Laboratory}

In the event comparable sensitivity data for the subject material are available from another laboratory, the EDC may approve the waiving of some developmental phase tests.

\section{Development Procedures}

\subsection{General}

An administrative procedure that defines the basic steps for development and evaluation of new explosives and explosive formulations shall be established at all DOE explosives handling facilities. The procedure shall require that each development effort proceed in phases from small to large quantities. Each phase shall limit the quantities of materials that may be handled. The EDC shall be responsible for establishing criteria for acceptable explosive behavior in each test of each phase of the explosives development procedure. The development procedure should consist of three phases plus a synthesis phase and compatibility testing, when required. Guidelines for establishing this procedure are proposed in the following paragraphs. Table VIII-1 summarizes these guidelines.

\subsection{Synthesis Phase}

Before mixing a new explosive with other materials, the sensitivity and stability of the explosive should be determined and should comply with the criteria set by the EDC. Recommended tests include the following:

a. Drop-weight impact

b. Friction

c. Spark

d. Thermal stability -these tests should include two or more of the following: 
Table VIII-1. Scaleup procedure guidelines for new explosives and formulations.

\begin{tabular}{|c|c|c|c|}
\hline $\begin{array}{l}\text { Quantity of new } \\
\text { material }{ }^{\alpha}\end{array}$ & Recommended data & Data desired & $\begin{array}{l}\text { Additional } \\
\text { recommendations }\end{array}$ \\
\hline \multicolumn{4}{|l|}{ Synthesis } \\
\hline $\begin{array}{l}\text { Specified by the lab } \\
\text { performing the } \\
\text { synthesis }\end{array}$ & $\begin{array}{l}\text { Impact, friction, spark, } \\
\text { thermal stability }\end{array}$ & $\begin{array}{l}\text { Before using the new } \\
\text { ingredient in a formulation }\end{array}$ & - \\
\hline \multicolumn{4}{|l|}{ Formulation } \\
\hline $\begin{array}{l}\text { Compatibility testing: } \\
2 \text { grams }\end{array}$ & $\begin{array}{l}\text { Thermal compatibility } \\
\text { of new ingredient with } \\
\text { other ingredients of } \\
\text { formulation }\end{array}$ & $\begin{array}{l}\text { Before proceeding to } \\
\text { Phase I }\end{array}$ & $\begin{array}{l}\text { Materials should be } \\
\text { processed remotely }\end{array}$ \\
\hline \multicolumn{4}{|l|}{ Phase I: } \\
\hline 10 grams & $\begin{array}{l}\text { Impact, friction, thermal } \\
\text { stability }\end{array}$ & $\begin{array}{l}\text { Before nonremote } \\
\text { processing and } \\
\text { handling in Phase I } \\
\text { or scaleup to Phase II }\end{array}$ & $\begin{array}{l}\text { Materials should be } \\
\text { processed remotely } \\
\text { before passing sensitivity } \\
\text { and stability tests }\end{array}$ \\
\hline \multicolumn{4}{|l|}{ Phase II: } \\
\hline 500 grams $^{b}$ & $\begin{array}{l}\text { Compatibility, impact, } \\
\text { friction, spark, thermal } \\
\text { stability, thermal } \\
\text { characterization before } \\
\text { elevated temperature } \\
\text { pressing }\end{array}$ & d & e \\
\hline \multicolumn{4}{|l|}{ Phase III: } \\
\hline Specified by EDC & $\begin{array}{l}\text { Compatibility, high } \\
\text { speed machining, } \\
\text { drop skid }\end{array}$ & $\begin{array}{l}\text { Before Phase III machining } \\
\text { or handling of billets } 7 \mathrm{~kg} \\
\text { or greater }\end{array}$ & $\begin{array}{l}\text { Composition of formulation } \\
\text { shall be fixed }\end{array}$ \\
\hline
\end{tabular}

- Quantities and recommended data apply to both new formulations and explosive ingredients.

b The EDC may allow more than $500 \mathrm{~g}$ in Phase II where larger quantities are needed for some tests.

c Compatibility of explosives and formulations with materials contacting the explosives in test and production assemblies.

d Before proceeding to Phase III if:

(1) The formulation to be scaled up to Phase III differs from that tested in Phase I, or

(2) The explosive or formulation prepared for Phase II development is produced by techniques different from those used in Phase I.

Before proceeding to Phase II if the composition of a formulation is modified so that the composition is no longer within the limits specified by the EDC.

- Materials investigated in this phase should be produced by techniques similar to those that will be used to produce larger batches in a subsequent phase.

- Differential thermal analysis or differential scanning calorimetry

- Thermal gravimetric analysis

- Gas evolution rate at elevated temperature (chemical reactivity test, vacuum stability, etc.)

- Time-to-explosion analysis.

\subsection{Compatibility Testing}

a. If a proposed formulation contains new ingredients (explosive or nonexplosive), the new ingredients should be tested for compatibility with the other ingredients before preparing 
batches for Phase I testing. Compatibility tests should include any of the stability tests listed under paragraph 2.2.d above.

b. No more than 2 grams of the new formulation should by prepared, handled, or stored before compatibility testing.

c. Formulations for compatibility testing should be processed remotely, whenever possible.

\subsection{Phase I-Preliminary Explosive Testing}

a. The total quantity of material that may be processed, handled, or stored at any one time in Phase I should not exceed 10 grams. Whenever possible, this material should be processed remotely.

b. The new explosive or formulation should be subjected to sensitivity and stability tests. As a minimum, drop-weight impact, friction, spark sensitivity, and thermal stability tests should be run. Thermal stability testing need not be performed here if one or more of the compatibility tests listed under paragraph 2.2.d above have already been conducted on the new formulation.

c. If the new explosive or formulation is acceptable in the above tests, it may be scaled up to Phase II. The EDC may impose handling or processing restrictions or precautions on the material if its performance in any of the above tests is questionable.

d. After Phase I testing of a formulation is complete, the EDC should define, on the basis of the test results, what variations in composition are permissible during Phase II development without retesting.

\subsection{Phase II-Experimental Characterization and Development}

a. The total quantity of materials that may be processed or handled at any one time in Phase II should not exceed 500 grams. No limit exists on the quantity that may be stored, other than the storage facility limits for Group L explosives.

b. Materials investigated in Phase II should be produced by techniques similar to those that will be used to produce larger batches in a subsequent scaleup phase. c. A thermal characterization test and evaluation should be run before pressing the new material at elevated temperature.

d. The Phase I sensitivity and stability tests should be rerun in Phase II if the following apply.

- The formulation to be scaled up to Phase III differs from that tested in Phase I. In this case, testing should be completed before Phase III scaleup.

- The explosive or formulation prepared for Phase II development is produced by tech-niques different than those used in Phase I. Test-ing should be completed before Phase III scaleup.

- During Phase II, the composition of a formulation is modified to an extent that the composition is no longer within the limits specified by the EDC. (Sce paragraph 2.4.d above.) Testing should be completed before proceeding with Phase II.

e. The compatibility of explosives and formulations with materials contacting the explosives in test and production devices shall be evaluated before any such device is assembled. If compatibility testing is required, one or more of the tests listed under paragraph 2.2.d above should be recommended.

\subsection{Phase III-Full Scale Testing and Production}

a. The maximum quantity of materials that may be processed or handled in Phase III should be defined in the EDC's grant of authorization to proceed with Phase III. No limit is imposed for the storage facilities except the limits imposed by the quantitydistance tables.

b. All additional testing necessary to define storage compatibility grouping should becom-pleted before committing bulk quantities of the material to storage. (See Chapter II, Section 17.4.)

c. During Phase III development, the composition of all formulations should be fixed.

d. Any new explosive material that is to be contact machined shall be subjected to a machining overtest. Reaction threshold should be determined if possible.

e. If billets of $7 \mathrm{~kg}$ or greater are to be produced in Phase III, drop-skid testing should be performed and EDC criteria for this test should be met.

f. Paragraph 2.5.e above should also lie applicable to Phase III development. 
-

$\bullet$

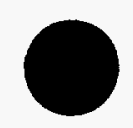

VIII-4 


\section{CHAPTER IX}

\section{INSENSITIVE HIGH EXPLOSIVES QUALIFICATION}

\section{Insensitive High Explosives (IHE)}

Some explosive substances, although mass detonating, are so insensitive that there is negligible probability of accidental initiation or transition from burning to detonation. Any explosive that is a candidate for classification as an IHE shall be subjected to the DOE qualification tests listed in Table IX-1. Test procedures, where not specified, are contained in MHSMP-84-22, IHE Material Qualification Tests, Description and Criteria. Test data for each explosive requested for this classification will be submitted by the DOE laboratory or contractor through the appropriate Operations Office to DOE Headquarters (OMA and OQP). The DOE Explosives Safety Committee will independ- ently analyze the data and recommend action on including the explosive in Table IX-2 as an approved IHE.

New candidate explosives formulations will not be classified by analogy as IHE until reviewed by the DOE Explosives Safety Committee. The general guidelines for requesting and obtaining an IHE approval by analogy include:

- All requests, including rationale, must be submitted in writing to the DOE Explosives Safety Committee for their analysis and recommended action.

- Approved IHE(s) with complete test data must be used for baseline comparison purposes.

Table IX-1. DOE qualification tests for IHE.

1. Drop-weight impact test $t^{a}$

2. Friction test ${ }^{b}$

3. Spark test ${ }^{a}$

4. Ignition and unconfined burning test (small-scale burn)

5. Card gap test ${ }^{b}$

6. Detonation (cap) test

7. Cookoff

8. Spigot test ${ }^{b}$

9. Skid test ${ }^{b}$

10. Susan test

11. Bullet impact
Comparable to or less sensitive than Explosive D (ammonium picrate). Minimum of 20 drops per test series.

No reaction on Pantex friction machine (10 trials).

No reaction at minimum of 0.25 joules (10 trials).

TB 700-2 test procedures, any shape, minimum thermal path of $25 \mathrm{~mm}$, no explosion.

No reaction at Explosive D 50\% gap thickness (or less) using a Pantex modified NOL card gap test ( 6 trials). The test diameter must be greater than the uncon fined failure (critical) diameter of the candidate IHE.

TB 700-2 test procedures-no detonation (5 trials).

No reaction of more than a pressure release using the large scale ODTX test conducted such that a reaction must occur in not less than 4 hours (6 trials).

No reaction for 120 foot drop in LANL test ( 3 trials).

No reaction up to 20-foot (or sample failure) drop at 14-15 degrees test angle using standard size billets ( 3 trial at worst case condition).

Less than or equal to 10 percent TNT output at a minimum of $333 \mathrm{~m} / \mathrm{sec}$ ( 3 trials).

No violent reaction with $5.56 \mathrm{~mm}$ and $.50 \mathrm{cal}$. projectile impact on material in schedule 40 steel pipe with closures on each end ( 6 trials in axial orientation).

\footnotetext{
a These tests are not applicable to compacted explosives.

b These tests are not applicable for explosives powders.
} 
Table IX-2. Approved IHEs.

TATB

TATB/Kel-F Formulations

More specific guidelines will depend on caseby-case circumstances surrounding the specific analogy request. In many instances a partial analogy can be drawn, resulting in only partial testing being required. This will depend on the type and extent of change in the candidate IHE relative to the baseline IHE and the potential effects of these changes on specific initiation mechanisms (shock, thermal, mechanical, impact, electrostatic, etc.). A candidate $\mathrm{IHE}$ can be placed in one of the following categorics to define the tests required for approval:

- CaseI (partial testing required). The candidate IHE formulation involves substitution of the inert binder component of the approved baseline IHE with a new inert binder component. Sufficient testing is required to verify that no chemical incompatibilities have been introduced that would desta- bilize the base IHE. In this case, test data normally generated by the requesting facility during their explosive development scale-up phasing process may be submitted for approval consideration in lieu of the qualification tests of Table IX-1. During this development phase, each facility EDC may dictate restrictions consistent with an IHE internal to their facility only. Final approval as an IHE must be obtained through the DOE Explosives Safety Committee. Tests $1,2,3$, and 7 of Table IX-1 or equivalent are required as a minimum.

- Case II (all IHE tests of Table IX-1 required; analogy inappropriate). The candidate IHE involves the addition of an untested (IHE tests) energetic component to the approved base-line IHE.

Or:

The candidate IHE involves the same energetic and inert components as the approved baseline IHE, with the only change being a volume-\% increase in the energetic component content.

Any data over and above that required in Table IX-1 will be considered by the DOE Explosives Safety Committee in its deliberations of the approval request.

\section{IHE Subassemblies}

IHE Subassemblies are composed of IHE hemispheres or spheres with booster charges, with or without detonators. Successful completion of the applicable DOE qualification tests listed in Table IX3 is required for classification as an IHE Subassembly. A test plan (defining specific test procedures) for candidates for this classification shall be submitted by the DOE contractor through the appropriate Operations Office to the DOE Explosives Safety Committee for review. On approval of the plan, tests shall be run and the DOE Explosives Safety Committee shall independently analyze the data and recom- mend approval or disapproval. DOE Headquarters will then issue a memorandum to appropriate Operations Offices and DOE Contractors classifying those configurations meeting the required test criteria as IHE Subassemblies. Approved IHE Subassemblies are listed in Table IX-4. Subassemblies will not be classified as IHE Subassemblies by analogy until reviewed by the DOE Explosives Safety Committee. When no other explosives are present in the same location, these subassemblies are classified as Class 1.3 explosives (see Table IX-5) for storage, processing, and transportation purposes.

\section{IHE Weapons}

IHE weapons are those weapons listed in DOEDNA TP 20-7 that are exempt from storage and transportation limits when stored or transported alone or in combination with each other. This classification is valid only if the spacing between indi- vidual units is that provided by storage containers, or if out of containers, by the spacing specified in TP 20-7. These weapons are classified as Class 1.3 explosives for storage, processing, and transportation purposes. 
Table IX-3. DOE qualification tests for IHE subassemblies."

1. Spigot test

2. Bonfire

3. Slow cookoff

4. Multiple bullet impact

5. Skid test
No burning or violent reaction of main charge of 120 feet drop on booster in LANL test ( 3 trials). No detonation or violent reaction of main charge when engulfed in a fire ( 3 trials).

No detonation or violent reaction of main charge when slowly heated to a reaction ( 3 trials).

No detonation or violent reaction of main charge with a 3-round burst of $7.62 \mathrm{~mm}$ projectile impact on booster ( 3 trials).

No burning or violent reaction of main charge up to a 20-foot (or sample failure) drop at 14 to 15 degrees test angle using subassembly configuration modified for impact on the booster ( 3 trials at worst case condition).

Tests are not required for subassemblies when main charge and booster charge explosives have been qualified as IHE by tests in Table IX-1.

Note: The test plan shall specify applicable testing for cased and/or uncased configurations with or without detonators.

Table IX-4. Approved IHE subassemblies.

\begin{tabular}{lll}
\hline $\mathrm{B61}^{\mathrm{a}} 3 / 4 / 6 / 7 / 8$ & $W 80^{2}$ & W85 \\
$\mathrm{B83}^{\mathrm{a}}$ & $\mathrm{W81}^{2}$ & W87 \\
& W84 & W89 \\
\hline
\end{tabular}

-Approval limited to boosters of the size tested or smaller. Any redesign that dimensionally increases the booster size requires resubmission of an experimental plan and additional testing as another IHE subassembly.
Table IX-5. IHE hazard classification.

\begin{tabular}{ll}
\hline IHE alone & 1.3 \\
IHE at magazine distance or greater from Class 1.1 & 1.3 \\
IHE at magazine distance or greater from Class 1.2 & 1.3 \\
IHE with 1.1 items & 1.1 \\
IHE with 1.2 items & 1.1 \\
IHE with other 1.3 items & 1.3 \\
IHE with 1.4 items & 1.3 \\
IHE at less than magazine distance from Class 1.1 & 1.1 \\
IHE at less than magazine distance from Class 1.2 & 1.1 \\
\hline
\end{tabular}

Note: IHE may be stored with mock HE without regard to the quantity of mock HE.

\section{Reference Documents}

The following documents set forth some of the non-DOE procedures to be used in the IHE and IHE subassembly testing required by Tables IX-1 and IX-3:

- TB-700-2, NAVSEA INST 8020.8A, TO 11A1-47, DLAR 8220.1, "Department of Defense Explosives Hazard Classification Procedures," Departments of the Army, the Navy, the Air Force, and the
Defense Logistics Agency, Washington, D.C.; U.S. Government Printing Office: 1989-261-869:00062.

- MHSMP-84-22, IHE Material Qualification Tests, Description and Criteria (Rev. 1, July 1985), National Technical Information Service, U.S. Department of Commerce, 5285 Port Royal Road, Springfield, VA 22161. 
$\bullet$

$\bullet$

IX-4 


\section{Index}

Acceptor(s), VI-4-5

Access control, II-11, II-37, II-40, VI-5

Access ramps, VI-5

Accident, vehicle, II-51

Accident potential, VI-4-5

Accidental releases, VI-5

Accounting procedure(s), II-3

Actuators, II-38, II-45, II-57, II-65

Adiabatic heating, II-29

Administration area(s), II-47, VI-3

Advisory standard(s), I-1

Agitation, II-33, II-34-35

Airspace, II-38

Aisle(s), II-53

Alarm(s), II-4, II-28, II-33, II-34-35

Ammunition, I-6, II-41, II-56-58

Analogy, IX-2

Approval procedure, II-7

Approved IHE(s), IX-2, IX-3

Arm, I-2, II-40

Assembly, II-33, VI-4

Audio monitoring, II-9, II-31

Audit(s), VII-2

Ball or jar milling, II-35-36

Bare explosive(s), II-3, II-31, II-45

Barricade(s), I-3, I-5, II-59

Battery-powered equipment, II-50

Bay, I-3

Bay of occurrence, VI-5

Bearing(s), II-15, II-35

Blast, I-6, II-3-4, II-33, II-37, VI-2, VI-5, VI-7

Blast vent, II-68

Blast-resistant door(s), II-4

Blending, I-3, II-32, VI-4

Blocking and bracing, II-47

Bonding, I-3, II-15

Booster, I-3, I-4, II-31, II-56, IX-2-3

Broadcast transmitter(s), II-38

Brushes or scraper(s), II-61

Burial, II-66

Burning area, II-65

Cart(s), II-45

Cased explosive(s), II-66

Casual, I-3, III-1

Cell, I-3

Checklist, vehicle, II-47, II-49

Chemical cleaning agent, II-61

Chemical processing, II-34

Chock block(s), II-47, II-49
Class 1, VI-2

Class 1.1 material(s), VI-3

Class B explosive(s), II 49

Class C explosive(s), II-49, II-57, II-59

Class I, VI-4-5

Class II, VI-4-6

Class III, VI-4-6

Class IV, VI-4-6

Classification test(s), VI-3

Classified by analogy, IX-2

Cleaning, II-7, II-25, II-32, II-35, II-61, II-64, II-67, IV-2

Cleanup procedure(s), II-47, II-61

Closed circuit television, II-9

Clothing, II-35, IV-1, IV-2

Cold trap, II-28

Combustible material(s), I-3, II-54, II-55, II-66

Commercial carrier, II-50

Common carrier(s), II-49, VI-3

Communication equipment, II-53

Compatibility, I-3, II-29, II-36, II-42, II-55-57, II-62, II-64, VI-2-3, VII-2, VIII-1-3

Compatibility testing, II-42, II-57, VIII-1-3

Compliance with procedure(s), VII-2

Concurrent burning operation(s), II-65

Concurrent contact machining, II-31

Concurrent operation(s), I-3, II-36

Condensation, II-28

Conductive floor(s), II-15-16

Conductive footwear, IV-1

Conductive shoe(s), II-15-16

Conductive wristband(s), II-15

Conductivity, IV-1

Construction operation(s), II-7

Contact machining, II-30-32

Contact operation(s), II-30-32, II-35, II-36, II-38, II-42

Container(s), II-36, II-45, II-47, II-50, II-53-54, II-55, II-57-58, II-65, II-67, IX-2

Contamination, II-1, II-16, II-19, II-21, II-23, II-29, II-32-36, II-40, II-54, II-57, II-61, IV-1, IV-2, VI-5

Contamination prevention, II-36

Contamination zone, II- 40

Control key, II-37, II-40

Control point, I-3, II-37

Control procedure(s), II-9, II-11, II-19, II-29

Cooking and eating, II-11

Cookoff, II-37, IX-1, IX-3

Coolant, II-30-32, II-34

Coring, I-3, II-31-32 
Coverall(s), IV-1

Crack(s), II-1, II-16, II-23, II-29, II-31-34, II-61, II-68

Crane(s), II-45, II-53

Critical temperature, I-3, II-27

Criticality, VI-6

Cubicle(s), I-3, II-23, II-41, II-57, II-63-64, VI-7

Curing, II-33

Current-limiting, II-43

Cushioning material, II-33

Cutting or welding, II-8

Cutting tool(s), II-30-31

DNA TP-20-7, II-58, VI-5-6, IX-2

DOD 6055.9-STD, II-69, VI-3-5, VI-7

DOT regulation(s), II-49

DTA, I-3, II-19, II-27

Damaged container(s), II-58

Danger zone, I-3, II-37-38, II-42, II-66

Dangerous good(s), VI-2

Deaerator(s), II-35

Debris impact, VI-5

Decomposition, I-5, II-46, II-55, II-61

Decontamination, I-4, II-7, II-61-62, II-64

Deflagration, I-3

Degraded explosive, II-54

Degree(s) of protection, VI-2

Deluge system(s), II-35

Desiccator(s), II-28

Design and siting, VI-1

Design criteria, I-1, II-3, VI-5, VI-6-7

Detonation(s), I-3, II-37, II-40-42, II-65-66, IX-1, IX-3

Detonator cable(s), II-39-40

Detonator(s), I-4, II-39-40, II-42, II-45, II-55-57, II-65-66

Development procedures, VIII-1-3

Diagnostic equipment, II-38

Die(s), II-28-29

Differential thermal analysis(es), II-19, II-27, VIII-2

Disassembly, II-21, II-33, VI-4

Disposal, II-61, II-65-66, VI-4

Disposal area, II-66

Dock, II-47

Donor(s), VI-3-4

Door(s), II-4, II-9, II-37-38, II-41, II-53

Drain(s), II-25, II-31, II-67

Drilling, II-31-32, VI-4

Drop test, II-42

Drop-skid test, II-46

Dry blending, II-32, VI-4

Dry dust collection, II-63
Dry machining, II-31, VI-4

Dry run(s), I-5, II-35, II-38, II-42

Dry screening, II-32, VI-4

Drying, I-3, II-28

Dual control(s), II-68

Dunnage, II-54

Dust collection, II-23, II-29, II-63-64

Dust generation, II-32

Dust hazard, II-19, II-23

Dynamic testing, II-41

EBW, I-3-4, II-56, II-66

EDC, II-34, II-57, VIII-1-3

EED(s), I-3, I-5-6, II-13, II-38, II-40, II-45, IV-1

Eardrum rupture, VI-5

Eight-hour supply, III-2

Elastomeric container, II-29

Electric blasting, II-38-39

Electric line(s), II-19

Electrical bonding, I-3, II-15

Electrical circuits, II-38, II-43

Electrical equipment, II-19-20

Electrical instrument(s), II-38, II-40, II-43

Electrical resistance, II-15, II-16

Electrical service entrance, II-20

Electrical storm(s), II-13, II-54

Electrical substation(s), II-20

Electrically bonded, II-32, II-64

Electroexplosive device(s), I-3, I-5-6, II-13, II-15, II-38, II-40, II-45, IV-1

Electrostatic sensitive, II-13, II-32, IV-1

Emergency, V-1, VII-2, VII-3

Emergency condition(s), II-51

Emergency control, II-69

Emergency cooling, II-68

Emergency emptying, II-33

Emergency exit(s), II-3-5

Emergency lighting, III-4

Emergency plan(s), II-35, II-51, II-69, VII-2

Emergency power, II-13

Emergency procedure, II-42-43, II-69

Emergency stop device(s), II-36

Environmental regulation(s), II-66

Environmental testing, II-41-42, VI-4

Equipment design, VI-5

Equipment maintenance, II-7-8, IV-1

Equipment speed and feed rate(s), II-30

Evacuation, II-3-4, II-13, II-69

Excelsior, II-65

Exhaust ventilation, II-23, II-29, II-34

Exemption(s), I-1-2, II-58, VII-2

Exit(s), II-3-5, II-53

Experimental characterization, VIII-3

Experimental explosive(s), II-57, II-68 
Experimental operating procedure, I-4, VII-1, VII-3

Exploding bridgewire (EBW), I-3-4, II-56, II-66

Explosion propagation, VI-5

Explosive, I-4

Explosive assembly(ies), II-29, II-39, II-41, II-45

Explosive device(s), II-55-57

Explosive occupancy, II-4

Explosive powder(s), II-3, II-29, II-35, IV-1

Explosive projectile, II-43

Explosives Development Committee, II-34, II-57, VIII-1-3

Explosives Safety Committee, I-2, II-43, IX-2

Explosives activity(ies), VI-1, VI-4-5

Explosives billet(s), II-34

Explosives circuit(s), II-43

Explosives classification, VI-2-3

Explosives development, VI-4, VIII-1-3

Explosives dust(s), II-7, II-16, II-19, II-23, II-32,

II-63, II-64, IV-1

Explosives formulation, II-35

Explosives in solution, II-47, II-68

Explosives inspection, II-34

Explosives limit(s), II-42, II-63, III-1, VI-1

Explosives recovery, II-64

Explosives shot, II-37

Explosives slurry(ies), II-35, II-64

Explosives target(s), II-41

Explosives waste, II-63-64, II-65-66

Explosives waste container(s), II-63, II-65

Explosives-carrying vehicle(s), II-13, II-47, II-49-50, V-1

Exposed explosive(s), II-15-16, II-19, II-28

Extrudable explosive(s), II-33

Extru(ding) (sion), I-4, II-29-30, VI-4

Eye protection, IV-1

Facility, I-4

Facility boundary(ies), II-47, VI-3

Facility management, I-1-2, I-4, II-1, II-3, II-7, II-19, II-32, II-35, II-39, II-50, II-54, III-1, VI-6

Facility operator, I-1, I-4

Facility siting and design, VI-6

Fatality(ies), VI-5

File(s), I-2, II-50, III-1, VII-2

Final decontamination, II-61

Fire alarm(s), VI-6

Fire control circuit, II-40

Fire extinguisher(s), II-49, II-51, II-53

Fire protection, II-5, II-67, VI-6

Fire symbol(s), II-69
Firebrand(s), I-4, II-37

Firefighting, II-66

Firing area(s), II-37-40

Firing circuit(s), II-38, II-40, II-42, II-65

Firing in tank(s), II-41

Firing key, II-65

Firing lead(s), II-39

Firing mechanism, II-41, II-43

Firing pad, I-4, II-38, II-39, II-40

Firing site, I-4, II-37-38

Firing unit capacitor, II-40

Firing vessel, II-41

Flame retardant coverall(s), IV-1

Flammable gas(es), II-15, II-19

Flammable liquid(s), I-4, II-15, II-19, II-34, II-35, II-54

Flammable vapor, II-15, II-19, II-61

Flanged connector(s), II-23

Flash point, I-4, II-7

Flashing, II-65

Floor resistance, II-16

Footwear, II-15, IV-1

Foreign material , II-30, II-34

Foreign object(s), II-31

Forklift(s), II-50

Formulation, II-35, II-68, VI-1, VIII-1

Four-hour supply, II-42

Fragment(s), I-4, II-3, II-37, II-38, II-67, VI-2, VI-5-6

Friction air, II-28

Fueling, II-50

Full-scale testing, VIII-3

Furnace, II-65

Gaging, II-32

Gas gun, II-41

Gasoline-powered, II-50

Gate(s), II-37-38

General operating procedure(s), VII-2

General operations safety, II-1

Glass container(s), II-58

Glassware, II-68

Glove(s), II-67, IV-1

Grass fire(s), II-39

Grinding, II-36

Ground fault circuit interrupter, II-17

Grounding, II-15-16, II-20, II-38, II-40

Guard(s), II-67

Gun firing(s), II-37, II-41

Gun(s), II-41, II-43

Hand blending, II-32

Hand tool(s), II-3, II-33

Hand truck(s), II-45 
Handling, I-1, II-3, II-19, II-45-46, II-50,

II-53-54, IV-1, VI-4, VII-3, VIII-1-3

Handling equipment, II-5, II-34, II-45, II-50, II-57-58, VII-2

Hard surface(s), II-33, II-45

Hazard class (explosives), II-58, VI-2

Hazard class (activities), VI-4-5

Hazard classification system, VI-2-3

Hazard communications, II-2

Hazardous condition(s), II-37, II-51, V-1, VI-3

Hazardous fragment(s), VI-5

Hazardous locations (NEC), II-19, II-50

Hazardous radioactive materials, II-42

Hearing protection, II-37

Heat-producing equipment, II-7

Heater control(s), II-27

Heating, II-27-28, II-32, II-35, II-42, II-53, II-61, II-68

Heating coil(s), II-7, II-53

Heating equipment, II-28

Heating fluid, II-35

Heating limits, I-4, II-27-28, II-42

High accident potential, VI-4-5

High energy initiator(s), I-4, II-43

High explosive(s), I-1, II-3, II-55-57, VI-1, VI-3, VI-5-6

Hoisting and rigging, II-7, II-45

Hoist(s), II-45, II-53

Holding fixture(s), II-30

Holding yard(s), II-47, VI-3

Hole, I-4

Hot-wire initiator(s), II-43

Hot work, I-4

Hot work permit(s), II-7

Hydraulic fluid(s), II-29

Hydraulic pressure, II-33

Hydraulically powered equipment, II-30

Hydrostatic pressing, I-4, II-29

IHE, I-4-5, II-31, III-2, VI-4-6, IX-1-3

IHE subassembly(ies), I-4, VI-4-6, IX-2-3

IHE weapon(s), I-4, VI-5-6, IX-2

Ignition train, II-65

In-process storage magazine, I-4

Inactive procedure(s), VII-2

Incinerator(s), II-65

Incompatible explosive(s), II-36, II-63, II-65

Industrial hygiene, II-2

Industrial occupancy(ies), II-3, II-4

Industrial truck(s), II-50

Inert mockup, II-31

Inhabited building distance, I-4, II-13, II-20, II-47, II-66, VI-3

Initiating explosive(s), II-55-56, II-65
Initiating systems, II-43

Initiation, I-5

Initiation circuit, II-43

Initiation stimul(us)(i), I-5

Insensitive High Explosive(s), I-4-5, II-31, III-2, VI-4-6, IX-1-3

Inspection, II-1, II-7, II-13, II-23, II-25, II-29,

II-32, II-34, II-35, II-36, II-37, II-40, II-41,

II-43, II-45, II-47, II-49, II-50, II-51, II-54,

II-61-62

Inspection equipment, II-34

Inspection frequency, II-1

Inspection station, II-47

Instrumentation, II-42

Instrumentation line(s), II-20

Interchange yard, II-47

Interlocking, II-9

Interlock(s), II-29-31, II-38, II-40, VII-2

Intraline distance, II-7, II-63, II-66

Intraplant shipping, II-49

Inventory, II-53-54, II-59

Isostatic pressing, I-5, II-28

Labeling, II-45

LEL, I-5

LFL, I-5

Lab sample(s), II-57

Laboratory coat(s), IV-1

Laboratory operation(s), I-5, II-1, II-19, II-67-68, VI-1

Large-scale test(s), II-37

Laundering, IV-2

Life Safety Code, II-3-4

Lifting device(s), II-41

Lighter(s), II-11, II-50

Lightning arrestor, II-20

Lightning protection, II-13

Lightning storm(s), II-38

Liquid addition, II-54

Loss criteria, VI-6

Low-energy EED, I-5

Low-energy initiator(s), II-39

Low-firing-current initiator(s), II-39, II-40

Lower explosive limit, I-5

Lower flammable limit, I-5

Lucite, II-67

Lung damage, VI-5

Machine speed, II-31

Machining, I-5, II-30-33, II-36, VI-4, VIII-2-3

Machining overtest, I-5, II-30, II-32, VIII-3

Magazine distance, I-5, II-13, VI-4, IX-3

Magazine(s), I-6, II-19, II-36, II-53-54, II-58-59, II-66, II-67, VI-5-6 
Magnetic separation, II-32, II-34

Maintenance, II-7, II-31, II-35, II-45, II-50, IV-1

Mandatory standard(s), I-1

Mandrel(s), II-29

Manual administration, I-2

Manual handling, II-45, IV-1

Mass-detonating, VI-2, VI-4, IX-1

Match(es), II-11, II-50

Materials handling, II-45, II-50

Materials receipt, II-47

Maximal effective pressure, VI-5

Maximum Credible Event, I-5, VI-3

Maximum explosives limit(s), VI-1

Mechanical handling equipment, II-45, II-58

Melt agitation, II-35

Melting, I-5, II-33, II-36

Metal article(s), II-11

Metal chip waste, II-30

Metal container(s), II-58, II-67

Metal scrap, II-64

Metal-to-metal, II-1, II-29, II-32, II-35

Metal/explosive(s), II-31

Metric system, VI-3

Milling, II-35-36, VI-4

Mirror(s), II-49, II-68

Misfire(s), II-40, II-41, II-42-43

Missile(s), II-13, II-33, II-37, VI-5

Mixed storage, II-55, II-57

Mixer(s), II-35

Mixing, I-3, I-5, II-35-36, VIIf-1

Mock, I-5, II-1, II-29, II-30, II-42, IX-3

Motor vehicle(s), II-47, II-49, VI-3

MSDS, II-2, V-2

National Electrical Code (NEC), II-19

New equipment, II-7, II-35

New explosive(s), I-5, II-29, II-34, II-54, VI-4, VIII-1-3

New explosives facility(ies), II-3, VI-1

No-fire rating, II-40, II-43

Noise, II-3, II-37

Non-DOE facility personnel, I-5, II-7

Noninitiating circuits, II-38, II-44

Nonpropagating array(s), II-58

Nonsparking footwear, IV-1

Nonworking hour(s), II-67

Nuclear test shot location(s), VI-1

Occupied area(s), VI-5

On-the-job training, V-1

Open burning, II-65-66

Open container(s), II-58

Open flame(s), II-1, II-67

Operating contractor, VI-1, VII-1, VII-2
Operating procedure(s), I-4, I-6, II-1, II-34-35,

II-61, II-67, III-1, IV-1, V-1, VI-1, VII-1-3

Operating temperature limit, II-28

Operational shield(s), I-3, I-5, II-33, II-63, VI-4

Outdoor operation(s), II-13

Oven(s), II-28

Overpressure(s), I-3, II-3, II-13, II-35, VI-5

Own means of initiation, I-5, II-55-56

Packing and shipping building(s), II-59

Packing material, II-54

Partially burned explosive(s), II-66

Pellet(s), II-31, II-56, II-58

Personnel access, II-37-38, II-40

Personnel barrier, I-5

Personnel casualty(ies), VI-2

Personnel limit(s), II-4, II-37-38, II-53, III-1

Personnel protection, II-3-4, II-9, II-33

Pilot plant, II-34-35

Pin switch(es), II-38, II-44

Pinch point(s), II-34, II-35

Pipe thread(s), II-21

Pit(s), II-65-66

Placarding, II-69

Plastic bonded explosive(s), II-35, II-56

Plastic explosive(s), II-29, II-33

Plutonium, II-3, II-42

Pneumatic tool(s), II-33

Polycarbonate, II-67

Portable building(s), VI-1

Powdered metal(s), II-64

Power tool(s), II-38

Power-operated door(s), II-4

Pressed explosive(s), II-58

Pressing, I-5, II-1, II-28-29, II-31, II-36, III-2, VI-4, VIII-3

Press setup procedures, II-29

Pressure controller(s), II-29, II-30

Pressure transducer(s), II-38, II-44

Pressure vessel, II-29, II-35, II-41

Pressurized unit(s), II-33

Primary explosive(s), I-4, II-31, II-57, II-66

Process equipment, II-13, II-35, II-36

Process operation, II-11, II-35

Projectile(s), II-6, II-37, II-41, II-43, II-55

Proof-testing, II-41

Propagation, I-6, II-57 III-1, VI-5

Propellant(s), I-1, I-6, II-3, II-15, II-43, II-54-57

Property damage, I-1, II-37, VI-2

Protective clothing, II-7, IV-1

Protective equipment, IV-1, VII-3

Protective shelter, II-13, II-37, II-40

Public highway(s), II-49 
Public traffic route(s), I-6, II-9, II-20, II-66,

VI-2-3, VI-5

Punch and die pressing, I-6, II-29

Purging, II-7

Pyrotechnic(s), I-1, I-6, II-3, II-15, II-16

Qualification program, V-1-2

Qualification tests for IHE, IX-1, IX-2

Quantity-distance, II-47, II-53, II-59, II-64, III-1, VIII-3

Quick-disconnect switch, II-49

RF transmitter(s), II-38-39

Radio transmitter(s), II-65

Radioactive material(s), II-42

Radiographic inspection, II-34

Radiography, II-31

Railcar(s), II-47, II-49, VI-3

Railroad car(s), II-13

Railroad crossing(s), II-50

Range standard(s), II-37

Raw material(s), II-34

Reaction vessel(s), II-34-35, II-68

Receipt, II-47, II-59

Record(s), II-7, II-43, II-54, II-64, II-66, V-1

Refresher training, V-1

Relative humidity, II-16

Remote control, II-41, II-67

Remote operation(s), I-7, II-9, II-28-32, VI-4

Remotely fired gun, II-43

Repair(s), II-7, II-31, II-35, II-43, II-51

Resistance check(s), II-40

Resistance-to-ground, II-15, II-32, II-64

Respirator(s), IV-1

Review, I-2, II-42, II-54-55, III-1, V-1, VII-1-2, IX-2

Revolving door(s), II-4

Risk analysis, II-37

Roadblock(s), II-37

Road(s), I-6, II-51, VI-5

Rocket(s), II-55-56

Roll milling, II-35, II-36

Rubbish, II-63, II-66

SOP(s), I-6, II-23, V-2, VI-1, VII-1, VII-2-3

Safe Secure Railcar (SSR), II-49-50

Safe Secure Trailer (SST), II-49-50

Safe attitude, V-1

Safe distance(s), II-38-39, II-51

Safety analysis, I-6, II-3, VI-5

Safety equipment, II-35

Safety override device(s), II-28

Safety plug, II-40

Safety procedure(s), II-33, VII-2
Safety shield(s), II-67

Salvaged explosive(s), II-56-57, II-64

Sawing, II-32

Scaleup, II-29, II-54, VIII-2-3

Scrap collection, II-36

Scraping, II-32

Screening, I-6, II-31, II-34, VI-4

Screw thread(s), II-1, II-23, II-61

Security alarm system(s), II-20

Security response munitions, II-59

Sensitive salt(s), II-67

Sensitivity data, VIII-1

Sensitivity testing, II-41-42

Serious injury(ies), II-9, III-1, VI-5

Service line(s), II-20, II-36, VI-3

Service magazine(s), I-6, II-36, II-59

Service personnel, II-37, II-40

Settling basin(s), II-25, II-64

Severe injury(ies), VI-5

Shelf life, II-54-55

Shield(s), I-3, I-5, II-33, II-49, II-63, II-67, VI-4, VI-6

Shipment(s), II-47, II-49-50, II-59

Shipping/receiving, II-59

Shoe covering(s), IV-1

Shot stand, II-38

Shunt(s), II-39, II-65

Shutdown of all operation(s), II-13

Simulated drill(s), II-69

Siting, VI-1, VI-6

Slapper detonator, I-6

Slide escape(s), II-4-5

Sling(s), II-45

Slurry coating, II-35

Small arm(s), I-6, II-41, II-57

Smoking, II-11, II-50, II-67

Solvent(s), II-15, II-28, II-35, II-57, II-61, II-63, II-66, II-67

Solvent/explosives mixture, II-66, II-68

Spark arrestor, II-49

Spark-producing device(s), II-11, II-38, II-50

Special operating procedure, I-6, VII-1, VII-3

Spray mist coolant, II-31

Squib(s), I-4, II-40, II-43, II-56, II-65

Stability testing, II-54, VIII-3

Stacks of explosive(s), II-53

Stair(s), II-45

Standard operating procedure(s), I-6, II-23, V-2, VI-1, VII-1, VII-2-3

Static electricity, II-15-17, IV-1

Static ground(s), II-15

Static spark, II-15

Steam, II-7, II-28, II-33, II-35, II-53, II-61, II-68 
Storage, I-6, II-3, II-40, II-47, II-53-59, VI-4-5, VIII-3

Storage compatibility, I-3, II-55-58, II-63, II-64, VI-2-3, VIII-3

Storage container, II-57-59, II-67

Storage in building(s), II-59

Storage magazine(s), I-6, II-19, II-53-54, VI-6

Storage review, II-54-55

Strain gage(s), II-38, II-44

Structural collapse, II-13, VI-5

Sublimation, II-19, II-50

Substantial dividing wall, I-6

Sump(s), II-25, II-67

Surge arrestor(s), II-20

Surge capacitor(s), II-20

Surveillance sampling, II-54

Suspect car, II-47, VI-3

Sweeping compound(s), II-7

Synthesis, I-6, II-34-35, II-68, VIII-1-2

TB 700-2, VI-3, IX-1, IX-4

TNT equivalent, I-6, II- 68

Target, I-6, II-41

Telephone, II-53

Temperature control, II-29, II-33, II-53

Tempered glass, II-67

Temporary storage, II-59

Test area, I-3, II-37-38, II-39-40, II-42

Test firing, I-4, II-37-41

Test instruments, II-43

Test planning, II-37

Test procedure(s), II-37-39, IX-1

Test shot, II-37, II-39, II-40, VI-1

Test site(s), I-3, II-37-38, II-40

Thermal analysis, II-27, II-42

Thermal conditioning, II-28, II-42

Thermal flux, VI-6

Thermal stability, II-19, II-27, II-29, VIII-1-3

Thermal testing, II-19, II-27

Thermocouple(s), II-38, II-44

Threaded fastener(s), II-34

Threaded fitting(s), II-21

Tiedown, II-45, II-49

Tool path control(s), II-30

Tool speed, II-31

Tooling, II-29-30, VII-3

Toxicity, II-1, II-23-24, II-38

Traffic rule(s), II-50

Training, V-1

Transfer line(s), II-35

Transient(s), I-6, II-4, II-9, II-37-38, III-1, VI-5

Transportation, II-7, II-49-51, II-57, II-69
Transportation vehicle(s), II-49, II-50-51, II-59

Trap(s), II-21, II-28, II-67

Trough(s), II-25, II-31

Unattended test assembly(ies), II-39-40

UNO, I-7, VI-1-2

Unit operating procedure(s), VII-2-3

Unloading, II-47

Utilities installation(s), VI-3

Vacuum chuck, II-30, II-31

Vacuum collection, II-63-64

Vacuum drying, II-28

Vacuum equipment, II-21

Vacuum lifting, II-45-46

Valve(s), II-33, II-34, II-36, II-56

Vapor concentration(s), II-28, II-34

Vault, I-6

Vegetation control, II-53, VI-6

Vehicle(s), II-13, II-47, II-49-51, II-53, II-59, II-65, VI-3

Vented, II-28, II-43, II-50

Ventilation, II-7, II-15, II-23-24, II-29, II-34, II-41

Viscous shear heating, II-35

Visual inspection, II-13, II-34, II-37

Visual monitoring, II-31

Waiting period, II-37, II-40, II-42

Waiver(s), I-1-2, VI-1, VII-2

Walkway(s), II-3, II-45

Warehouse(s), II-59

Warning light(s), II-38

Warning signal(s), II-39

Warning sign(s), II-35, II-39

Waste disposal, II-65-66

Waste water, II-64

Water jet, II-61

Water-explosives mixture(s), II-19

Water-steam mixture, II-61

Watertight equipment, II-19

Weapons courier(s), II-49

Wet box(es), II-64

Wet machining, II-30-32, VI-4

Wet type collector(s), II-23, II-63

Wheels chocked, II-47

Wiring, II-19-20, II-39, II-40, II-43-44

Work alone, III-1

Work environment, II-3-4

Wristband(s), II-15 